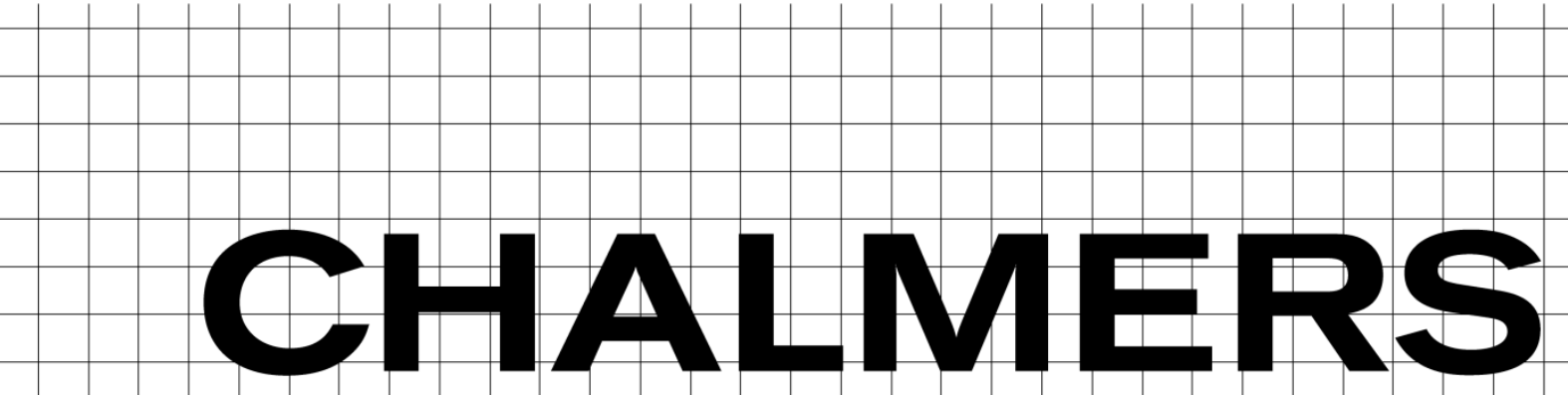





\title{
Effects of nuclear power phase-out in Germany on the Austrian power system
}

\author{
Master's Thesis in Sustainable Energy Systems programme \\ ANDREAS HOLZER \\ SUPERVISOR and EXAMINER \\ Anh Tuan Le, Division of Electric Power Engineering \\ Chalmers University of Technology
}

Department of Energy and Environment

CHALMERS UNIVERSITY OF TECHNOLOGY

Göteborg, Sweden 2014 
Effects of nuclear power phase-out in Germany on Austrian power system. Master Thesis within the Sustainable Energy System programme ANDREAS HOLZER

\section{(c) ANDREAS HOLZER, 2014.}

Department of Energy and Environment

Chalmers University of Technology

SE-412 96 Göteborg, Sweden

Telephone + $46(0) 31-7721000$

Chalmers Reproservice

Göteborg, Sweden 2014 
Effects of nuclear power phase-out in Germany on Austrian power system.

Master Thesis within the Sustainable Energy System programme

ANDREAS HOLZER

Department of Energy and Environment

Chalmers University of Technology

\section{Abstract}

The present German power system is using nuclear power to satisfy the electricity demand. More than $15 \%$ of the annual German power generation was provided by nuclear power plants in 2013 [1]. The decision of the German government to phase-out all nuclear power plants in Germany by 2022 hence has a significant impact on the power system. Also neighbor countries will be affected by the phaseout of nuclear power since they relied on power exchange of Germany.

This thesis studies the effects of a nuclear power phase-out in Germany on the Austrian power system. Therefore a model of the German and Austrian power system (GAPS) is developed within the general algebraic modeling system (GAMS). The aim of the model is to answer how the electricity generation and total costs in Austria and Germany are affected by a nuclear power phase-out in Germany in 2022. Further the transformation of the power exchange between Austria and Germany is analyzed. With GAPS is also investigated how the locational marginal price in Austria, usage of pumped storage hydro power and congestion of transmission lines in Austria are affected by a nuclear power phase-out in Germany.

The model simulates 24 hours of a day with high demand, contains over 300 nodes, uses DC optimal power flow framework and investigates different scenarios. The different scenarios are the present system, the present system without nuclear power in Germany and a model of the future system in 2022. All Scenarios are simulated with 3 different values for wind power penetration in order to investigate how the results depend on wind power generation. Export and import parameters from Austria and Germany to neighbor countries are based on historic values of the reference day.

The results of the different scenarios are compared to develop a conclusion how the nuclear power phase out affect the power system. It could be shown that the electricity imports of Austria from Germany increase sharply in 2022 without nuclear power in Germany. In Austria between $46 \%$ and $10 \%$ more natural gas is used, depending on wind conditions, in 2022. In total, in Germany and Austria together, between 39 and $26 \%$ more coal power is used in the future power system.

The total generation costs in Austria and Germany depend strongly on the wind power conditions in the future. The fluctuation range of total generation costs increases due to a higher dependency on wind power in 2022 but the increase of total costs of electricity generation is low with respect to a demand increase in 2022. It can be also noticed that the usage of pumped storage hydro power decreases in 2022 because of a change of the generation mix and hence the number of economic operation hours for pumped storage hydro power are reduced in Austria and Germany.

Index Terms-Power generation dispatch, Power system modeling, Power system economics, GAMS 



\section{Preface}

This thesis work, starting in January 2014, has been performed within the Division of Electric Power Engineering at the Department of Energy and Environment at Chalmers University of Technology.

Thanks to Valle Vincenz at Austrian Power Grid AG for allowing me to use the real grid data of the Austrian power grid within this thesis

I would like to thank my supervisor Anh Tuan Le for guidance within this thesis. Finally I would like to thank my family for their support during my studies. Especially I would like to thank my brother Stefan for his support.

Gothenburg November 2014

Andreas Holzer 


\section{Table of Contents}

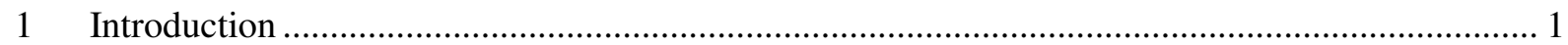

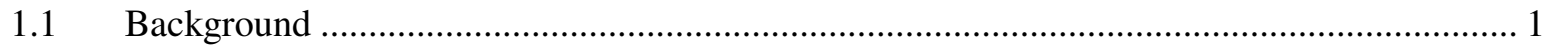

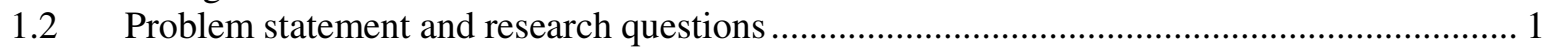

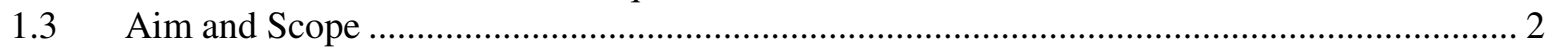

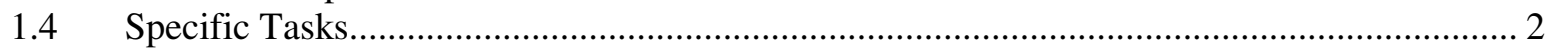

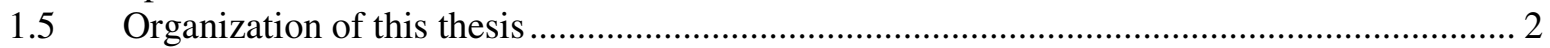

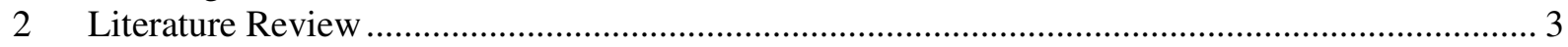

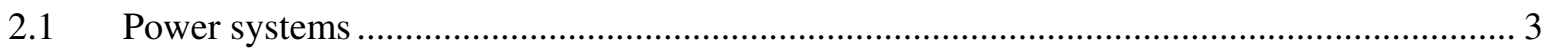

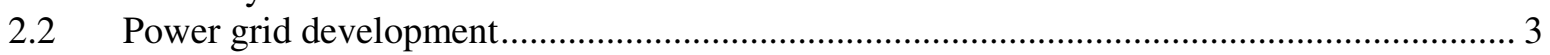

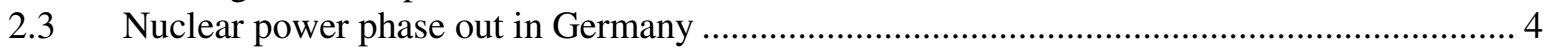

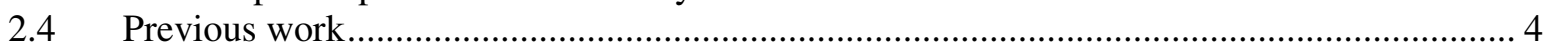

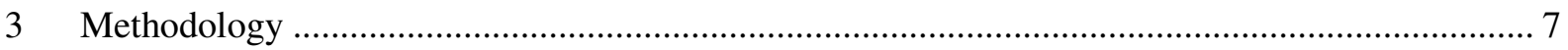

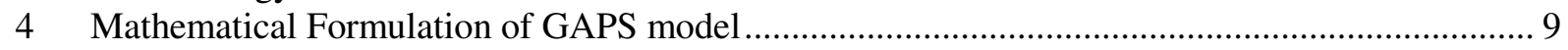

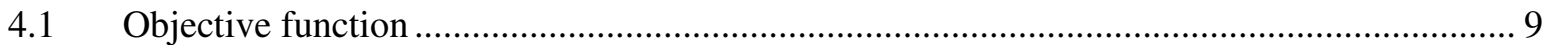

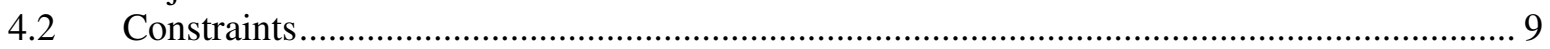

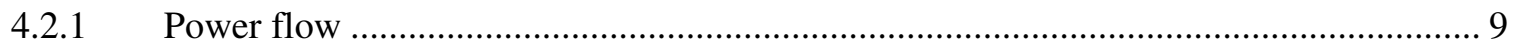

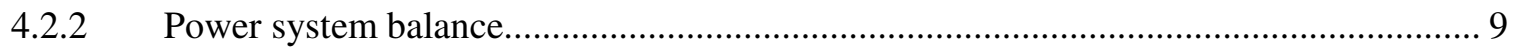

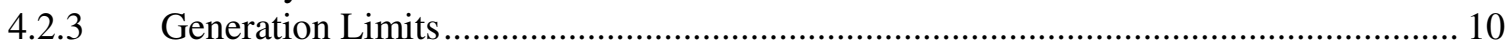

4.2.4 Energy generation limit of seasonal storage hydro power............................................ 10

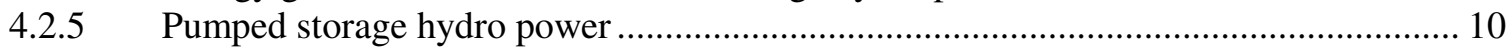

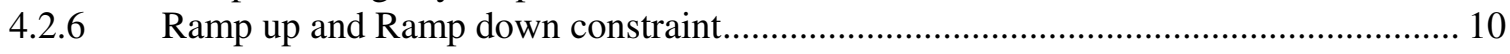

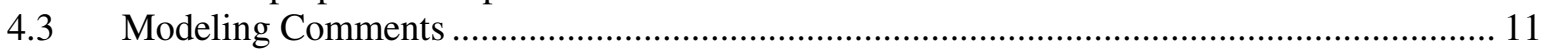

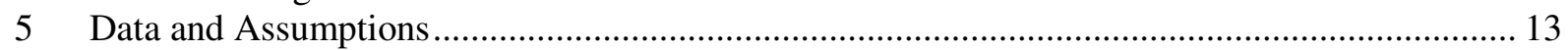

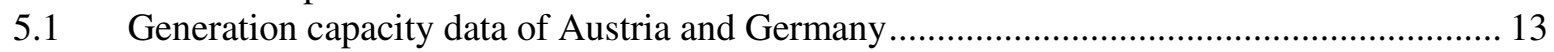

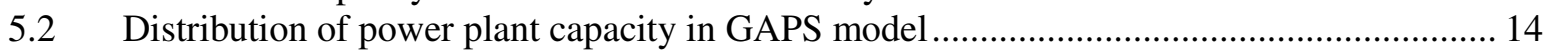

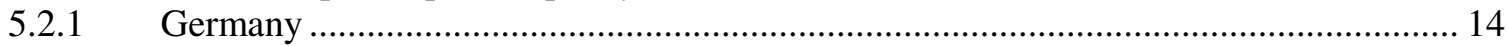

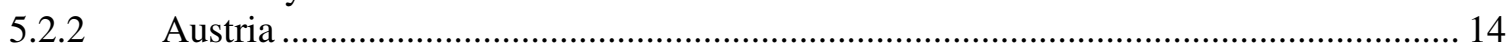

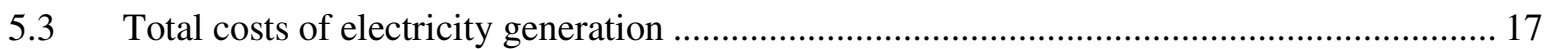

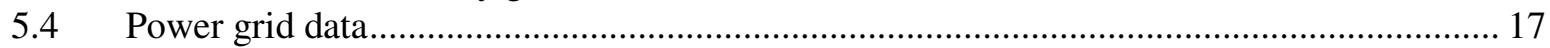

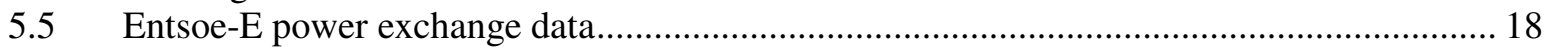

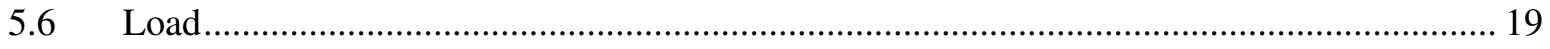

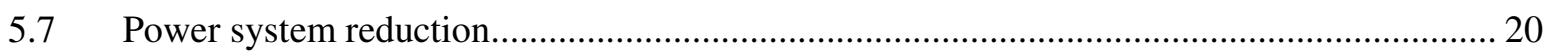

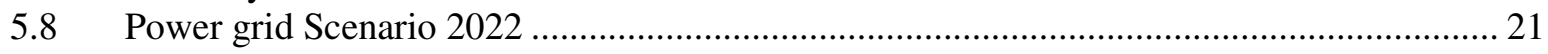

$5.9 \quad \mathrm{CO}_{2}$-Emissions of electricity generation in Austria and Germany .................................... 21

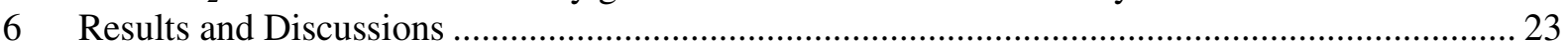

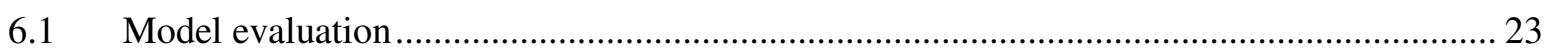

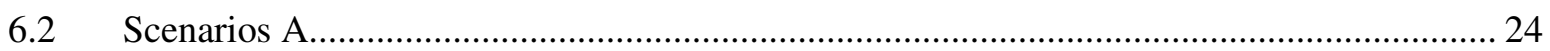

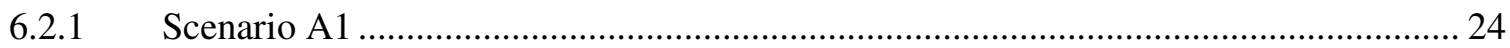

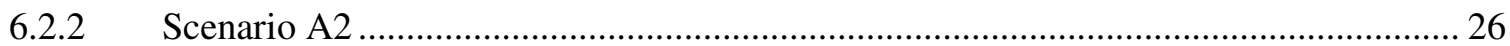

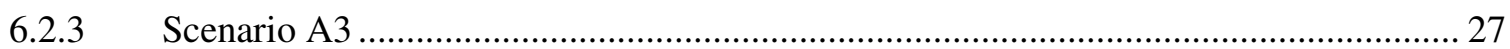

6.2.4 Power exchange between Germany and Austria in scenarios A ................................... 29

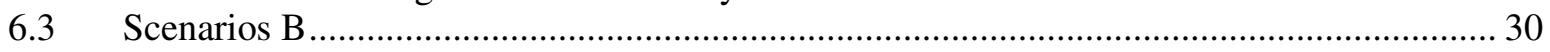

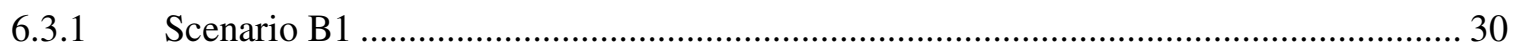

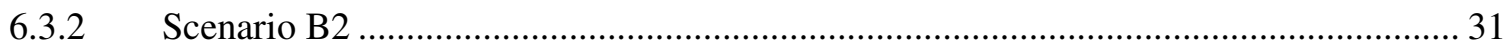

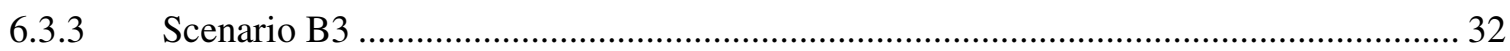

6.3.1 Power exchange between Germany and Austria in scenarios B................................... 33

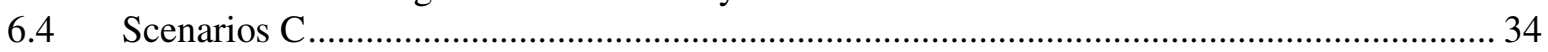

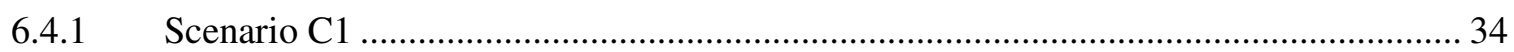

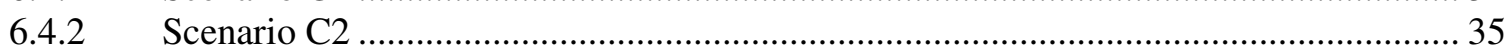

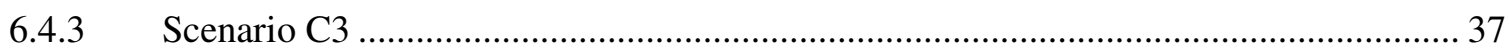

6.4.4 Power exchange between Germany and Austria in scenarios C................................... 38

6.5 Summary and Comparison of electricity generation in Austria and Germany ...................... 39 
6.6 Total cost of power generation in Austria and Germany ................................................... 41

6.7 Wind power curtailment in the Austrian power system ..................................................... 42

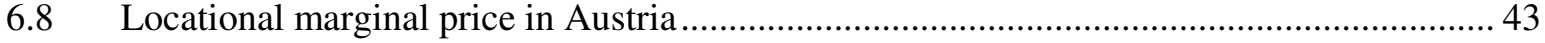

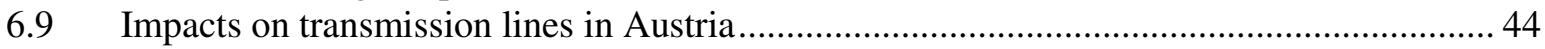

6.10 Impact on pumped storage hydro power in Austria and Germany …................................... 45

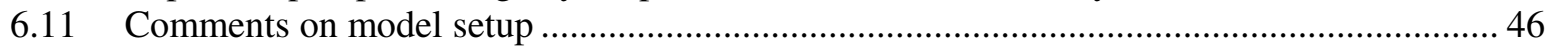

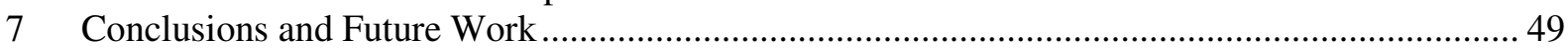

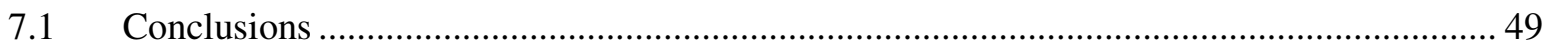

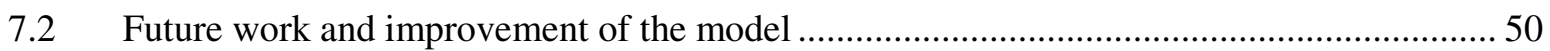

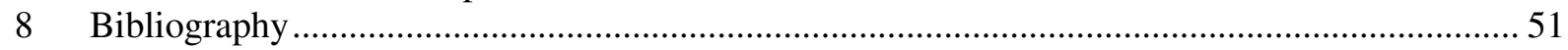

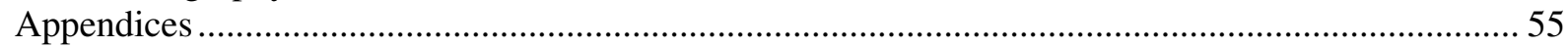




\section{List of Figures}

Figure 3.1: Methodology for construction of power system model ................................................. 7

Figure 3.2: Methodology for the study of scenarios using the GAPS model ....................................... 8

Figure 5.1: APG Network Map with main nodes in Austria [8] .................................................... 15

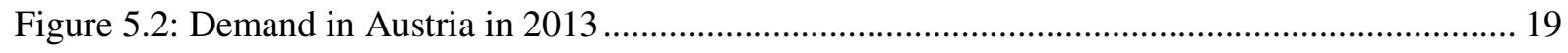

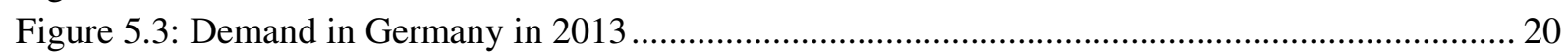

Figure 6.1: Import of Austria from Germany of real system and scenario A1 .................................... 23

Figure 6.2: Power generation profile of Austria and Germany in case A1 ........................................ 24

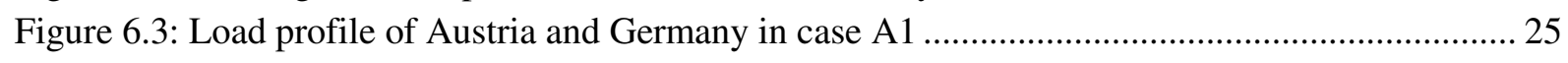

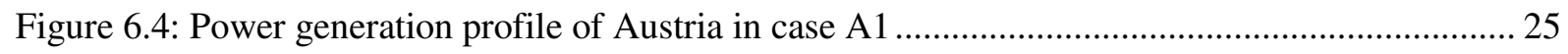

Figure 6.5: Power generation profile of Austria and Germany in case A2 ........................................ 26

Figure 6.6: Power generation profile of Austria in case A2 ............................................................ 27

Figure 6.7: Power generation profile of Austria and Germany in case A3 ........................................ 28

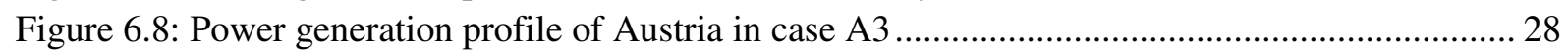

Figure 6.9: Power exchange between Austria and Germany in scenarios A........................................ 29

Figure 6.10: Power generation profile of Austria and Germany in case B1 ....................................... 30

Figure 6.11: Power generation profile of Austria in case B1 ......................................................... 31

Figure 6.12: Power generation profile of Austria and Germany in case B2 ..................................... 31

Figure 6.13: Power generation profile of Austria in case B2 ......................................................... 32

Figure 6.14: Power generation profile of Austria and Germany in case B3 ........................................ 32

Figure 6.15: Power generation profile of Austria in case B3 .......................................................... 33

Figure 6.16 Power exchange between Austria and Germany in Scenarios B ..................................... 34

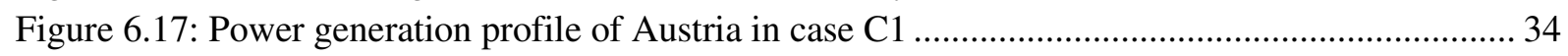

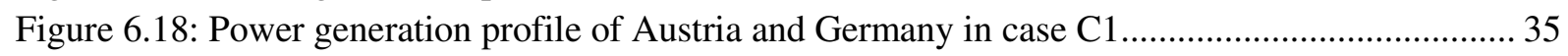

Figure 6.19: Power generation profile of Austria and Germany in case C2....................................... 36

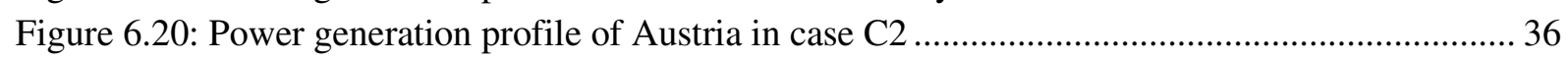

Figure 6.21: Power generation profile of Austria and Germany in case C3....................................... 37

Figure 6.22: Power supply curve Austria 2022 Strong Wind........................................................... 37

Figure 6.23: Power exchange between Austria and Germany in Scenarios C .................................... 38

Figure 6.24: Electricity generation change in Austria and Germany compared to case A1 ................. 40

Figure 6.25: Total Costs of power generation in Austria and Germany.............................................. 41

Figure 6.26: Total cost changes of cases B and C compared to cases A ............................................ 42

Figure 6.27: Total power generation cost differences compared to base Case in percent...................... 42

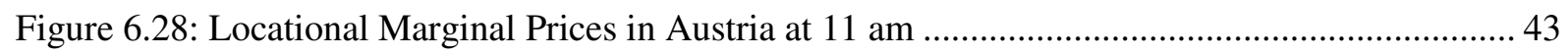

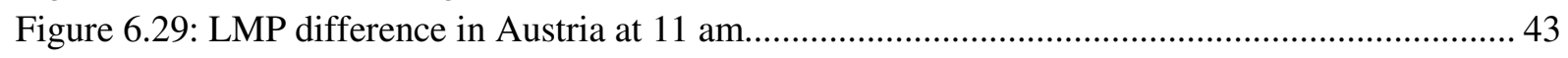

Figure 6.30: LMP curves of scenarios A and C at node Wien in Austria .......................................... 44

Figure 6.31: Number of congested transmission lines in model at 11 am........................................... 44

Figure 6.32: Electricity generation from pumped storage hydro power in Austria and Germany ........ 45 


\section{List of Tables}

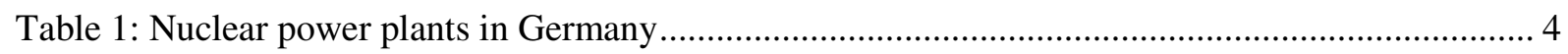

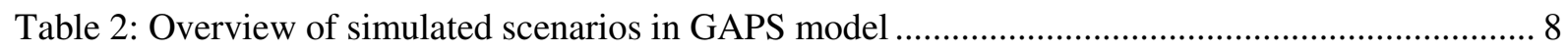

Table 3: Applied capacity factor for wind power generation .............................................................. 8

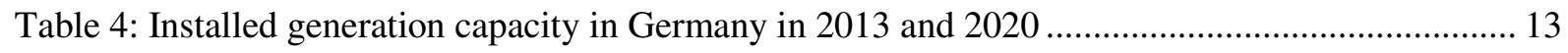

Table 5: Installed generation capacity in GAPS model............................................................... 14

Table 6: Table with node names and allocated generation capacity in MW in 2013 in Austria ........... 16

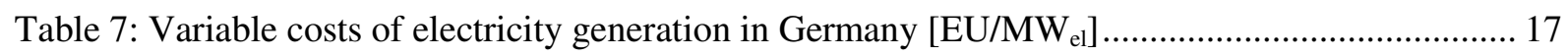

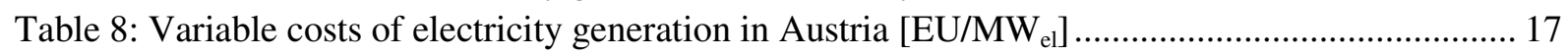

Table 9: Grid exchange data of Germany with neighbor countries of $16^{\text {th }}$ January 2013 in MW......... 18

Table 10: Grid exchange data in MW of Austria with neighbor countries of $16^{\text {th }}$ January 2013 .......... 19

Table 11: Transmission network development projects in Austria [46] ............................................. 21

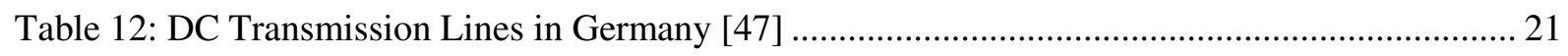

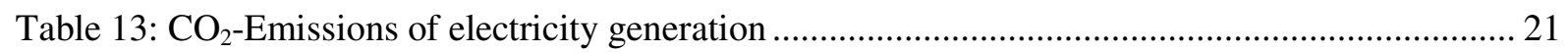

Table 14: Exchange balance between Austria and Germany in Scenario $\mathrm{A}^{1}$....................................... 29

Table 15: Exchange balance between Austria and Germany in Scenarios B and A1 ${ }^{1}$......................... 33

Table 16: Exchange balance between Austria and Germany in Scenarios $\mathrm{C}$ and $\mathrm{A} 1^{1}{ }^{1}$........................ 38

Table 17: Total electricity generation [GWh/d] and $\mathrm{CO}_{2}$ emissions in Austria and Germany.............. 39

Table 18: Total electricity generation $[\mathrm{GWh} / \mathrm{d}]$ and $\mathrm{CO}_{2}$ emissions in Austria ................................... 39

Table 19: Generation change in Austria and Germany compared to corresponding case A [\%] ......... 40

Table 20: Changes of power generation in Austria compared to corresponding cases A [\%] .............. 41

Table 21: Change of pumped storage hydro power in Germany and Austrian compared to cases A .. 46

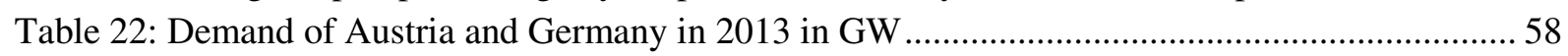




\section{Nomenclature}

\section{Indices}

$i$

j

$k$

n

$t$

\section{Parameters}

$B_{i, j}^{\prime}$

$B_{i, j}$

$\operatorname{cost}_{n}$

costPS

Pwind $_{i, t}$

Psolar $_{i, t}$

PHP $_{i, t}$

$P D_{i, t}$

PGmax $_{i, n}$

$\operatorname{Emax}_{i, n}$

$X_{i, j}$

$\operatorname{Pmax}_{i, j}$

Variables

$P G_{i, n, t}$

$P D P S_{i, t}$

$P G P S_{i, t}$

PPSlevel $_{i, t}$

PGseasonal $_{i, t}$

$\delta_{j, t}$

$\delta_{i, t}$

Pflow $_{i, j, t}$ node within network

node within network

with system reduction reduced node

power plant types $n$, biomass, coal, lignite, natural gas, nuclear, oil, several fuel sources and seasonal storage

time

susceptance matrix from transmission lines between node $i$ and $j$ or $k$ [S]

susceptance matrix of reduced system [S]

variable costs of fuel type $n$ [€/MWh]

variable costs of pumped storage hydro power [€/MWh]

generation from wind power at node $i$ and time $t$

generation from solar power at node $i$ and time $t$

generation from run of the river hydro power plans at node $i$ and time $t$

load at node $i$ and time $t$ [MW]

maximum generation capacity of power plant type $n$ at node $i$ [MW]

maximum energy generation of power plant type $n$ at node $i$ at one day [MWh/d]

reactance of transmission line from node $i$ to $j[\Omega]$

maximum power flow from node $i$ to $j$ [MW]

power generation of power plant type $n$ at node $i$ and time $\boldsymbol{t}$ [MW]

demand for hydro pumped storage hydro power at node $i$ and time $t$ [MW]

generation from pumped storage hydro power at node $i$ and time $t$ [MW]

pumped storage hydro power reservoir level [MWh]

generation from seasonal storage hydro power [MW]

voltage angle of node $j$ at time $t$ [rad]

voltage angle of node $i$ at time $t[\mathrm{rad}]$

power flow from node $i$ to $j$ [MW] 


\section{Abbreviations}

GAMS

TSO

APG

ATG

RES

DCLF

NTC

CCGT

O\&M

LP

LMP

CHP

AT

DE

$\mathrm{CH}$

CZ

HU

IT

SI

DK

FR

LU

NL

PL

SE
General Algebraic Modeling System

Transmission System Operator

Austrian Power Grid AG

Nuclear power act (Atomgesetz)

Renewable Energy Systems

DC Load Flow

Net Transfer Capacity

Combined Cycle Gas Turbines

Operation and Maintenance

Linear Programming

Locational Marginal Price

Combined Heat and Power

Austria

Germany

Switzerland

Czech Republic

Hungary

Italy

Slovenia

Denmark

France

Luxembourg

Netherlands

Polen

Sweden 


\section{Introduction}

This chapter gives a brief description of the background and the discussed research questions in this thesis. It also describes the main tasks, organization, aim and scope of this work.

\section{$1.1 \quad$ Background}

In 2011 Germany's Government decided, after the nuclear power accident in Fukushima, to phase out all nuclear power plants in Germany in 2022. This decision led to research about how Germany will satisfy its power demand without nuclear and how it will affect the electricity market in Europe.

The present German power generation is based to a relevant extent on nuclear power. More than 15\% of the total power generation in Germany is provided by nuclear power plants in 2013 [1]. Nowadays, Germany is also in general an exporter of electricity within the European power market. Without the use of nuclear power the power exchange between Germany and other countries might change in order to satisfy the power demand of Germany. Therefore also the power supply of Germany's neighbor country Austria is influenced by the nuclear power phase-out in Germany.

In contrast to Germany, no nuclear power plants are used in Austria. The Austrian power supply is based to large extend on hydro power. Approximately 55\% of the Austrian power demand is supplied by hydro power [2]. Further the Austrian power system has installed more than $3.3 \mathrm{GW}$ capacity of pumped storage hydro power which gives Austria the possibility to store energy.

Until 2022 the power system will also move towards more renewable energy. Both, the nuclear power phases out and the increase of renewable energy will challenge the power system. Improvements of the power transmission and new investments in power plant capacities might be necessary to avoid a reduction of supply security and an increase of the market price.

\subsection{Problem statement and research questions}

It is less investigated how the nuclear power phase out in Germany will affect the Austrian power system. Detailed studies on total costs, marginal price development and transmission line congestion in Austria are not available for a nuclear power phase-out in Germany. Therefore the following questions are answered within this thesis.

- How does the electricity generation in Austria and Germany change after a nuclear power phase-out in Germany?

- What are the effects of a nuclear power phase-out in Germany on the power exchange of Austria and Germany in 2022?

- How do the total costs of power generation in Austria and Germany change after a nuclear power phase-out?

- How is affected the locational marginal price in Austria by a nuclear power phase-out in Germany?

- What are the effects of a nuclear power phase-out in Germany on the pumped storage hydro power?

- Will the nuclear power phase-out in Germany cause congestion in the Austrian power system? 


\subsection{Aim and Scope}

The purpose of this thesis is to analyze the effects of the phase-out of nuclear power in Germany on Austrian power system. Therefore a model of the Austrian and German power system (GAPS) is developed in order to analyze the impact of a nuclear power phase-out in Germany. Different scenarios are discussed in order to discuss the effects of the phase out on the Austrian power system. A difficulty in studying a power system is gaining the data to construct a model which represents a real system. Different sources are used in order to construct a model which provides representative results. This thesis answers the research questions based on the simulation of a reference day with 24 time steps and a high electricity demand. Changes in the future system are assumed in order to simulate the future power system in 2022. Therefore generation capacity, power transmission network and demand is updated according to the expectations of the transmission system operators (TSO) and federal agencies.

The model is limited to the investigation of one day with high demand due to long computing time of the model. Neighbor countries of Austria and Germany are included by fixed historic values and effects on those countries are not studied. The impact of wind power on the results is analyzed by using 3 different wind power capacity factors which are constant within the simulation of one scenario. The effects of a $\mathrm{CO}_{2}$ tax are not part of this thesis and hence excluded from the fuel costs.

\section{$1.4 \quad$ Specific Tasks}

Within this thesis a model of the German and Austrian power grid (GAPS) is developed. The GAPS model is based on DC optimal power flow framework and built in GAMS (General Algebraic Modeling System)[3]. This thesis combines power grid data from different sources. It uses the real power grid data of the Austrian power grid [4] and data for the German grid is gained from a public source [5]. Based on this model the behavior of the power system under a nuclear power phase-out in Germany is studied for different scenarios.

First of all a system reduction on data from [5] is applied to reduce the system to relevant nodes. After this step are allocated power plants in the model to the corresponding nodes. One of the main tasks is to develop a power system model which is representative for the power system of Austria and Germany. The basic scenario simulates the $16^{\text {th }}$ January 2013 which is the reference day. This model is validated and adjusted in order to reach a model which gives results which are similar to the values of the real power grid. At next this model is further developed to simulate different scenarios. Each scenario is modeled for different wind power generation levels, Low, Medium and Strong. Finally, the results of all scenarios are compared in order to answer the research questions of this thesis.

\subsection{Organization of this thesis}

- Chapter 2 shows a literature review which includes the previous research and relevant decisions of the German government.

- Chapter 3 explains the methodology of this thesis and the investigated scenarios.

- Chapter 4 describes how the model is constructed and which equations are used to simulate the power flow in the network.

- Chapter 5 shows the applied data and assumptions within this thesis

- Chapter 6 presents the results and discussion of each scenario. At the end of this chapter a comparison and summary of all scenarios is made In addition, the developed GAPS model is also critical discussed.

- Chapter 7 shows the arrived conclusions to each of the research questions and gives recommendations for future work. 


\section{Literature Review}

This chapter gives an overview about the German and Austrian power systems. At first the responsible parties for the operation and development of the power systems in Austria and Germany are described. Then important decisions of the German government concerning the phase-out of nuclear power in Germany are summarized. Finally previous works with respect to the phase-out of nuclear power in Germany are discussed.

\subsection{Power systems}

The aim of a power system is to transfer power from the producer to the consumer. For a stable operation of the system it is necessary to always balance generation and load. Differences in generation and load lead to frequency changes which can increase the instability of the power system. A careful operation of the power system is important for a secure power supply. The transmission system operator (TSO) is responsible for a secure operation of the high voltage power grid.

In Germany the power system is divided into four control areas with different TSO's. The TSOs Ampiron, 50Hertz, TransnetBW and TenneT are responsible for different areas of the grid. Change from fossil fuel to renewable sources, which is also known as "Energiewende" in Germany, creates a higher demand on the extra high voltage network. Sometimes wind power production already exceeds the network capacity and it will be one of the main tasks of the TSOs to establish an infrastructure which fits for the demands of sustainable future [6]. Another important institution is the Federal Network Agency for Electricity, Gas, Telecommunications, Post and Railway which is also known as Bundesnetzagentur. This organization is responsible to ensure that all users can access the power grid and TSOs do not take advantage of their monopoly market position. The Bundesnetzagentur and the TSOs contribute together to the power grid expansion plans in Germany [6][7]. The Austrian equivalent to Germanys TSOs is the Austrian Power Grid AG (APG). APG is responsible for the operation and development of high voltage power system in Austria [8].

In general trading on the wholesale market is done on the spot market of one country. However price differences between countries creates benefits from cross border trading. Therefore several power spot markets for trading between countries are established. E.g. Germany, Austria, France and Switzerland are members of the EPEX Spot power spot market [9]. The EPEX Spot is divided into submarkets where Austria and Germany build together the PHELIX market.

\subsection{Power grid development}

One of the main challenges for future power systems will be the increased integration of renewable energy sources. This is one of the driving forces for the development of the power system infrastructure in Europe. A higher penetration of renewable energy increases the demand for a better interconnection between countries [10]. Power generation from intermittent sources has a lower predictability as conventional power plant types like coal or nuclear power. A better power system interconnection with the Alpine and Scandinavian area will allow increased access to storage capacities in these regions [10]. Therefore grid development is important for the integration of renewable sources. Moreover, long implementation times of power system infrastructure changes of up to 10 years make it crucial to plan and observe power system development [10]. 


\section{$2.3 \quad$ Nuclear power phase out in Germany}

In autumn 2010 the German Federal Government decided to extend the life time of nuclear power plants. As a consequence of this the last nuclear power plant would have been shut down in 2036 . However the nuclear power accident in Fukushima in 2011 led to a revision of Germany's nuclear power plans. The new plan is to phase-out all nuclear power plants in Germany by 2022. [11]

The German nuclear power phase out is established in the "Atomgesetz" (ATG). ATG is an act for handling nuclear power in Germany. It states when the right of electricity generation for nuclear power plants will expire and hence the nuclear power plants will retire. Eight out of 17 nuclear reactors have already been shut down in Germany in 2011 [12]. This reduced significantly the gross electricity production from nuclear power in Germany from 169 TWh in 2002 to 97 TWh in 2013[1]. The phaseout of the remaining nuclear power will be done stepwise until 2022. Table 1 gives an overview when the remaining nuclear power plants will be shut down [12] [13].

Table 1: Nuclear power plants in Germany

\begin{tabular}{lll}
\hline Nuclear power plant & Power plant capacity [MW] & Shut down Date \\
\hline Grafenrheinfeld & 1480 & 31th of December 2015 \\
Grundremmingen B & 1344 & 31th of December 2017 \\
Philippsburg & 1468 & 31th of December 2019 \\
Grohnde & 1430 & 31th of December 2021 \\
Gundremmingen C & 1344 & 31th of December 2021 \\
Brokdorf & 1480 & 31th of December 2021 \\
Isar 2 & 1485 & 31th of December 2022 \\
Emsland & 1400 & 31th of December 2022 \\
Neckarwestheim 2 & 1400 & 31th of December 2022 \\
\hline
\end{tabular}

Bundesnetzagentur [14] analyzed import and export data of Germany in 2011 before and after the shutdown of eight nuclear reactors in 2011. The power exchange of Germany was influenced significantly by the start of the nuclear power moratorium for a short term.

\section{$2.4 \quad$ Previous work}

According to Bundesnetzagentur [14], the previous shut down of nuclear reactors changed the level of supply security to "just adequate". It is noticeable that no additional imports are required to maintain the level of supply security under the previous nuclear power phase-out. Due to high wind power conditions and phase out of nuclear reactors increases the stress on the North-South and East-West transmission paths in Germany. Therefore security related interventions by TSOs (e.g. redispatch, wind curtailment) will be necessary more frequently. Additionally the contribution of Germany to security of supply in neighbor countries cannot be sustained which could cause problems for countries which relied on Germanys exports. To which extend the neighbor countries are affected was not part of the investigations of Bundesnetzagentur.

Hoster [15] already discussed a nuclear power phase-out by 2005. Based on a European inter regional electricity model is studied how the structure of the European electricity sector could have changed in 2005. It is a multi-regional model where each country is modeled as one region. The results of the research showed that mainly hard coal and too some extend gas power plants will be used to substitute nuclear power in Germany. Hence $\mathrm{CO}_{2}$ emissions will increase significantly. Another result was that 
average generation costs should increase on a moderate level and depend on the power trade within Europe.

Another model was created by Knopf et al. [16] with focus on dispatch of power plants without consideration of power flow constraints. According to Knopf et al., the nuclear power phase-out will increase the wholesale electricity market price by $11 \%$ in 2015 and $23 \%$ in 2020 . Additionally, Knopf et al. [16][15] also states that the uncertainty in gas price or demand has higher impact on the electricity price as the nuclear power phase-out.

Fürsch et al. [17] applied a dispatch model for the European electricity and combined heat markets (DIME) with net transfer capacities (NTC) as constraint for exchange between countries. In contrast to Knopf et al., Fürsch et al. reported a lower wholesale market price in the future with nuclear power phase out in Germany because of increased implementation of RES.

Kunz et al. [18] used the ELMOD model to investigate the effect of a phase out of Germany's nuclear plants. ELMOD is based on DC optimal power flow framework and has been developed by Leuthold et al. [19][20]. It was developed to analyze market design, congestion management and in investment decisions on the European electricity market. Kunz et al. [18] used a reduced version of the ELMOD model for a typical winter day with focus on Germany. The model simulates the market for 24 hours of November 2010. It is applied for scenarios with partly and entire nuclear power shutoff in Germany. A future scenario for 2022 was not performed. The results showed that exports in Germany dropped by $25 \%$ and the imports increased by nearly the same amount at start of the nuclear moratorium where eight nuclear reactors are offline in Germany. In this case France and Czech Republic increased their export to Germany by $20 \%$. A complete phase out of nuclear power in the ELMOD model resulted in an export drop to $20 \%$ and the imports double of Germany. In this scenario only Switzerland and Poland remain as net importer from the German power grid. Austria and Netherlands shifted from importer to exporter. All in all, generation from nuclear power will be replaced by coal and gas power and no significant supply securities or network constraints will appear if the planned projects will be realized.

Another model based on DC optimal power flow equations with focus on Germany was developed by Bruninx et al. [21]. The aim of this model was to investigate different scenarios for a nuclear power phase out in Germany. In this model Germany is represented by 26 nodes and the neighbor countries have fixed export or import values. The model is used to simulate one day of different years (2012, 2017 and 2022) with different RES profiles. Results from Bruninx et al. confirmed the increase of coal and gas power as already [15], [16] and [18] reported. Another conclusion was that wind power curtailment is required at higher RES penetration. Further transmission line congestion is critical along the North-South lines, around Hamburg and between the connections from Germany to Poland. To some extent a prolonged lifetime of nuclear power could mitigate congestion. Finally an expansion of generation capacity and transmission grid will be necessary.

All models, except Bruninx et al. [21], are created before the start of the nuclear power phase-out in Germany in 2011. The models focus mainly on Germany or either neglect future development of the power system. As main finding of this review, none of the above mentioned works models the Austrian power grid in detail. Regional models without using the DC optimal power flow framework are applied in many cases or a constant power exchange between Austria and Germany is assumed. Therefore this thesis focuses on Austria, uses the DC optimal power flow framework and investigates the effect of a nuclear power phase-out on Austria for different scenarios. 


\section{Methodology}

This section presents the applied methodology for the study of the nuclear power phase-out in Germany. It is described how the model of the Austrian and German power system is created. Furthermore, the different scenarios in this thesis are explained.

First of all, the power grid data has to be gained and converted to an appropriate format. Figure 3.1 shows how the model is constructed for the base case. A power system reduction method is applied to reduce the power system to relevant nodes. In order to validate the reduced system the power flow is compared with the power flow from Hutcheon and Bialek [5]. When the deviation of this comparison was within an acceptable range the model was combined with the data of the Austrian power grid. At next power plants are allocated in the model. The allocation of the power plants to nodes was revised if the power flow result between Austria and Germany did not fit with power flow values from the real data [8]. The base case model was completed when the power flow between Austria and Germany was similar.
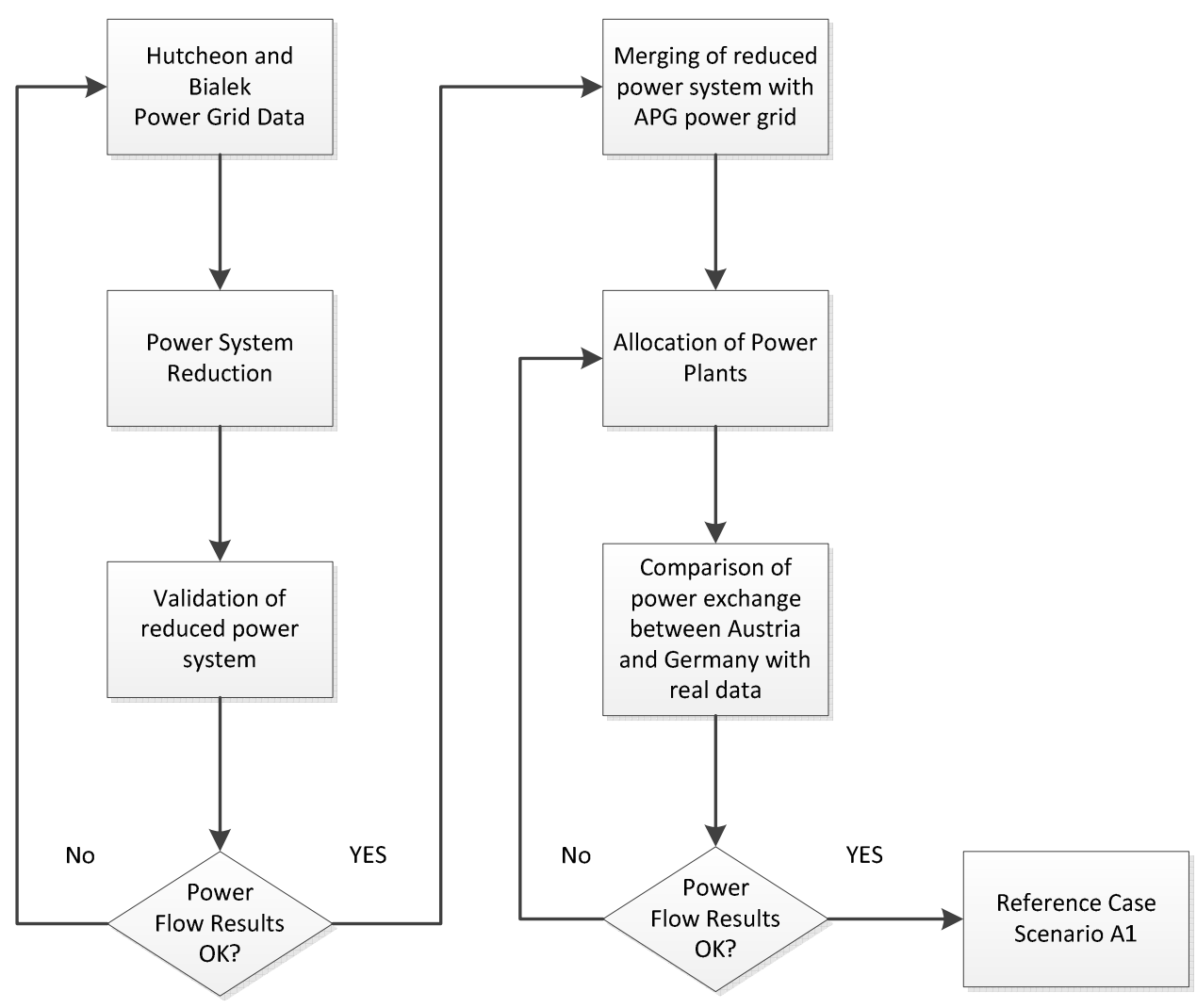

Figure 3.1: Methodology for construction of power system model

Nine different scenarios are simulated with the GAPS model. The GAPS model will be describe in detail in chapter 4. An overview about the different scenarios is given in Table 2. Scenario A1 describes the base case which is the power system in 2013. The scenarios B simulate the year 2013 without nuclear power and different wind power generation levels. Finally, the scenarios C1, C2 and C3 represent the power system in 2022 where all nuclear power plants are phased out in the German power system. In the scenarios $\mathrm{C}$ new power plant capacities and planned transmission lines are added. 
Each scenario is tested for different wind power generation levels, low, medium and strong. (See Table 3) The low wind power capacity factor represents the real wind power generation of the reference day in 2013 which is $3.3 \%$ of the installed capacity in 2013. For medium and strong it is assumed that $20 \%$ and $40 \%$ of the installed wind power capacity will produce power.

Table 2: Overview of simulated scenarios in GAPS model

\begin{tabular}{|c|c|c|c|}
\hline & \multicolumn{3}{|c|}{ Simulated Power Systems } \\
\hline Power & 2013 & 2013 & 2022 \\
\hline Generation Level & With nuclear power & Without nuclear power & Without nuclear power \\
\hline Low & A1 & B1 & $\mathrm{C} 1$ \\
\hline Medium & $\mathrm{A} 2$ & B2 & $\mathrm{C} 2$ \\
\hline Strong & A3 & B3 & C3 \\
\hline
\end{tabular}

Table 3: Applied capacity factor for wind power generation

\begin{tabular}{lccc}
\hline & Low & Medium & Strong \\
\hline Wind power capacity factor [\%] & 3.3 & 20 & 40 \\
\hline
\end{tabular}

Figure 3.2 shows the methodology applied in this thesis. For all scenarios the total costs, power generation and transmission line congestion are calculated. Finally, the results of each scenario are discussed and compared with each other. After the comparison a conclusion is developed, which answers the research questions.

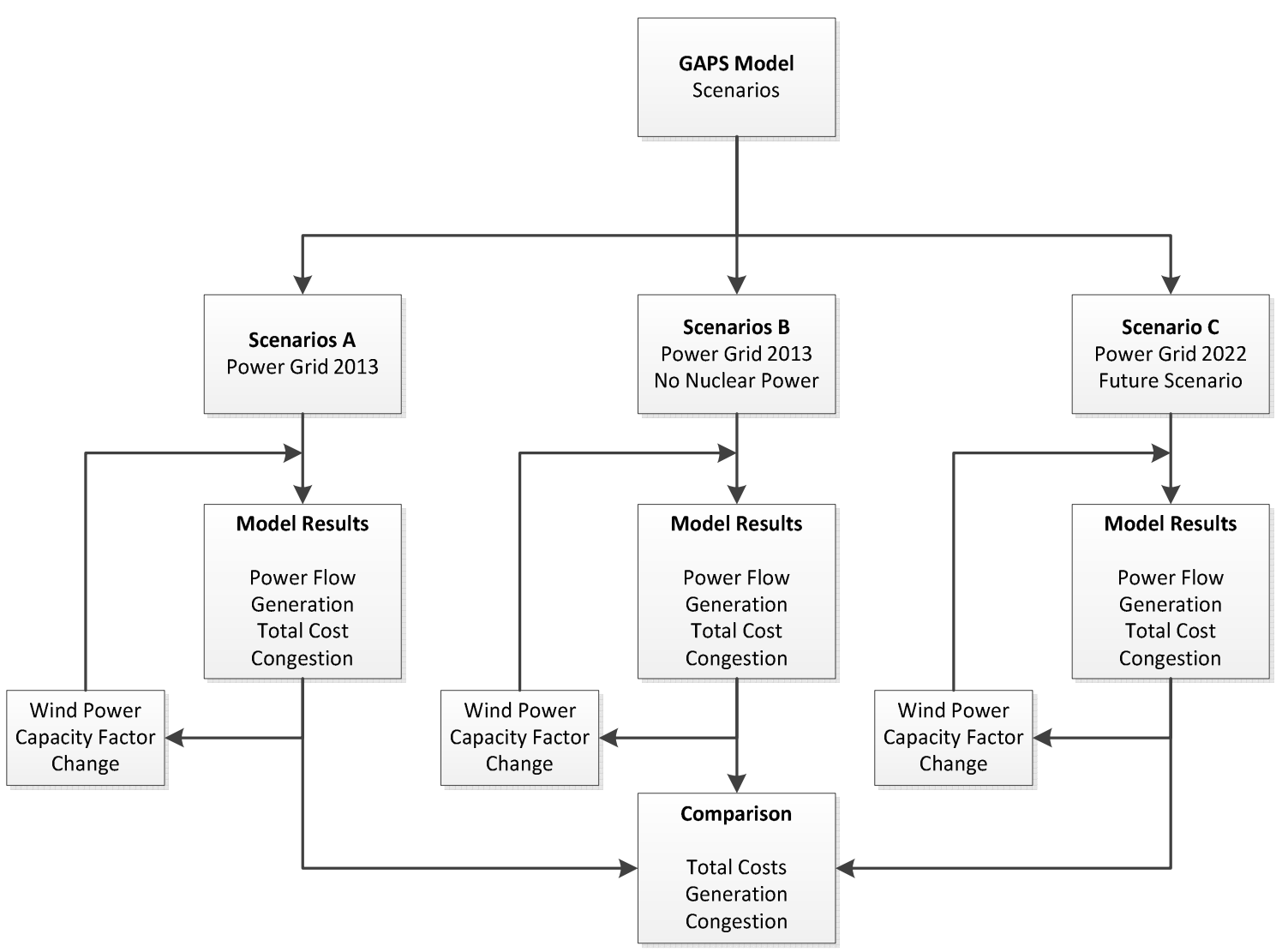

Figure 3.2: Methodology for the study of scenarios using the GAPS model 


\section{Mathematical Formulation of GAPS model}

This section presents the mathematical formulation of the GAPS model for the study. It is based on the multi-period dc optimal power framework [22]. The model of this thesis has 352 nodes which are connected via transmission lines. The transmission networks of both Germany and Austria are included in the model. The connections to the neighboring countries are represented by equivalents.

\subsection{Objective function}

The aim of the model is to minimize the total costs in the power system. As shown in (1) the total cost includes the generation cost from different conventional generation types $\left(P G_{i, n, t} * \cos _{n}\right)$ and also the cost from the application of pumped storage hydro power generation $\left(P G P S_{i, t} * \operatorname{costPS}\right)$. For the cost calculation of pumped storage hydro power only O\&M costs are considered because the cost for electricity generation are already accounted in the cost of conventional generation from power plants.

$$
\begin{aligned}
\text { Total Costs }= & \sum_{t=1}^{T} \sum_{i=1}^{I}\left(\sum_{n=1}^{N}\left(P G_{i, n, t} * \operatorname{cost}_{n}\right)+P G P S_{i, t} * \operatorname{cost} P S\right) \\
& \forall ; t, n, i, j
\end{aligned}
$$

\subsection{Constraints}

\subsubsection{Power flow}

In this thesis the DC optimal power flow framework is applied [22][23]. One of the main constraints is the power flow on transmission lines between busses $i$ and $j$ at time $t$. Equation (2) determines the power flow between the nodes based on the voltage angle difference and the susceptance $B_{i, j}$.

$$
\begin{array}{lc}
\text { Pflow }_{i, j, t}=\left(\delta_{i, t}-\delta_{j, t}\right) * B_{i, j} & \forall ; i, j, t \\
B_{i, j}=\frac{1}{X_{i, j}} & \forall ; i, j
\end{array}
$$

In the real power system the security plays an important role. The N-1 one condition allows a secure operation if one transmission line is not available due to a failure in the power system. In order to consider this in the model a limit for the power flow on transmission lines is set which is $75 \%$ of the thermal limit of the line (4).

$$
\text { Pflow }_{i, j, t} \leq 0.75 * \operatorname{Pmax}_{i, j} \quad \forall ; i, j, t
$$

\subsubsection{Power system balance}

An important constraint is that the power balance has to be satisfied between generation, demand, export and import at each time and node, Equation (5) [22] describes this constraint under consideration of the voltage angle and line admittance. Wind power, run of the river hydro power and solar power have fixed generation in the power system (see chapter 5).

$$
\begin{gathered}
\sum_{n=1}^{N} P G_{i, n, t}+P \text { wind }_{i, t}+P H P_{i, t}+P \operatorname{solar}_{i, t}+P G P S_{i, t}-P D P S_{i, t}-P D_{i, t}==\sum_{j=1}^{J} \delta_{j, t} * B_{i, j} \\
\forall ; t, n, i, j
\end{gathered}
$$




\subsubsection{Generation Limits}

The nodes in the system have a maximum power capacity per generation type. For simplification the minimum generation capacity is 0 in the model. Whereas $P G \max _{i, n}$ is the installed capacity of power plant type $n$ at node $i$.

$0 \leq P G_{i, n, t} \leq P \max _{i, n} \quad \forall ; i, n, t$

\subsubsection{Energy generation limit of seasonal storage hydro power}

Some power plants have also an energy generation limit besides their power capacity limit. This is due to the consideration of downtime for maintenances or fuel availability. E.g. hydro power as seasonal storage can only use a certain amount of water in one year. This means that output of the power plant is limited by the water availability. Therefore the amount of water is distributed over the simulated days and only certain amount of electricity can be generated per day of a seasonal storage hydro power plant (7).

$$
\begin{gathered}
\sum_{t=1}^{T} \text { PGseasonal }_{i, t} \leq \text { Emax }_{\mathrm{i}} \\
\forall ; i, t
\end{gathered}
$$

\subsubsection{Pumped storage hydro power}

Hydro power and pumped storage plays a significant role in the Austrian power system. Therefore hydro pumped storage is introduced in the model based on a constraint. First of all, the start value of pumped storage level and pumped storage generation is set zero. This assumption is made due to the fact that the pumped storage level of the first period is not known and that it differs from day to day.

$$
\begin{array}{ll}
\text { PPSlevel }_{i, t}=0 & \forall ; i, t=1 \\
\text { PGPS }_{i, t}=0 & \forall ; i, t=1
\end{array}
$$

For the calculation of the hydro pumped storage level (10) is used. The storage level PPSlevel i,t $_{\text {of }}$ period $t$ is calculated by the sum of the storage level of the previous period and the stored hydro power in period $t$ minus the electricity generated from pumped storage hydro power in period $t$. It is assumed that the efficiency $\eta$ of the hydro turbine and pump is constant at 0.9 .

$$
\begin{aligned}
& \text { PPSlevel }_{i, t}=\text { PPSlevel }_{i, t-1}-\frac{P G P S_{i, t}}{\eta}+P D P S_{i, t} * \eta \\
& \forall ; t>1, i
\end{aligned}
$$

\subsubsection{Ramp up and Ramp down constraint}

The power plants types $n$ are allowed to increase or decrease their output by $P_{c h a n g} e_{n}$. It is assumed that Pchange $_{n}$ is the same for the ramp up and ramp down process. The following two equations (12) and (13) represent the ramp up and ramp down constraint in the model.

$$
\begin{array}{ll}
P G_{i, n, t} \leq P G_{i, n, t-1}+\text { Pchange }_{n} & \forall ; i, n, t>1 \\
P G_{i, n, t} \geq P G_{i, n, t-1}-\text { Pchange }_{n} & \forall ; i, n, t>1
\end{array}
$$




\subsection{Modeling Comments}

The model described above has been implemented in GAMS and solved using XA solver [3]. The model has been formulated as linear programming (LP) problem. It simulates 24 hours and different scenarios are applied for this day (see chapter2).

During the creation and execution of the model a workspace error appeared. The simulation was running out of work space or could not allocate a suitable amount of workspace to the simulation of the model. In order to solve the problem the GAMS support [24] was contacted. The problem was solved by allocating a certain amount of workspace manually to the simulation. However the utilization of workspace was limited at 4 GB RAM due to the used GAMS license. Therefore the total amount of $16 \mathrm{~GB}$ installed workspace in the computer could not be utilized. This led to high computing times of 6 hours on an average for the simulation of one scenario. 


\section{Data and Assumptions}

This chapter describes how data for the model is gained and combined from different sources. Main sources for data are Bundesnetzagentur, APG, Entso-E, EEX and Hutcheon \& Bialek. Data for each $3^{\text {rd }}$ Wednesday of each month of the year 2013 is collected. For power generation from wind, solar, seasonal storage and run of the river power plants is used the historical data. Each neighbor country of Austria and Germany is represented by on node with fixed generation and demand levels based on historic values.

\subsection{Generation capacity data of Austria and Germany}

Bundesnetzagentur provided data of the installed generation capacity in Germany in 2013 [25]. Values for power generation capacities in Germany in 2020 are gained from [10] and [26] and stated in the following Table 4. The scenario A of Entso-E represents a conservative scenario for 2020. In this scenario only power plants are considered which are assumed to be planned. Scenario B also called best estimate scenario in [26] shows the potential future development under certain market incentives. The composition of the power plant type"several fuel sources" is unclear. It is assumed that it is coal power because it is a cheap fuel. Furthermore future scenarios from Entso-E and Energy Agency do not apply this term.

Table 4: Installed generation capacity in Germany in 2013 and 2020

\begin{tabular}{lrrrr}
\hline Power plant types & $\begin{array}{r}\text { Bundesnetzagentur, } \\
\mathbf{2 0 1 3}[\mathbf{M W}][\mathbf{2 5}]\end{array}$ & $\begin{array}{r}\text { Energy Agency } \\
\mathbf{2 0 2 0}[\mathbf{M W}][\mathbf{1 0}]\end{array}$ & $\begin{array}{r}\text { Entso-E 2020 } \\
\text { Scenario A [MW][26] }\end{array}$ & $\begin{array}{r}\text { Entso-E 2020 } \\
\text { Scenario B [MW][26] }\end{array}$ \\
\hline Natural Gas & 21641 & 18000 & 23340 & 32450 \\
Hard coal & 21092 & 20400 & 35130 & 28990 \\
Lignite & 19867 & 24300 & 20920 & 19222 \\
Biomass & 5813 & 6200 & 7700 & 8100 \\
Nuclear & 12068 & 6700 & 8100 & 8100 \\
Pump Storage & 6351 & 8400 & 7300 & 7300 \\
Onshore wind energy & 32005 & 37000 & 42000 & 44500 \\
Hydroelectric power & 3523 & 5800 & 4800 & 4900 \\
Offshore wind energy & 508 & 14000 & 8100 & 10300 \\
Solar power & 35651 & 17900 & 54400 & 57100 \\
Several fuel sources & 1630 & & & \\
\hline
\end{tabular}

German power system in 2013 and 2022 is modelled based on the values in Table 4. It is assumed that no changes of generation capacity appear between 2020 and 2022. For the nuclear power phase-out scenario in 2022 no nuclear power capacity is available. It is noticeable that the installed solar power capacity in 2013 is already twice as much as the expectations for 2020 of the German Energy Agency in 2010. Both Entso-E scenarios consider a strong development of RES in Germany until 2020 and differ mainly in use of fossil fuels. Scenario B is used as "best estimation" as input data for the model in 2022 .

Entso-E scenarios are not detailed enough for Austria in 2020. Therefore an assumption is made based on Data from APG [27] for installed capacity in Austria in 2022. Table 5 shows the input data for the 
model. It is assumed that in Austria are mainly new capacity of wind power and photovoltaic are installed.

Table 5: Installed generation capacity in GAPS model

\begin{tabular}{lrrrr}
\hline Generation systems & $\begin{array}{r}\text { Austria 2013 } \\
\text { [MW] [28] }\end{array}$ & $\begin{array}{r}\text { Austria 2022 } \\
{[\mathbf{M W}]}\end{array}$ & $\begin{array}{r}\text { Germany 2013 } \\
{[\mathbf{M W}][\mathbf{2 6}]}\end{array}$ & $\begin{array}{r}\text { Germany 2022 } \\
\text { [MW] [27] }\end{array}$ \\
\hline Natural Gas & 3139 & 3139 & 21641 & 32450 \\
Hard Coal & 1226 & 1226 & 21092 & 28990 \\
Lignite & 0 & 0 & 19867 & 19222 \\
Biomass & 0 & 0 & 5813 & 8100 \\
Nuclear & 0 & 0 & 12068 & 0 \\
Storage power plants & 3364 & 3364 & 6351 & 7300 \\
Wind power & 1689 & $3000[27]$ & 32513 & 54800 \\
Hydroelectric power & 5368 & 5368 & 3523 & 4900 \\
Solar power & 326.8 & $1200[27]$ & 35651 & 57100 \\
Several fuel sources & 1898 & 1898 & 1630 & 0 \\
Seasonal storage & 2914 & 2914 & 0 & 0 \\
\hline
\end{tabular}

Due to low electricity market prices and high gas prices gas power plants have difficulties to compete with other technologies in the power system. This led to a temporary shutdown of gas power plants in Austria. A big market player in Austria, Verbund AG, decided to shut down an approx. $800 \mathrm{MW}$ gas power plant in Mellach which was built in 2011. Due to low profitability it is assumed that the power plant will be shut down for at least 4-5 years [29]. Therefore this capacity is already removed from values in the table above but could be used in 2022 if a shortage of natural gas power plant appears.

\subsection{Distribution of power plant capacity in GAPS model}

\subsubsection{Germany}

Power plant capacites in Germany are roughly distributed by region [25] and location of power plants in the Entso-E network map [30].For simplicity generation types are neglected if below $50 \mathrm{MW}$ in a region. Data for hydro power generation in Germany is gained from AGEB [31] and the hydro power generation is assumed to be constant over the year. The allocation of capacity was revised if too much capacity was allocated to some nodes. Transmission line congestion during tests indicated that too much capacity was allocated to one node.

The available generation information of wind power plants [32] is distributed by the installed wind power capacity in one area [25]. According to IWES [33] most of the wind power plants are located in the northern parts in Germany.

\subsubsection{Austria}

Allocation of power plants above $100 \mathrm{MW}$ to nodes in the Austrian power system is done based on [32]. The mismatch of capacities between [32] and [28] is allocated manually based on scaling and ENTSO-E [30]. The remaining gas power plant capacity is assumed to be connected to nodes close to big cities in Austria. 
Solar power capacity is distributed to nodes which are located in regions with a high average annual sum of the yearly global radiation [34]. Therefore all solar power capacity is installed in South and East Austria. Wind power capacity is allocated to the system by information of the Austrian Wind Energy association [35]. Wind power plants are mainly installed in northern and eastern parts of Austria. Therefore the wind power capacity is evenly distributed to network nodes in these regions.

Run of the river and seasonal storage hydropower plants are allocated by the Entso-E network map [30] and [21]. The available energy for hydro power plants per year is gained from the electricity generation report of the year 2012 [36]. It is assumed that run of the river hydro power plant have a constant power flow over the year. In contrast to this the seasonal hydro power storage can dispatch the allocated energy amount over one day and pumped storage hydro power plants can schedule the generation under consideration of constraints.

In Figure 5.1 one can see the main nodes of the power system in Austria. The amount of installed generation capacity at each Node in Austria is stated in Table 6.

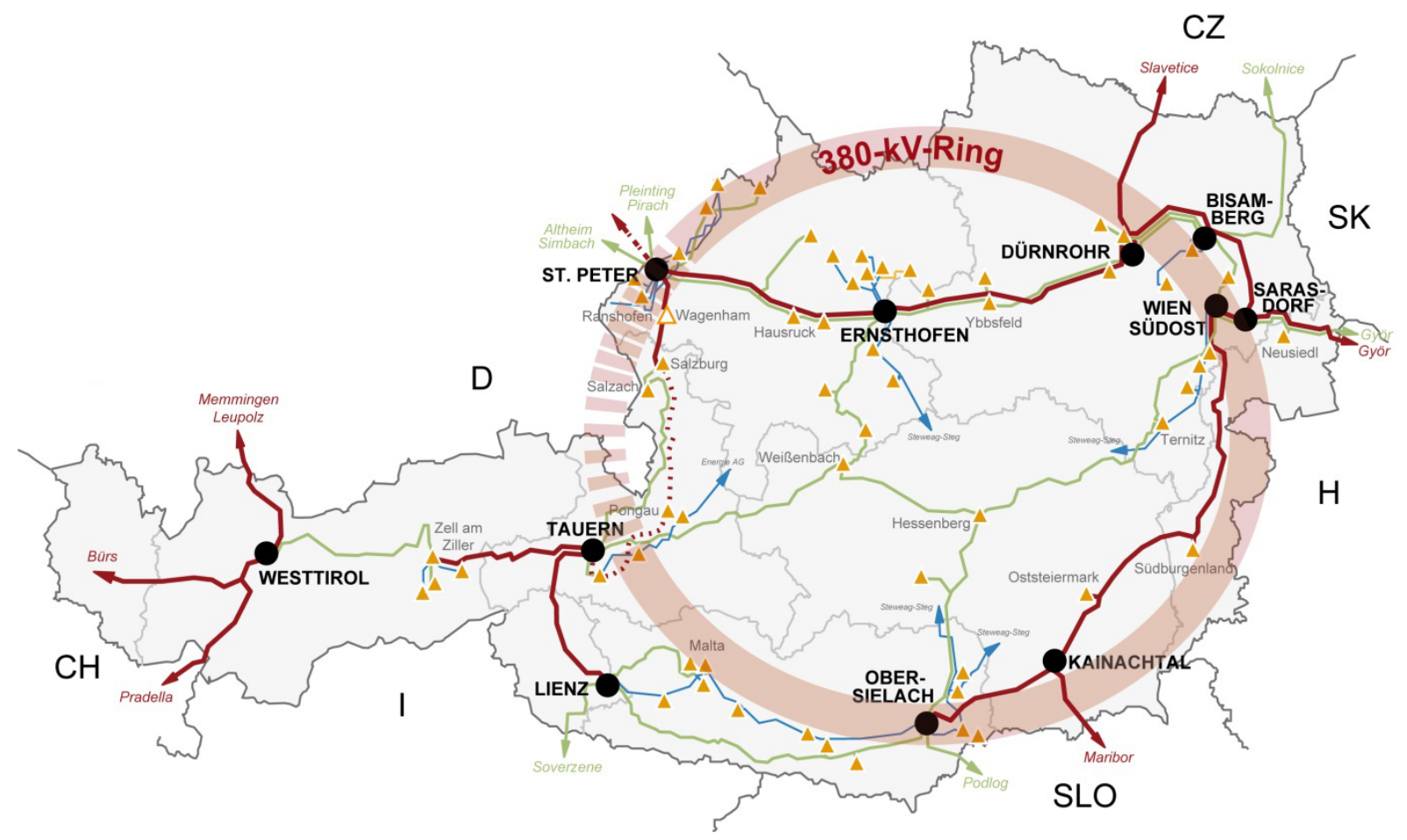

Figure 5.1: APG Network Map with main nodes in Austria [8] 
Table 6: Table with node names and allocated generation capacity in MW in 2013 in Austria

\begin{tabular}{|c|c|c|c|c|c|c|c|c|c|}
\hline Node & $\begin{array}{c}\text { Voltage } \\
{[\mathrm{kV}]}\end{array}$ & Coal & $\begin{array}{c}\text { Natural } \\
\text { Gas }\end{array}$ & $\begin{array}{l}\text { Several } \\
\text { Sources }\end{array}$ & $\begin{array}{l}\text { Seasonal } \\
\text { Storage }\end{array}$ & $\begin{array}{l}\text { Run of } \\
\text { the river }\end{array}$ & Solar & Wind & $\begin{array}{l}\text { Pumped } \\
\text { Storage }\end{array}$ \\
\hline Meiningen 1 & 220 & & & & & & & & 124 \\
\hline Meiningen 2 & 220 & & & & 287 & 472 & & & \\
\hline Walguwerk & 220 & & & & 287 & & & & 247 \\
\hline Werben & 220 & & & & & 472 & & & \\
\hline Silz & 220 & & & & 287 & 472 & & & 124 \\
\hline Aschach & 220 & & & & & 287 & & & \\
\hline Bisamberg & 380 & & 83 & & & & & & \\
\hline Bisamberg & 220 & & 290 & & & 293 & & & \\
\hline Dürnrohr & 380 & 807 & & & & & & & \\
\hline Dürnrohr & 220 & & & & & 328 & & 338 & \\
\hline Ernsthofen & 380 & & 83 & & & & & & \\
\hline Etzersdorf & 380 & & 625 & 444 & & 187 & 65 & 338 & \\
\hline Feistritz & 220 & & & & 287 & 472 & & & 124 \\
\hline Kainachtal & 380 & & & 166 & & & 65 & & \\
\hline Kaprun & 220 & & & & 647 & 472 & & & 236 \\
\hline Limberg & 380 & & & & & & & & 480 \\
\hline Malta 2 & 220 & & & & & & & & 730 \\
\hline Malta 2 & 220 & & & & & & & & 120 \\
\hline Mayrhofen & 220 & & & & 345 & & & & 360 \\
\hline Mellach & 380 & 249 & & & & & & & \\
\hline Neusiedel & 220 & & & & & & 65 & 507 & \\
\hline Obersielach & 380 & & 83 & & & & & & \\
\hline Oststeiermark & 380 & & & & & & 65 & 169 & \\
\hline Rosegg & 220 & & & & & & & & 465 \\
\hline Salzburg & 220 & 170 & 483 & 444 & & & & & \\
\hline Ternitz & 220 & & & & & & 65 & 338 & \\
\hline Wallsee & 220 & & & & & 210 & & & \\
\hline Weißenbach & 220 & & & & & 472 & & & 124 \\
\hline Westtirol & 380 & & 83 & & & & & & 231 \\
\hline Wien 1 & 380 & & 1726 & 444 & & 172 & & & \\
\hline Wien 2 & 220 & & & & & 179 & & & \\
\hline YBBS & 220 & & & & & 237 & & & \\
\hline Zell & 220 & & & & 774 & 472 & & & \\
\hline Sum & & 1226 & 3455 & 1497 & 2914 & 5200 & 327 & 1690 & 3364 \\
\hline
\end{tabular}




\subsection{Total costs of electricity generation}

Fuel and O\&M costs are taken from IEA [37]. Different costs are used for Germany and Austria in the model. For simplification, it is assumed that all gas power plants are CCGT. Fuel costs for solar, Wind and hydro are set zero because the fuel is free available. Furthermore are set the costs of biomass zero because it is assumed that it will be used always as base load and hence it will be not dispatched by the nuclear power phase-out. The O\&M costs of RES are also neglected because those power plants will always feed in their electricity generation to the grid. An investigation of the impact of a $\mathrm{CO}_{2} \operatorname{tax}$ is not included in the scope of this thesis. Therefore no $\mathrm{CO}_{2}$ tax is considered for the different power plants.

It is assumed that power plants with several fuel options in Germany use hard coal because of price and availability of coal. Fuel costs for heavy oil are 7.3 EU/MWh [38]. Under the assumption of an efficiency of $40 \%$ the costs will be 198 EU/MWhel. Table 7 shows the variable costs for the different types of electricity generation in Germany.

Table 7: Variable costs of electricity generation in Germany [EU/MW $\left.\mathrm{el}_{\mathrm{el}}\right]$

\begin{tabular}{cccccccc}
\hline Biomass & Coal & Natural Gas & Lignite & Nuclear & Oil & $\begin{array}{c}\text { Several fuel } \\
\text { sources }\end{array}$ & $\begin{array}{c}\text { Pumped storage } \\
\text { hydro power }\end{array}$ \\
\hline 0 & 27.77 & 44.4 & 17.21 & 12.33 & 198 & 27.77 & 7.17 \\
\hline
\end{tabular}

In Table 8 the variable costs for electricity generation in Austria are listed. Costs for coal and gas are assumed to be 20 per cent higher because of the natural availability of the fuels in Austria. Further the price difference between Austria and Germany is important to create a similar export/import pattern between Austria and Germany as in reality.

Table 8: Variable costs of electricity generation in Austria [EU/MW $\left.\mathrm{el}_{\mathrm{el}}\right]$

\begin{tabular}{cccccc}
\hline Biomass & Coal & Natural Gas & Oil & $\begin{array}{c}\text { Several fuel } \\
\text { sources }\end{array}$ & Pumped storage hydro power \\
\hline 0 & 33.33 & 53.28 & 198 & 60 & 7.17 \\
\hline
\end{tabular}

In Austria is no lignite or nuclear power plant in operation. Therefore are considered no variable costs of these sources in Austria. It is uncertain which fuel is used for power plant with several fuel sources. In order to maintain a power exchange pattern between Austria and Germany which is close to reality it is assumed that the power plants with several fuel sources have a higher price in Austria than in Germany.

\subsection{Power grid data}

This thesis uses real grid data and load data of the Austrian power grid which is provided by APG [4]. Therefore it is not allowed to publish the grid data in this thesis. Within this it was not possible to acquire the real grid data of Germany because of a long and complex procurement process for the German power grid data [39]. Therefore public available data from Hutcheon \& Bialek [5] is used in order to model the German power grid. This data set was used to model the European power system with focus on the exchange between the countries. The power flow of this model between countries is validated by comparisons with real data [5]. However, a comparison of the flow within Germany is not made with real data. This means that values from the power flow within Germany are fraught with uncertainties. Additionally, was used no transmission line limit for transmission lines within Germany 
in the studies of Hutcheon \& Bialek. Therefore the transfer capacity limit of all transmission lines in Germany is set manually to a high level since the focus of this thesis is on Austria.

\subsection{Entsoe-E power exchange data}

The power exchange data is provided by Entso-E for each $3^{\text {rd }}$ Wednesday at 3 am and 11 am at each month [40]. It is assumed that the power exchange is constant from $8 \mathrm{pm}$ till 7 am with the power exchange value of $3 \mathrm{am}$ and for the period $7 \mathrm{am}$ till $8 \mathrm{pm}$ with the value of $11 \mathrm{am}$. The power transfer is split if one neighbor country has more than one bus in the model. Table 9 shows the power flow between the Germany and the neighbor countries. A positive value is export from Germany and a negative value is import to Germany.

Table 9: Grid exchange data of Germany with neighbor countries of $16^{\text {th }}$ January 2013 in MW

\begin{tabular}{ccccccccc}
\hline Hour & $\mathbf{C H}$ & $\mathbf{C Z}$ & $\mathbf{D K}$ & $\mathbf{F R}$ & $\mathbf{L U}$ & $\mathbf{N L}$ & $\mathbf{P L}$ & $\mathbf{S E}$ \\
\hline 0 & 2314 & -2169 & 1053 & 80 & 1044 & 3245 & -148 & 0 \\
1 & 2314 & -2169 & 1053 & 80 & 1044 & 3245 & -148 & 0 \\
2 & 2314 & -2169 & 1053 & 80 & 1044 & 3245 & -148 & 0 \\
3 & 2314 & -2169 & 1053 & 80 & 1044 & 3245 & -148 & 0 \\
4 & 2314 & -2169 & 1053 & 80 & 1044 & 3245 & -148 & 0 \\
5 & 2314 & -2169 & 1053 & 80 & 1044 & 3245 & -148 & 0 \\
6 & 2314 & -2169 & 1053 & 80 & 1044 & 3245 & -148 & 0 \\
7 & 1253 & -2292 & -1329 & 24 & 378 & 2922 & -672 & -591 \\
8 & 1253 & -2292 & -1329 & 24 & 378 & 2922 & -672 & -591 \\
9 & 1253 & -2292 & -1329 & 24 & 378 & 2922 & -672 & -591 \\
10 & 1253 & -2292 & -1329 & 24 & 378 & 2922 & -672 & -591 \\
11 & 1253 & -2292 & -1329 & 24 & 378 & 2922 & -672 & -591 \\
12 & 1253 & -2292 & -1329 & 24 & 378 & 2922 & -672 & -591 \\
13 & 1253 & -2292 & -1329 & 24 & 378 & 2922 & -672 & -591 \\
14 & 1253 & -2292 & -1329 & 24 & 378 & 2922 & -672 & -591 \\
15 & 1253 & -2292 & -1329 & 24 & 378 & 2922 & -672 & -591 \\
16 & 1253 & -2292 & -1329 & 24 & 378 & 2922 & -672 & -591 \\
17 & 1253 & -2292 & -1329 & 24 & 378 & 2922 & -672 & -591 \\
18 & 1253 & -2292 & -1329 & 24 & 378 & 2922 & -672 & -591 \\
19 & 1253 & -2292 & -1329 & 24 & 378 & 2922 & -672 & -591 \\
20 & 2314 & -2169 & 1053 & 80 & 1044 & 3245 & -148 & 0 \\
21 & 2314 & -2169 & 1053 & 80 & 1044 & 3245 & -148 & 0 \\
22 & 2314 & -2169 & 1053 & 80 & 1044 & 3245 & -148 & 0 \\
23 & 2314 & -2169 & 1053 & 80 & 1044 & 3245 & -148 & 0 \\
\hline & & & & & & & &
\end{tabular}

The power flow between Austria and its neighbor countries is shown in Table 10. A positive value is export from Austria and a negative value is import to Austria. The power transfer is split up if one neighbor country has more than one bus in the system. This distribution is done roughly by data from APG. 
Table 10: Grid exchange data in MW of Austria with neighbor countries of $16^{\text {th }}$ January 2013

\begin{tabular}{|c|c|c|c|c|c|}
\hline Hour & $\overline{\mathrm{CH}}$ & $\mathbf{C Z}$ & $\mathbf{H U}$ & IT & $\overline{\text { SI }}$ \\
\hline 0 & 1102 & -467 & -587 & 255 & -665 \\
\hline 1 & 1102 & -467 & -587 & 255 & -665 \\
\hline 2 & 1102 & -467 & -587 & 255 & -665 \\
\hline 3 & 1102 & -467 & -587 & 255 & -665 \\
\hline 4 & 1102 & -467 & -587 & 255 & -665 \\
\hline 5 & 1102 & -467 & -587 & 255 & -665 \\
\hline 6 & 1102 & -467 & -587 & 255 & -665 \\
\hline 7 & 1480 & -129 & -175 & 184 & 350 \\
\hline 8 & 1480 & -129 & -175 & 184 & 350 \\
\hline 9 & 1480 & -129 & -175 & 184 & 350 \\
\hline 10 & 1480 & -129 & -175 & 184 & 350 \\
\hline 11 & 1480 & -129 & -175 & 184 & 350 \\
\hline 12 & 1480 & -129 & -175 & 184 & 350 \\
\hline 13 & 1480 & -129 & -175 & 184 & 350 \\
\hline 14 & 1480 & -129 & -175 & 184 & 350 \\
\hline 15 & 1480 & -129 & -175 & 184 & 350 \\
\hline 16 & 1480 & -129 & -175 & 184 & 350 \\
\hline 17 & 1480 & -129 & -175 & 184 & 350 \\
\hline 18 & 1480 & -129 & -175 & 184 & 350 \\
\hline 19 & 1480 & -129 & -175 & 184 & 350 \\
\hline 20 & 1102 & -467 & -587 & 255 & -665 \\
\hline 21 & 1102 & -467 & -587 & 255 & -665 \\
\hline 22 & 1102 & -467 & -587 & 255 & -665 \\
\hline 23 & 1102 & -467 & -587 & 255 & -665 \\
\hline
\end{tabular}

\section{$5.6 \quad$ Load}

Load values for Germany, on an hourly basis, are taken from Entso-E for $16^{\text {th }}$ January 2013[41]. The values for Austria are gained from APG [42]. In Figure 5.2 and Figure 5.3 the demand for Austria and Germany is shown. The peak loads are during hours 10,11, 17 and 18.

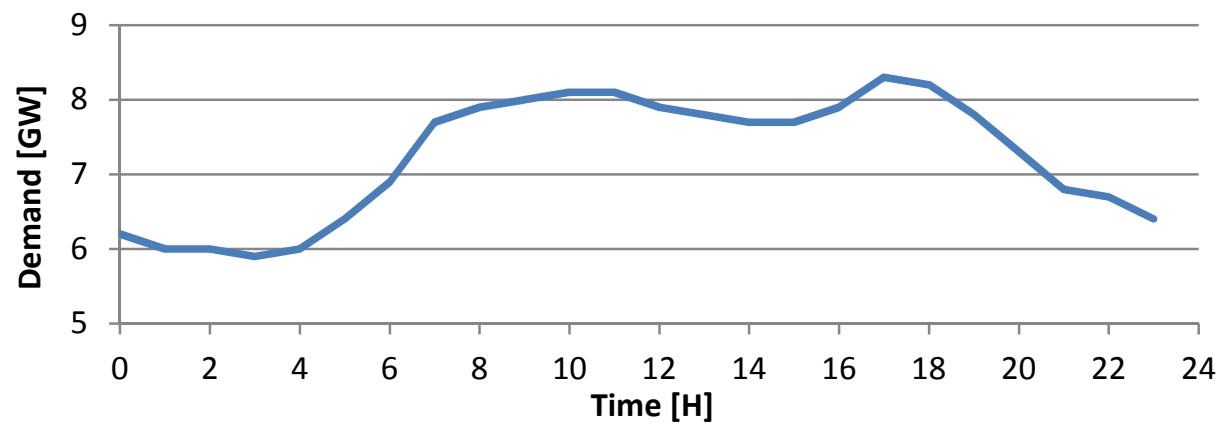

Figure 5.2: Demand in Austria in 2013 


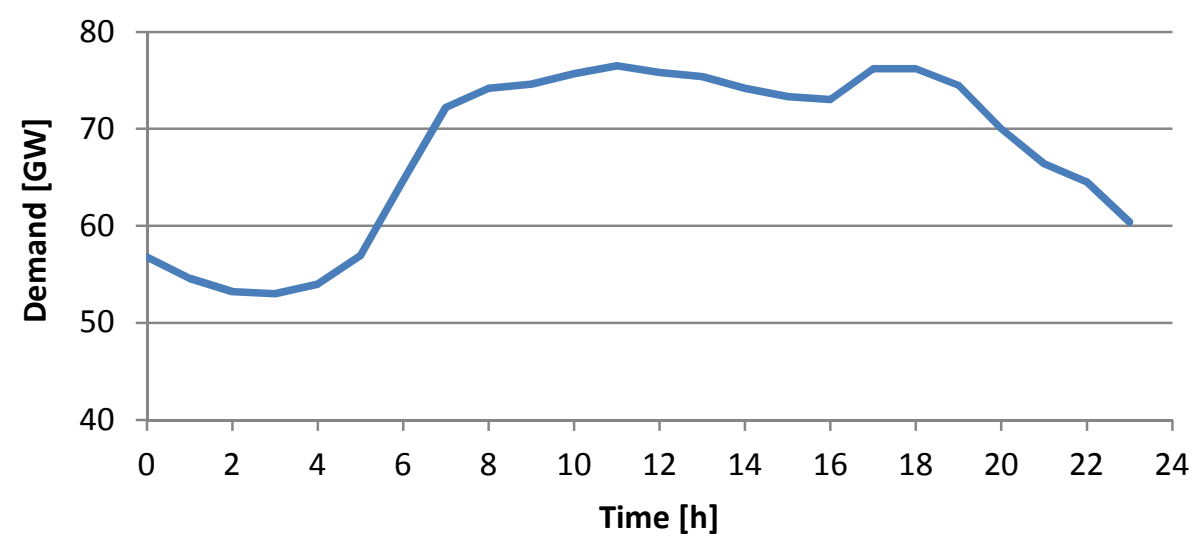

Figure 5.3: Demand in Germany in 2013

A table with the exact values of the demand in Austria and Germany in 2013 can be found in appendix 9.

Electricity demand for future scenarios is provided by IEA Energy Outlook report [43]. The report estimated an average annual growth of electricity demand between $1.1 \%$ and $0.5 \%$ till 2035 for Europe. Further IEA [43] states also that electricity demand growth depends on implemented policies and economic growth. APG [27] assumed a demand growth of 1.3\% per year till 2020. For this thesis is considered an annual demand growth of $1 \%$. Therefore the electricity demand in Austria and Germany in 2022 is $8 \%$ higher compared to 2013.

\subsection{Power system reduction}

The main purpose of this thesis is to investigate how the phasing-out of nuclear power in Germany affects the Austrian power system. Data for the real Austrian power grid is provided by the transmission system operator APG [4]. Within this thesis it was not possible to gain the real power grid data for Germany since it is a process which requires a lot of resources and time [39]. Therefore data for the German power grid data is gained from a public source [5]. This source provides a model of the whole European power system. Since the focus of this thesis is on Germany and Austria and the real data is available for the Austrian power grid, only the power grid data for Germany is used from the public source. A system reduction is applied to reduce the nodes of the German neighbor countries in the public data set. At first a susceptance matrix $\boldsymbol{B}_{i, j}^{\prime}$ with the susceptance values of the transmission lines between the nodes was created. The system reduction is based on (14) [44]. In this equation the indexes $i$ and $j$ are the regular nodes whereas $k$ is the node which will be reduced from the system. The current in the entire interconnected system is assumed to be constant because it is not relevant for the further use of the model. As result of the system reduction the susceptance matrix $B_{i, j}$ contains the information of only relevant transmission lines within Germany and connections to neighbor countries of Germany.

$$
B_{i, j}=B_{i, j}^{\prime}-\frac{B_{i, k}^{\prime} B_{k, j}^{\prime}}{B_{k, k}^{\prime}} \quad \forall ; i, j, k
$$

In order to complete the new susceptance matrix one has to calculate again the bus susceptance $B_{i, i}$ based on the new $B_{i, j}(15)$. 


$$
B_{i, i}=-\sum_{j=1}^{J} B_{i, j}
$$

$$
\forall ; i, j
$$

\subsection{Power grid Scenario 2022}

In Table 11 are listed all considered network development projects of Austrian power grid for a future model of the grid. The characteristic values of new transmission lines are calculated with electric parameters of overhead lines [45] and the length of the new transmission lines

Table 11: Transmission network development projects in Austria [46]

\begin{tabular}{ll}
\hline APG Project number & \multicolumn{1}{c}{ Description } \\
\hline $11-5$ & Update of connection Etzersdorf and St.Peter to 380KV \\
$11-6$ & 2 additional $380 \mathrm{kV}$ circuits from Bisamberg to Sarasdorf \\
$11-7$ & St. Peter to Germany (Isar/Ottenhofen) update to $380 \mathrm{kV}$ \\
$11-10$ & Update of connection St. Peter - Tauern to $380 \mathrm{kV}$ \\
\hline
\end{tabular}

For Germany in 2022 the implementation of DC transmission lines [47] and the previously mentioned improvement of connection from St. Peter to Germany is considered. Table 12 shows the planned transmission line path of DC transmission lines in Germany. Three DC transmission line corridors should be established by 2022. The aim of the DC lines is to increase the power transmission capacity between the northern and southern part of Germany. Due to increased RES penetration this corridors will be important for the operation of the future grid. The transmission line capacity limit of each DC transmission line is set to $1000 \mathrm{MW}$.

Table 12: DC Transmission Lines in Germany [47]

\begin{tabular}{lll}
\hline DC transmission line & From & To \\
\hline Corridor A & Emden & Düsseldorf \\
Corridor A & Düsseldorf & Karlsruhe \\
Corridor C & Wilster & Grafenrheinfeld \\
Corridor C & Brunsbüttel & Großgartach \\
Corridor D & Lauchstädt & Meitingen \\
\hline
\end{tabular}

\section{9 $\mathrm{CO}_{2}$-Emissions of electricity generation in Austria and Germany}

The $\mathrm{CO}_{2}$ emissions of electricity production depend on the fuel type and the efficiency of the power plant type. It is assumed that all power plants of one fuel type have the same $\mathrm{CO}_{2}$ emissions. The $\mathrm{CO}_{2}$ emissions presented in Table 13 are based on average values of [48].

Table 13: $\mathrm{CO}_{2}$-Emissions of electricity generation

\begin{tabular}{lccc}
\hline & Natural Gas & Coal & Lignite \\
\hline $\mathrm{CO}_{2}$-Emissions $\left[\mathrm{gCO}_{2} / \mathrm{kWh}_{\mathrm{el}}\right]$ & 450 & 900 & 1100 \\
\hline
\end{tabular}




\section{Results and Discussions}

In this chapter the results of the model evaluation and different scenarios are presented. At first the result of the model evaluation is shown. Then the results of the scenarios A with different wind power levels are displayed. At next the behavior of the power system without nuclear power is simulated in scenarios B. Finally, the results of the future system in 2022 are stated in the C scenarios. An overview of the investigated scenario is shown in Table 2. At the end of this chapter the results of each scenario with focus on total costs, change of generation, change of locational marginal price, congestion of transmission lines and usage of pumped storage hydro power are discussed and compared.

\subsection{Model evaluation}

The developed power system model is evaluated based on the power exchange between Austria and Germany. Power exchange results of the model are compared with the values of the real system [8]. In order to reach a comparable shape of the power exchange curves, it is assumed that the variable costs of electricity generation are higher in Austria as in Germany. Figure 6.1 shows the exchange between Austria and Germany. A positive value refers to import from Germany to Austria whereas a negative power exchange value means export from Austria to Germany. The results of the simulated case A1 are similar to the real system. Therefore the results of this thesis are representative for the real system. Only from hour 18 till 23 a high difference can be noticed. This can be explained by the simulation of only one day because pumped storage hydro power is not applied to store energy for the next days.

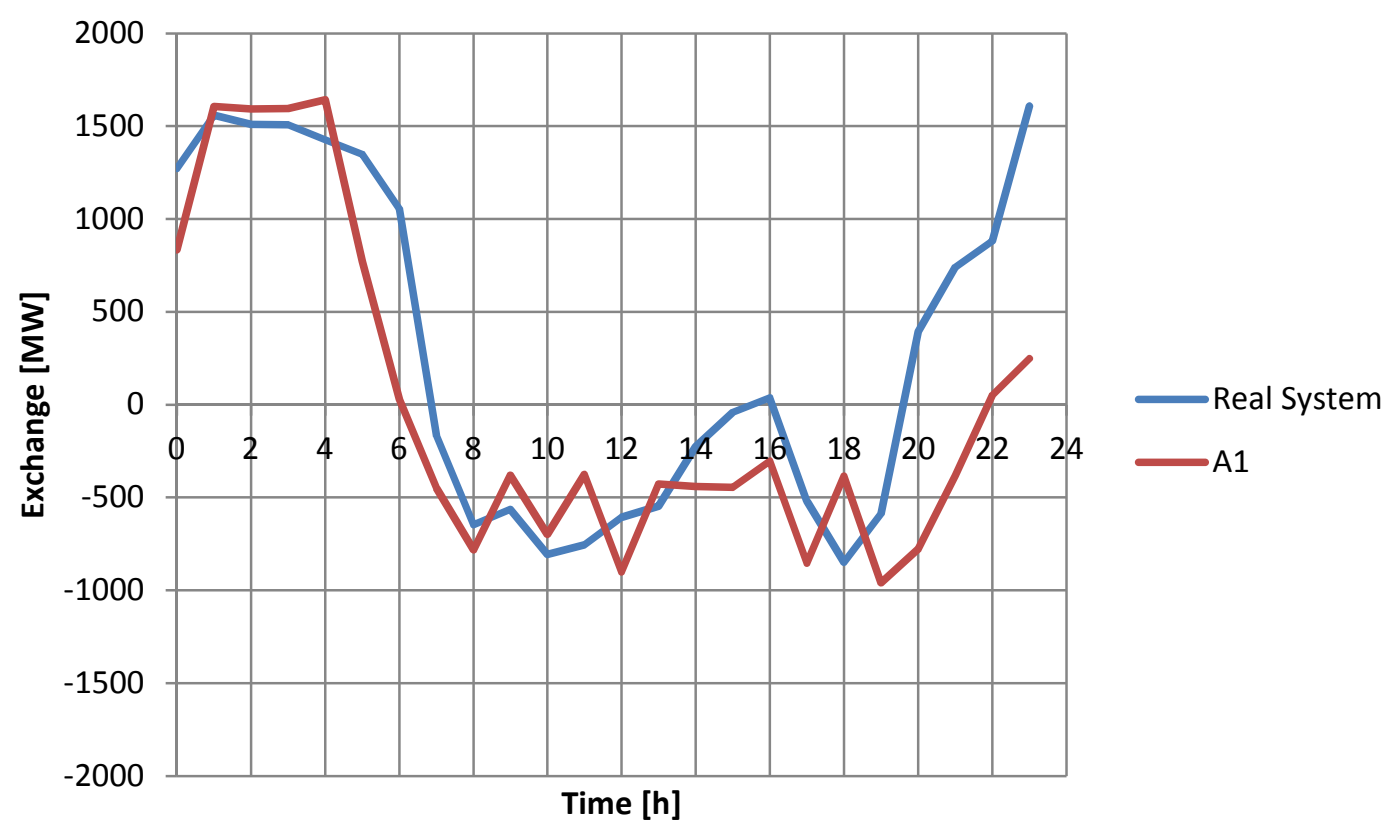

Figure 6.1: Import of Austria from Germany of real system and scenario A1 


\subsection{Scenarios $\mathrm{A}$}

\subsubsection{Scenario A1}

Scenario A1 is simulating the reference day which is the $16^{\text {th }}$ January 2013 . The main assumption of this case is that only $3.3 \%$ of the installed wind power capacity is generating electricity. Figure 6.2 shows the power generation profile for the base case A1 under low wind conditions.

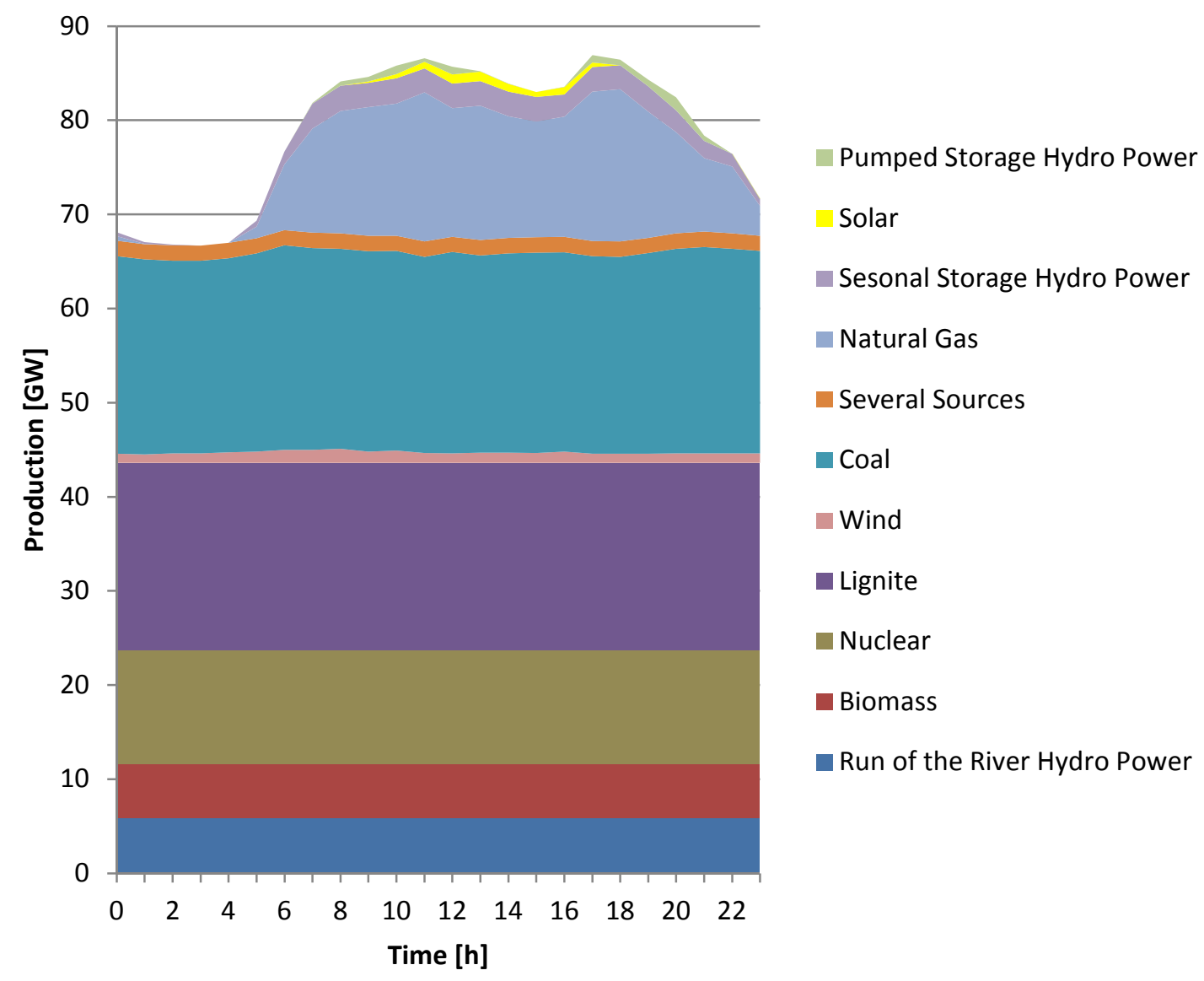

Figure 6.2: Power generation profile of Austria and Germany in case A1

Under low wind conditions the available base load power plants are fully utilized over the whole day. Changes of the load profile over the day are mainly satisfied by natural gas or seasonal storage hydro power plants. Solar power only contributes with approx. $1 \mathrm{GW}$ at the daily peak because the reference day is a winter day with low hours of sunshine. During the summer solar power can contribute with peak values of up to $22 \mathrm{GW}$ [32], hence solar power plays an important role in the German power system in summer. Pumped storage hydro power is only used to a small extend because natural gas power is most of the time on the margin and it is too costly to store power generated from natural gas.

Figure 6.3 presents the corresponding load curve to scenario A1. Pumped storage hydro power is used during the night for storage where base load coal power plants would not be fully utilized if pumped storage is not applied. Pumped storage hydro power is used for storing until the demand increases in hour 6. 


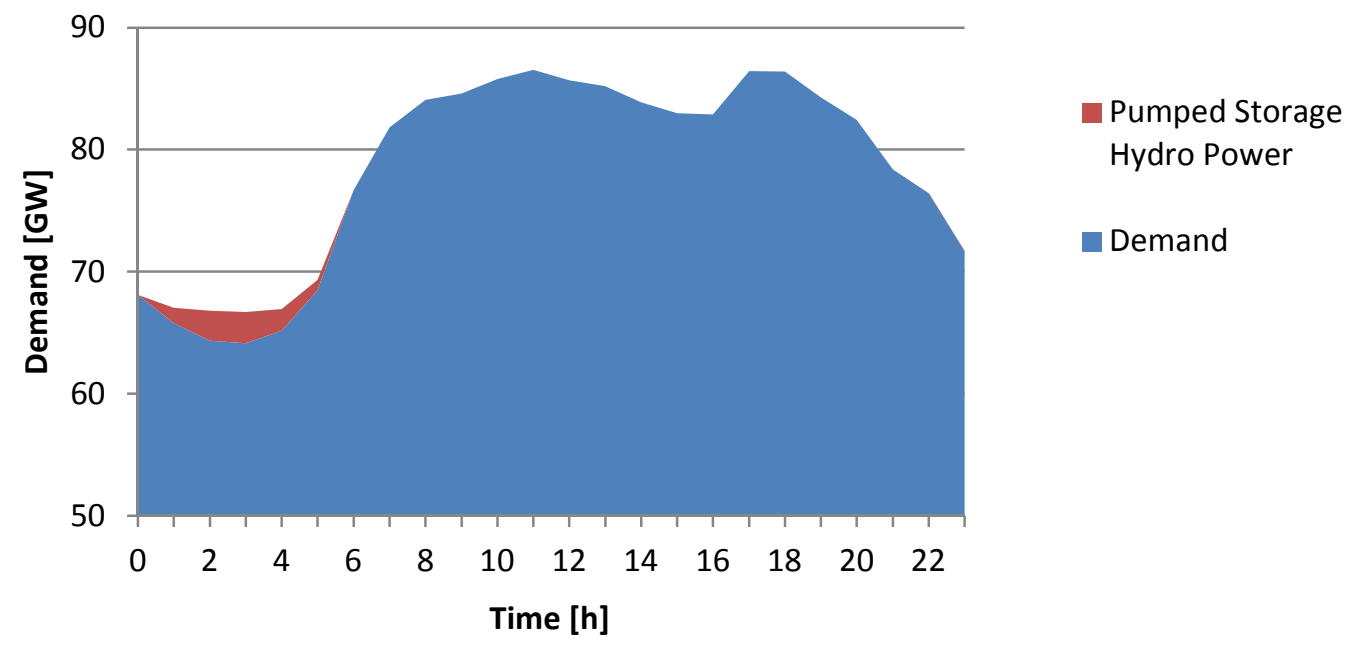

Figure 6.3: Load profile of Austria and Germany in case A1

Figure 6.4 shows the power generation profile of Austria for the case A1. A high amount of hydro power is characteristic for the Austrian power system. The coal power plants in Austria are fully utilized over one day. Generation from wind and solar power is very small in this case. Natural gas, seasonal storage hydro power and pumped storage hydro power is activated to cover the peak load demand. The running natural gas power plants are mainly located around Vienna.

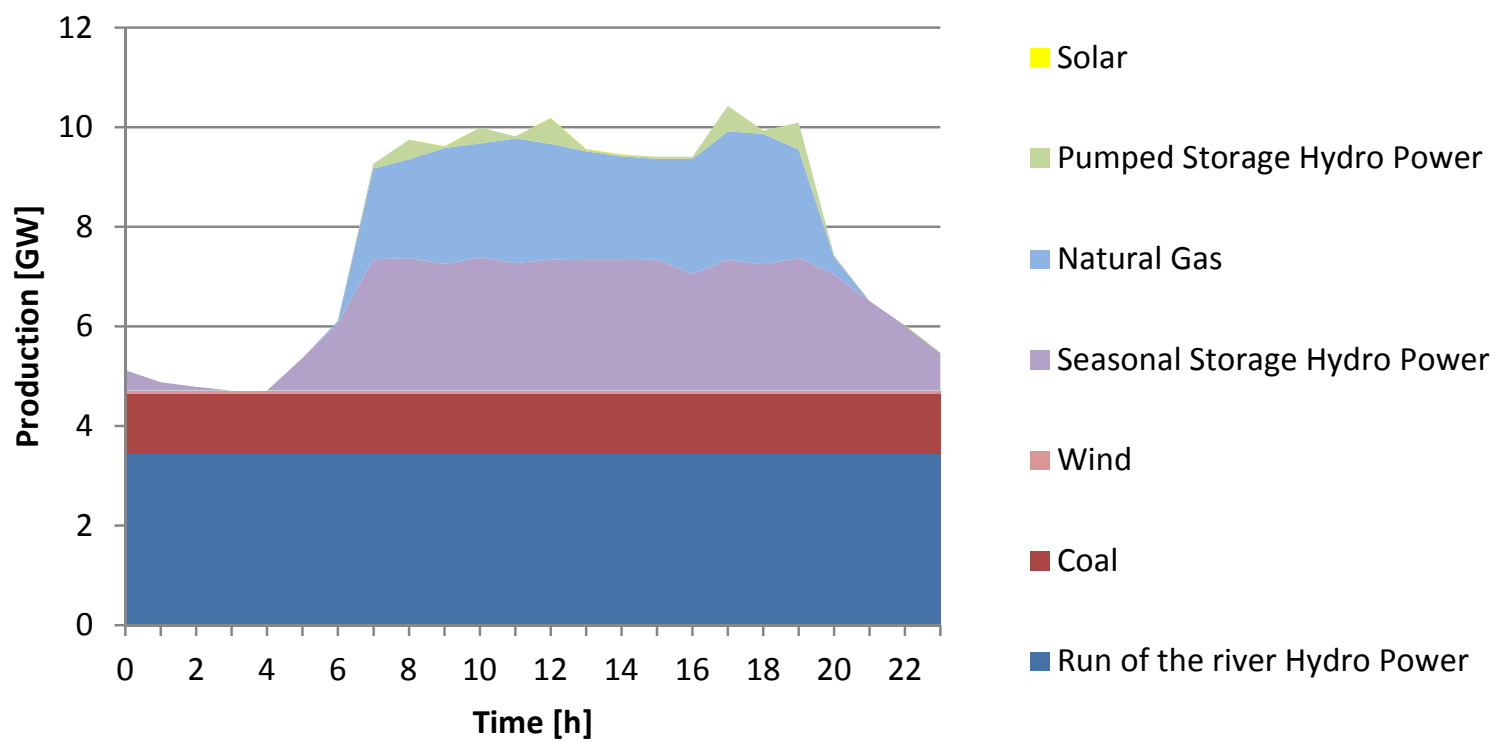

Figure 6.4: Power generation profile of Austria in case A1 


\subsubsection{Scenario A2}

In this scenario wind power plants produce $20 \%$ of their max power. Therefore the supplied power from wind power is $6.3 \mathrm{GW}$ in this scenario. Figure 6.5 shows the power generation profile for Austria and Germany in case A2. Coal power plants are nearly fully utilized in this case. Only at hour 0 are not all coal power plants running. This is caused by the constraints of the model which does not allow pumped storage hydro power at hour 0 . In this scenario pumped storage hydro power plays an important role as peak load generation power plant. Therefore the maximum used gas power plant capacity is only $6.8 \mathrm{GW}$ in this case.

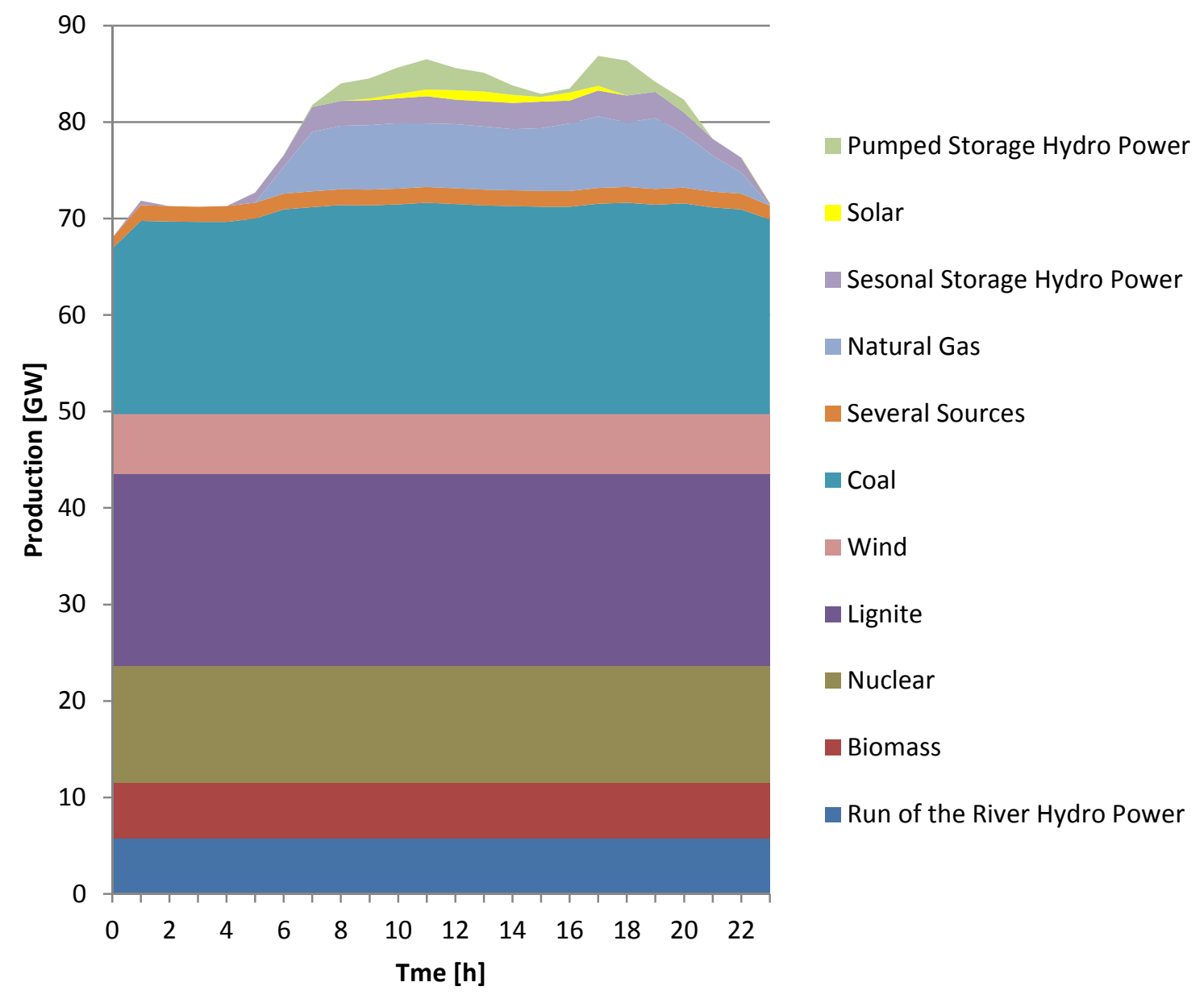

Figure 6.5: Power generation profile of Austria and Germany in case A2

The demand is in all A and B cases the same and only the application of pumped storage hydro power influences the demand. The corresponding load profile for case A2 can be found in the appendix 1. In case A2 employment of pumped storage is high because a lot of cheap coal power is available for storage during between hours 0-6.

Figure 6.6 shows the power supply curve of Austria for A2. For the electricity generation from wind power is now applied a capacity factor of $20 \%$. Therefore $340 \mathrm{MW}$ are supplied by wind power in this case. This reduces the amount of natural gas power in the Austrian power system. 


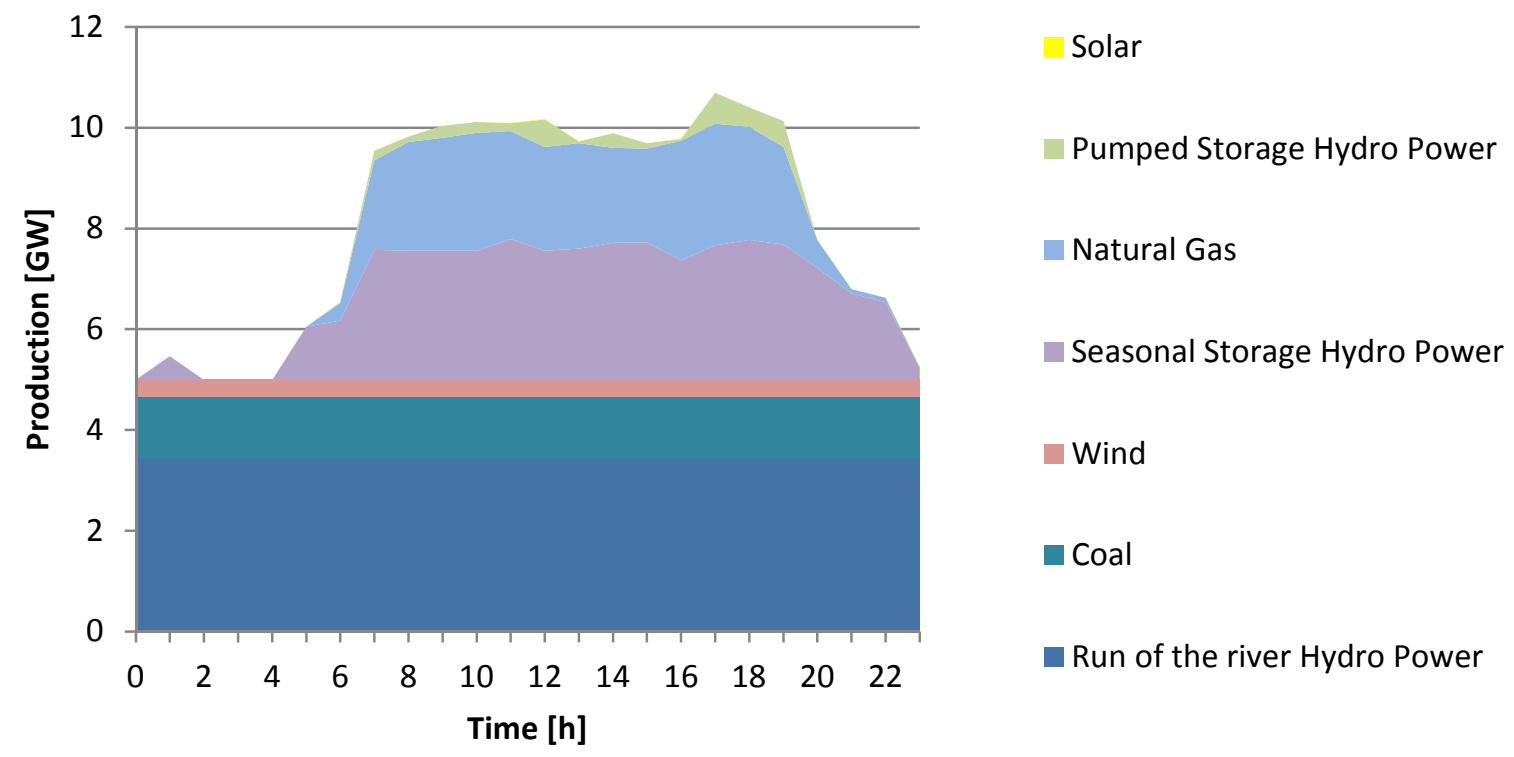

Figure 6.6: Power generation profile of Austria in case A2

\subsubsection{Scenario $\mathbf{A 3}$}

Figure 6.7 shows the power generation profile for Austria and Germany in case A3. This case applies a capacity factor of $40 \%$ for wind power plants. Thus wind power generation increased to $12.5 \mathrm{GW}$. This changes the application of coal power plants significantly. Coal power plants have a reduced power output during the beginning and the end of a day. Also the usage of gas power is with max 1.8 GW low.

How the pumped storage hydro power is applied for storage in this case is shown in the load profile curve in the appendix 2. Less natural gas is used since coal power is available to substitute them in this case. This reduces also the usage of pumped storage hydro power because the demand for pumped storage hydro power as peak load generation.is reduced

The power generation profile of Austria in scenario A3 is shown in Figure 6.8. The application of natural gas power plants decreased due to a higher availability of wind power. In this case is applied more pumped storage hydro power because of the availability of cheap power sources for storage during night periods. 


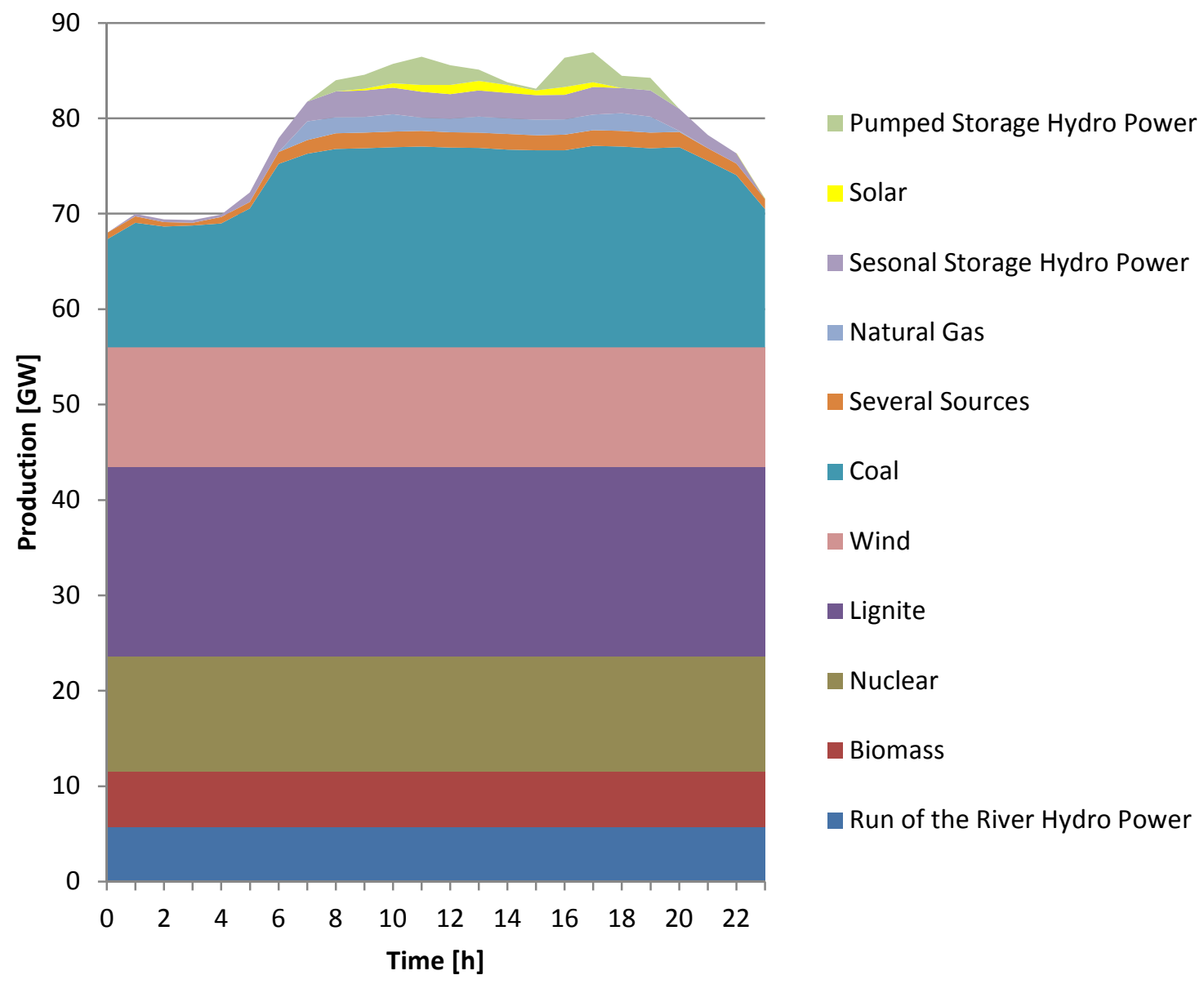

Figure 6.7: Power generation profile of Austria and Germany in case A3

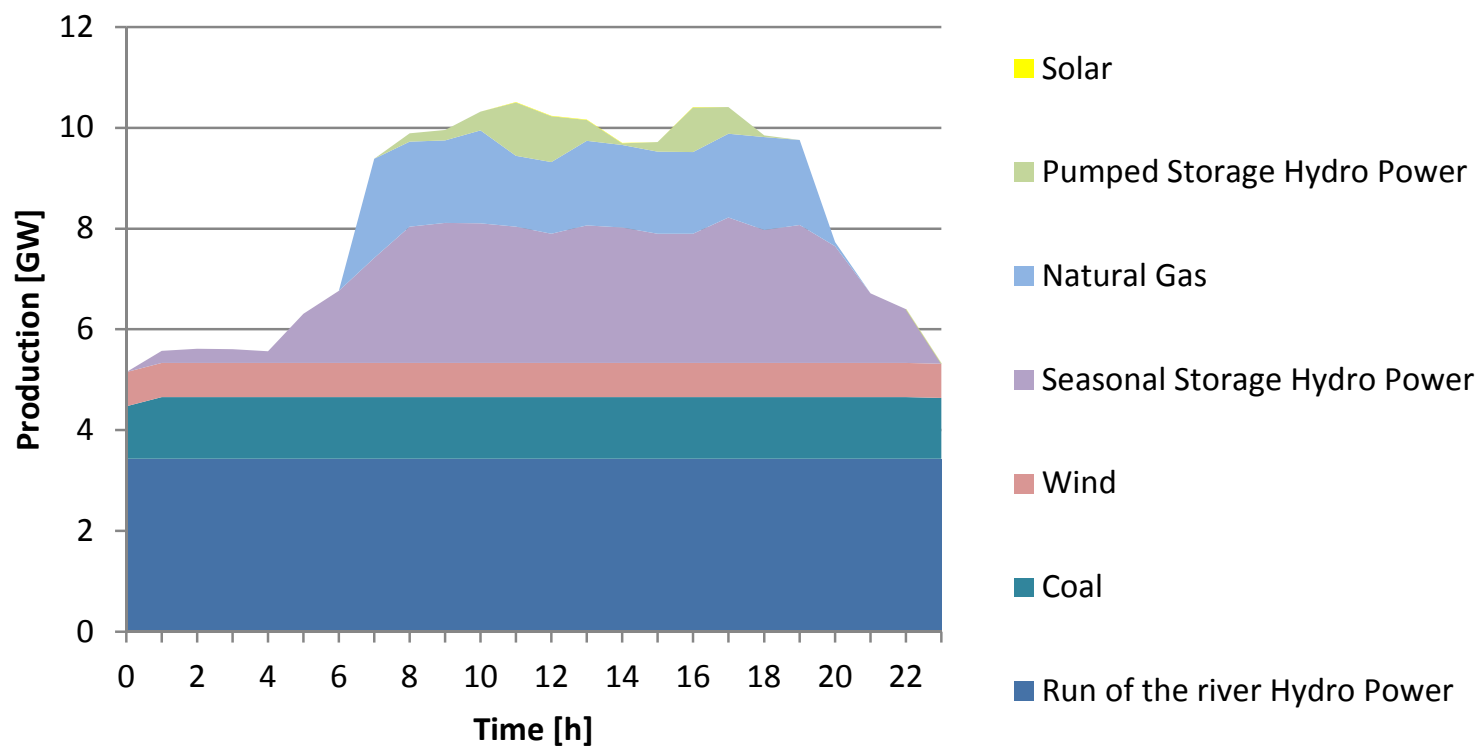

Figure 6.8: Power generation profile of Austria in case A3 


\subsubsection{Power exchange between Germany and Austria in scenarios A}

Power exchange between Austria and Germany is influenced by the amount of wind power in the system. Figure 6.9 shows how the power exchange between Austria and Germany behaves under different wind power penetration levels in scenarios A. A positive value refers to export from Germany to Austria, whereas a negative power exchange means export from Austria to Germany.

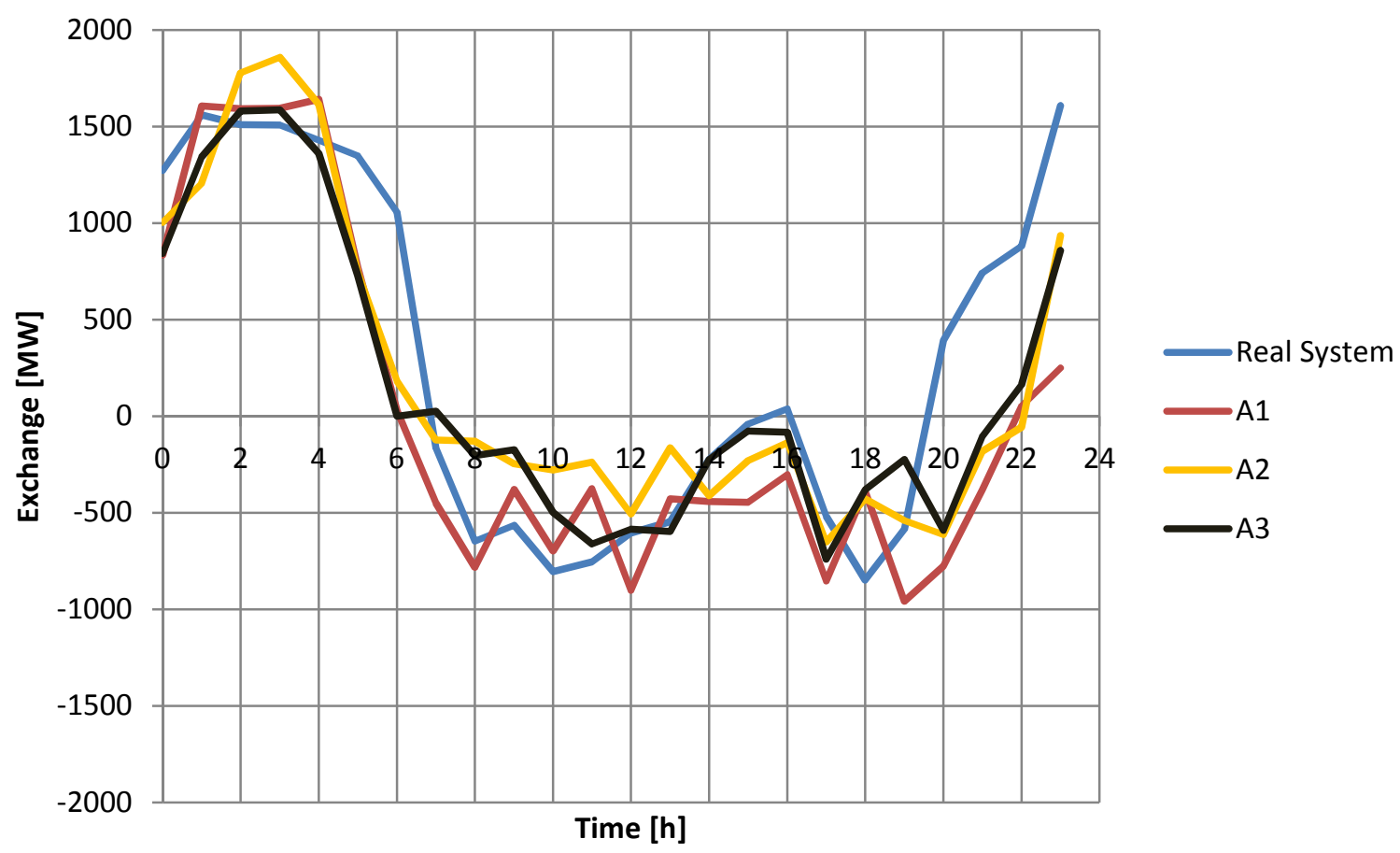

Figure 6.9: Power exchange between Austria and Germany in scenarios A

Table 14 states electricity import of Austria from Germany over one day. During low wind condition the total electricity import of Austria from Germany reached the lowest level. More wind power in the system increases the electricity import of Austria since more wind power plants are installed in Germany. Electricity generation from coal or natural gas is also cheaper in Germany in the model. Therefore natural gas and coal power plants in Austria will be less used if capacities are available in Germany. In scenario A3 is the import of Austria lower than at medium wind conditions because coal is sometimes on the margin in Austria which is cheaper than imports from Germany which are based on natural gas power plants in Germany.

Table 14: Exchange balance between Austria and Germany in Scenario $\mathbf{A}^{1}$

\begin{tabular}{ccc}
\hline A1 $[\mathbf{M W h}]$ & A2 $[\mathbf{M W h}]$ & A3 [MWh] \\
\hline${ }_{\text {a }}$ negative value means export from Austria whereas a positive value refers to export from Germany to Austria
\end{tabular}




\subsection{Scenarios $B$}

In the cases B only the nuclear power plants are removed from the power system in 2013. The power grid data and demand are the same as in the scenarios A. The GAPS model has to substitute the nuclear power plants with remaining power plants, which are more costly, in order to satisfy the demand.

\subsubsection{Scenario B1}

A wind power capacity factor of $3.3 \%$ is applied in the Case B1. Figure 6.10 shows the power generation profile for Austria and Germany. Coal power plants are nearly fully utilized and natural gas power plants are always on the margin. Natural gas is in the model cheaper in Germany than in Austria. Thus natural gas power plants in Germany are used to provide energy for pumped storage hydro power in Austria. The max applied natural gas power plant capacity is $25.1 \mathrm{GW}$ in this case. Therefor natural gas becomes the major source in this scenario. The load profile for this scenario can be found in the Appendix 3.

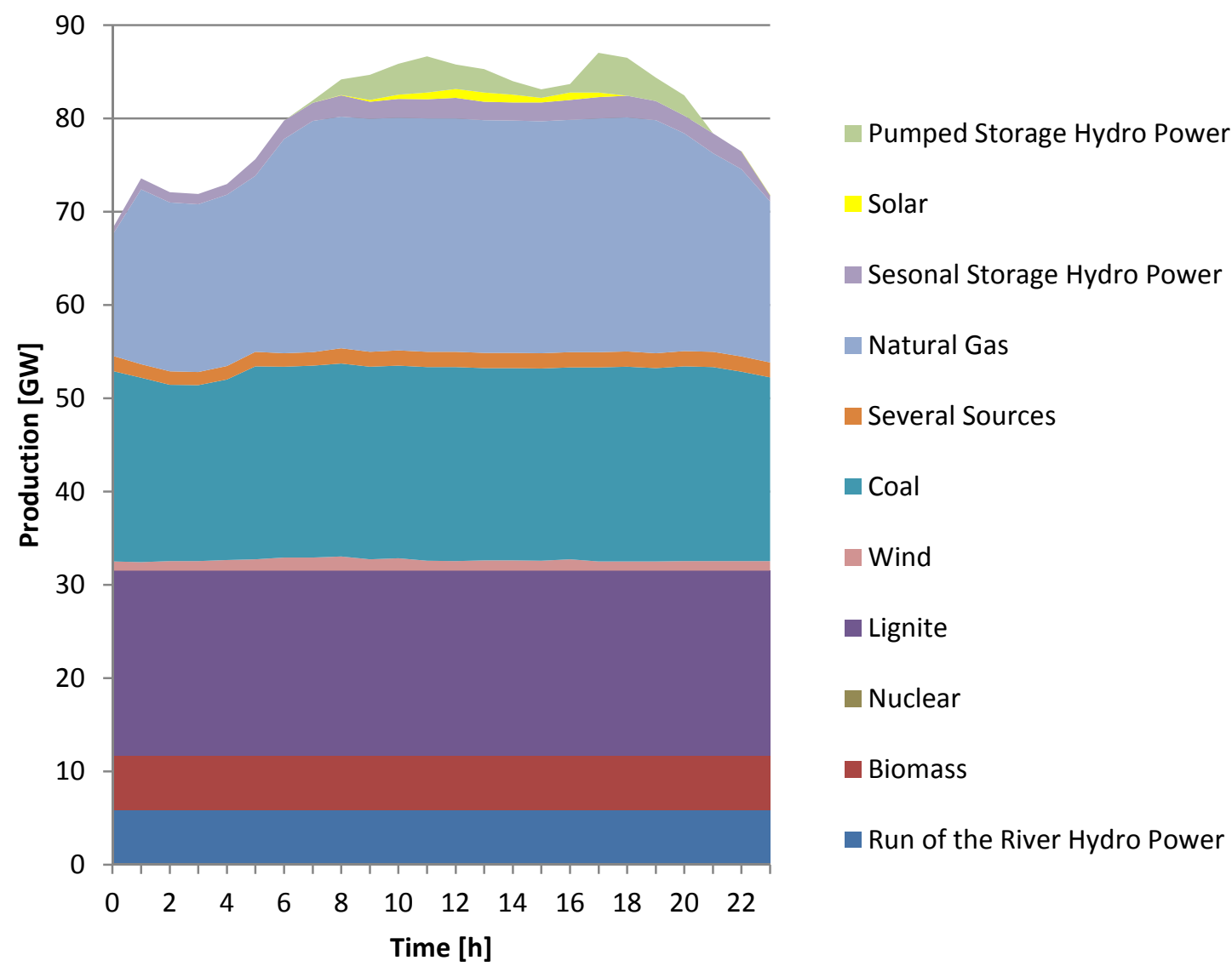

Figure 6.10: Power generation profile of Austria and Germany in case B1

Figure 6.11 shows the power generation profile of Austria in case B1. The wind power generation is almost zero in Austria in this case. Natural gas power is always on the margin in Austria if the nuclear power plants in Germany are phased-out and the wind power penetration level is low. Approx. $3 \mathrm{GW}$ of natural gas power is needed during peak demand in Austria. The usage of seasonal storage hydro power is distributed over the day since natural gas is always on the margin in Austria. The pumped storage hydro power capacity is used to cover the peak demand. 


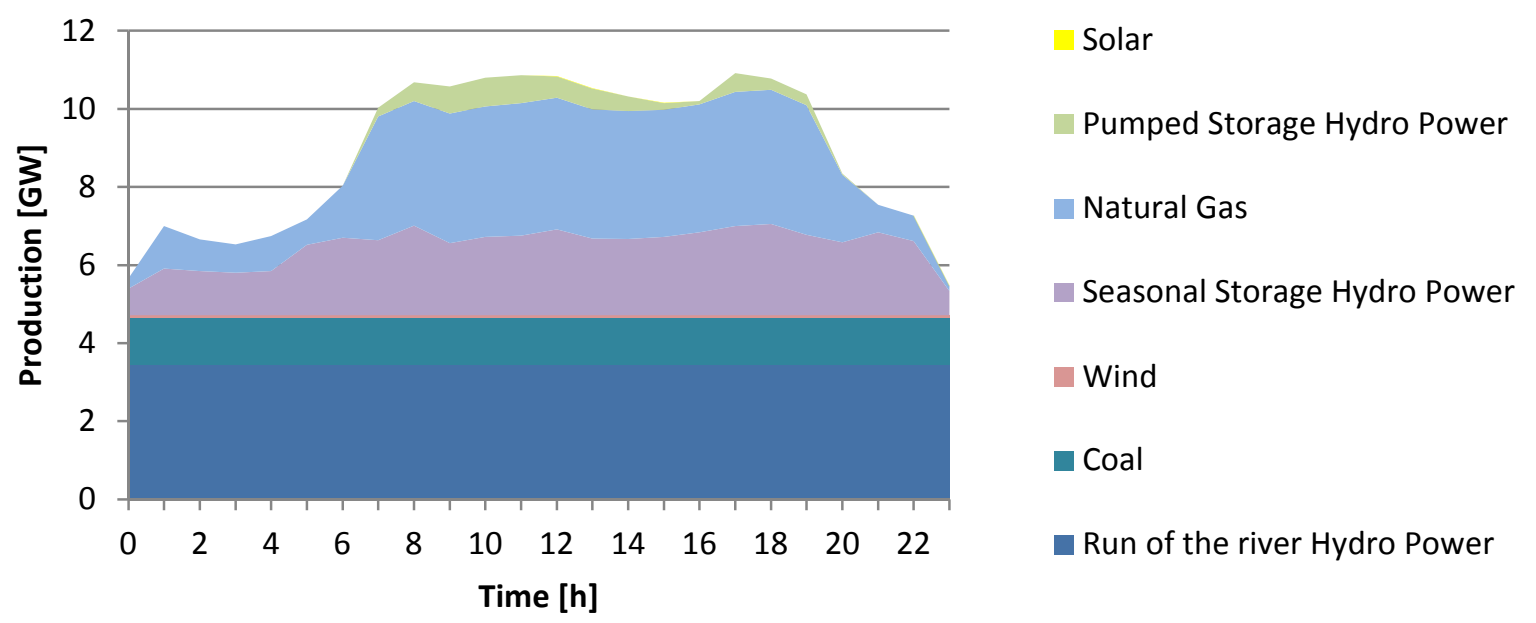

Figure 6.11: Power generation profile of Austria in case B1

\subsubsection{Scenario B2}

In scenario B2 all nuclear power plants are phased-out in Germany and wind power generation is constant at $6.3 \mathrm{GW}$. Figure 6.12 shows that natural gas power plants are on the margin because the other sources utilize already their maximum power output. In this case is the maximum applied natural gas capacity is $20.4 \mathrm{GW}$. The amount of used pumped storage hydro power depends on the variable fuel costs of the marginal power plant during night and day time. When and how much pumped storage hydro power is applied for generation and storage can be seen in Figure 6.12 and the load profile of case B2 in the appendix 4. Natural gas power plants in Austria are more costly in the model. Therefore the model uses natural gas in Germany for pumped storage to avoid natural gas power generation in Austria.

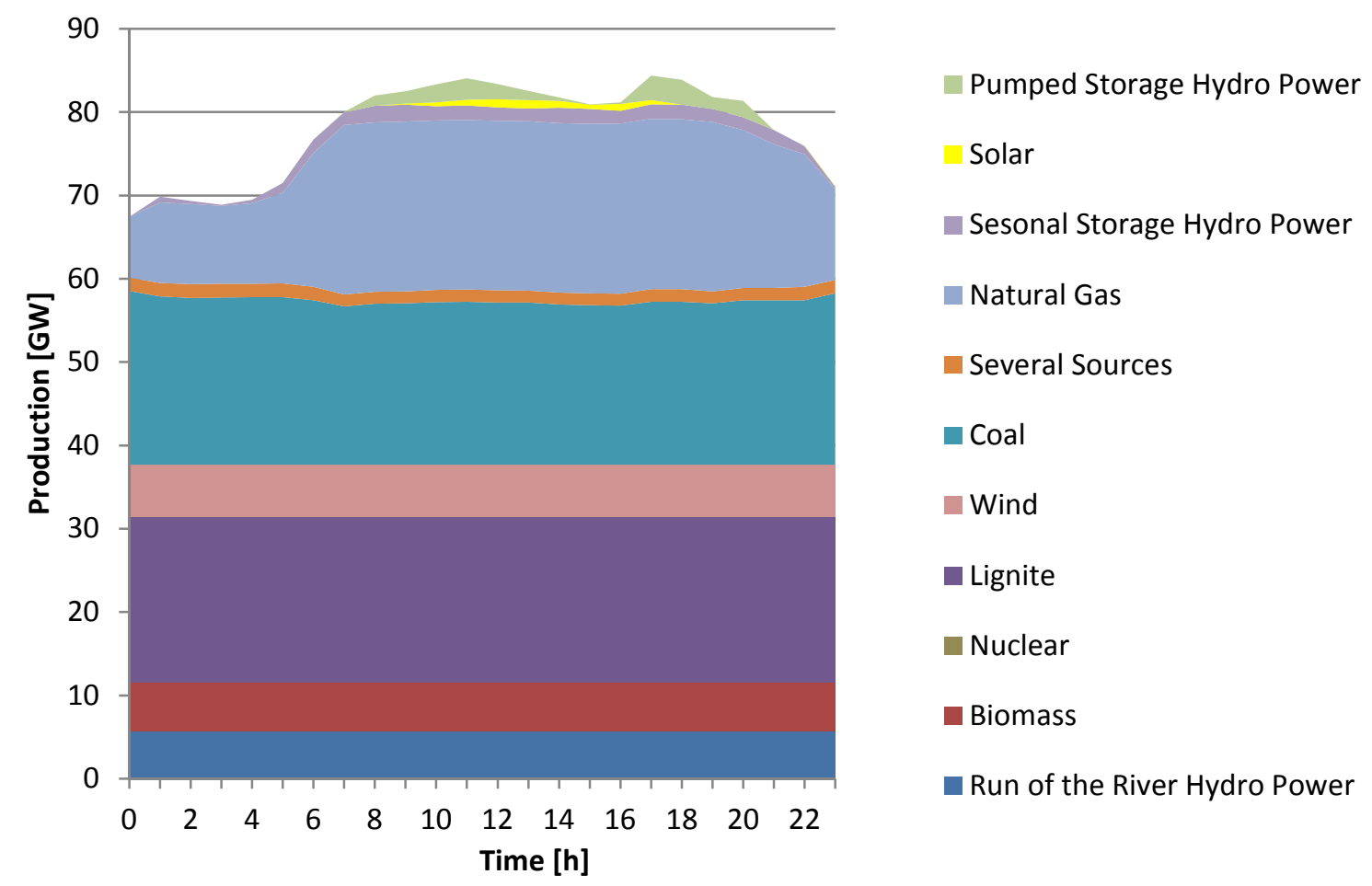

Figure 6.12: Power generation profile of Austria and Germany in case B2 
Figure 6.13 shows the power generation profile of Austria in scenario B2. More wind power in the system reduces the application of natural gas power. Thus the usage of natural gas power is almost zero during the night times. Seasonal storage hydro power is used to avoid natural gas power during night.

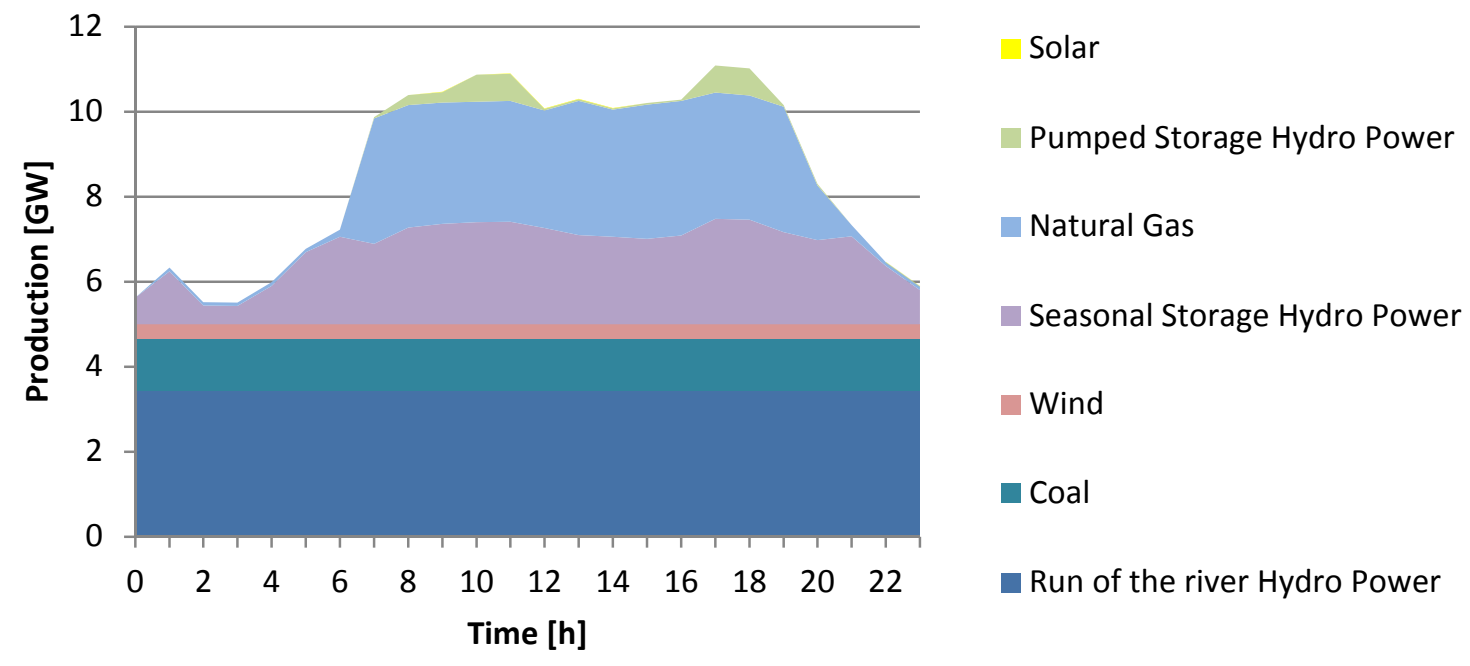

Figure 6.13: Power generation profile of Austria in case B2

\subsubsection{Scenario B3}

In scenario $\mathrm{B} 3$ the generation from wind power is constant at $12.5 \mathrm{GW}$. The power generation profile for Austria and Germany is shown for this case in Figure 6.14. In this case is still natural gas always on the margin. The max used natural gas capacity is $17.5 \mathrm{GW}$ at hour 17.

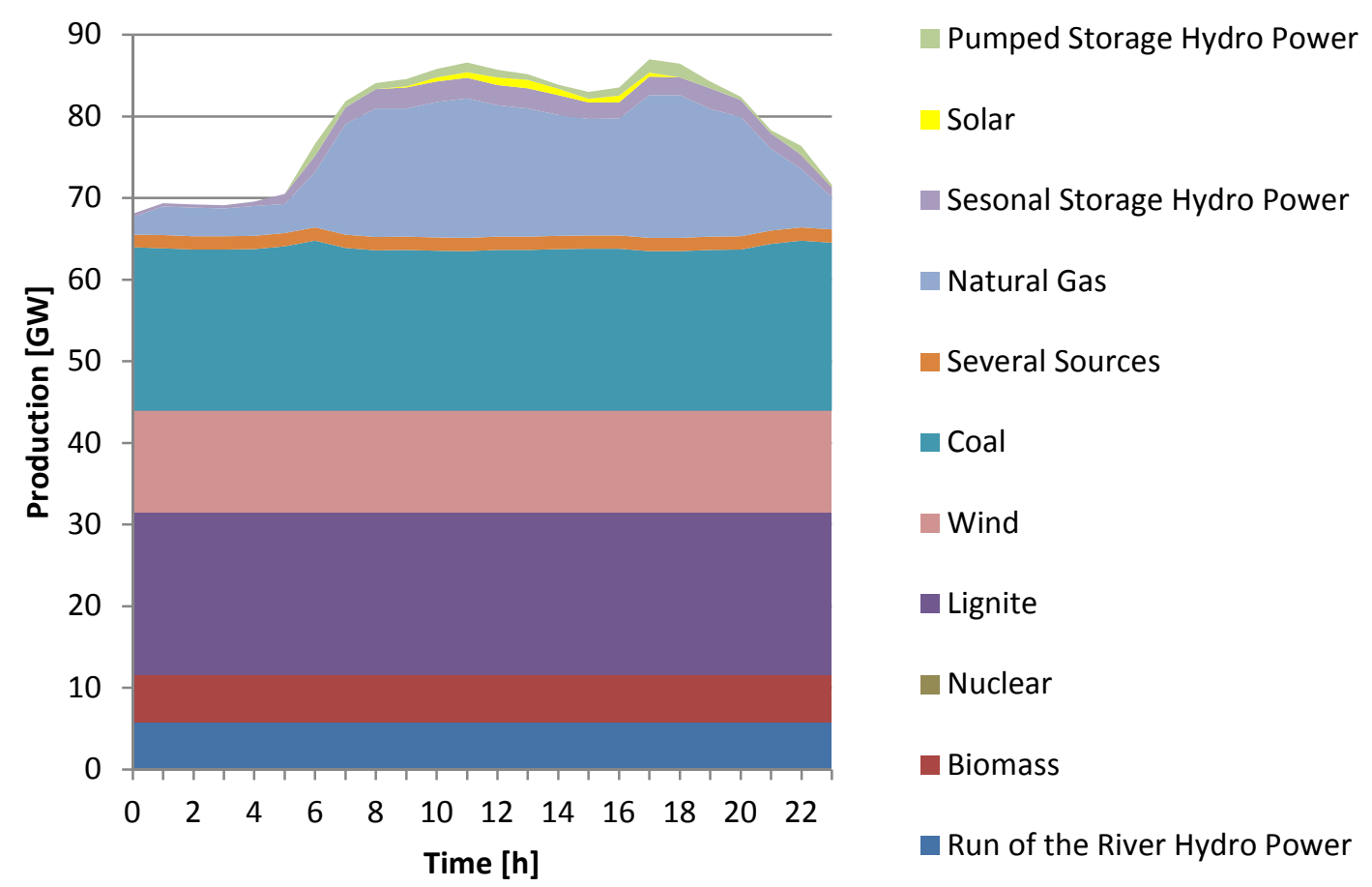

Figure 6.14: Power generation profile of Austria and Germany in case B3 
The load profile and the storage application of pumped storage hydro power can be found in the appendix 5. Figure 6.15 shows the power generation profile of Austria in case B3. Due to more wind power in the total system less natural gas is needed in Austria compared to case B1 and B2.

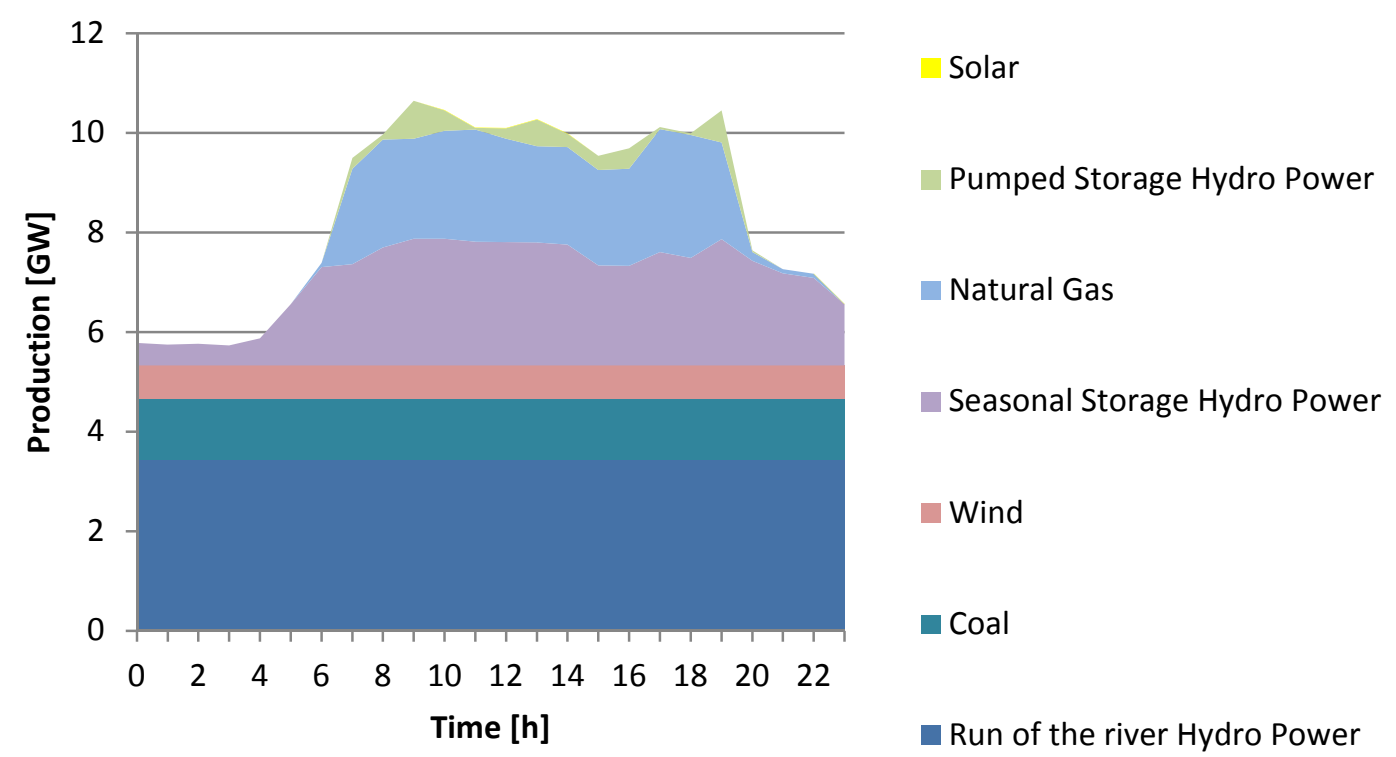

Figure 6.15: Power generation profile of Austria in case B3

\subsubsection{Power exchange between Germany and Austria in scenarios B}

The power exchange is compared to the case A1 which was also the reference case for evaluation of the model and compared with the power exchange data from the real system. Figure 6.16 shows how the power exchanges of the B cases behave over on day compared to case A1. A positive value refers to import from Germany to Austria, whereas a negative power exchange means export from Austria to Germany.

The power imports of Austria strongly decrease between the hours 0 and 6 compared with the case A1. In the case B1 the power exchange between Austria and Germany changes dramatically. Imports of Austria are reduced a lot and the exports of Austria are high between hours 6 and 20. In the cases B2 and $\mathrm{B} 3$ are the differences to the case A1 smaller. It can be noticed that less electricity is exported from Austria to Germany in cases B2 and B3 compared to B1 because of more wind power generation in the system in the cases B2 and B3. Compared with Figure 6.9, Figure 6.16 shows also that the change of the power exchange between the different wind conditions is much stronger in the Scenarios B than in Scenarios A.

Table 15 shows the balance of the electricity import of Austria from Germany of the whole day. In case B1 Austria is exporting most electricity to Germany. An increase of wind power leads always to a reduction of the exports from Austria to Germany in the B cases.

Table 15: Exchange balance between Austria and Germany in Scenarios B and A1 ${ }^{1}$

\begin{tabular}{ccccc} 
& $\mathbf{A 1}[\mathbf{M W h}]$ & $\mathbf{B 1}[\mathbf{M W h}]$ & $\mathbf{B 2}[\mathbf{M W h}]$ & $\mathbf{B 3}[\mathbf{M W h}]$ \\
\hline 1 a negative value & -200 & -22209 & -6152 & -150 \\
\cline { 2 - 4 } & means export from Austria whereas a positive value refers to export from Germany to Austria
\end{tabular}




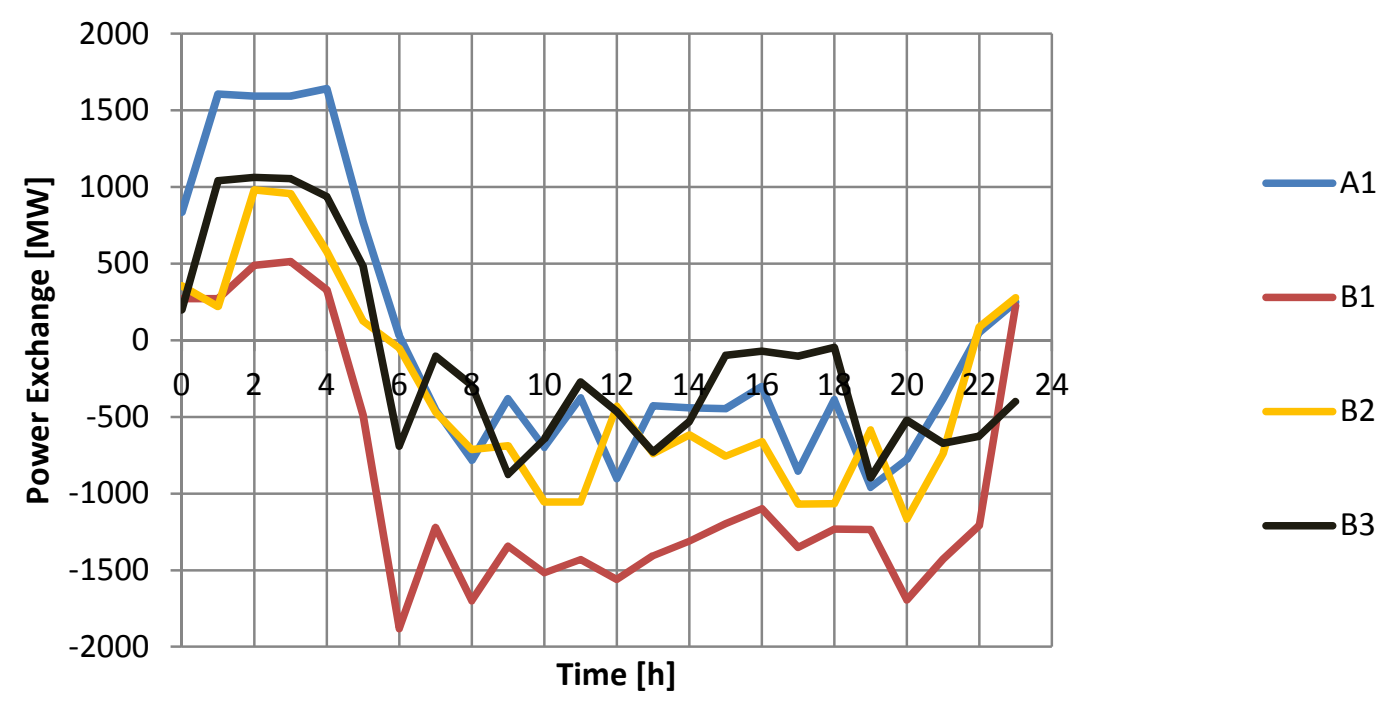

Figure 6.16 Power exchange between Austria and Germany in Scenarios B

\section{$6.4 \quad$ Scenarios $C$}

Scenarios C simulate the future power grid of Austria and Germany in 2022 without nuclear power in Germany. The power system of the cases A and B is updated to the expected power grid in 2022 Thus specific additional transmission lines are installed respectively upgraded to a higher voltage level according to plans of the TSO's. The installed nuclear power capacity is removed agreeing with the plans of the German government. Further, additional power plant capacities are installed in the system. The amount of installed coal power capacity increased a lot in Germany. Wind and solar power capacities are also increased in Germany and Austria. Moreover, it is assumed that the demand increases by 8 percent in 2022 compared to 2013.

\subsubsection{Scenario C1}

In this case is wind power generation is constant at a level of $1.8 \mathrm{GW}$. This corresponds to a capacity factor of $3.3 \%$ for wind power plants in 2022. Figure 6.17 shows the power generation profile of Austria in case $\mathrm{C} 1$. The power generation from pumped storage hydro power and wind power is low in this case. On the other hand is used a lot of natural gas power in Austria because of the low wind conditions.
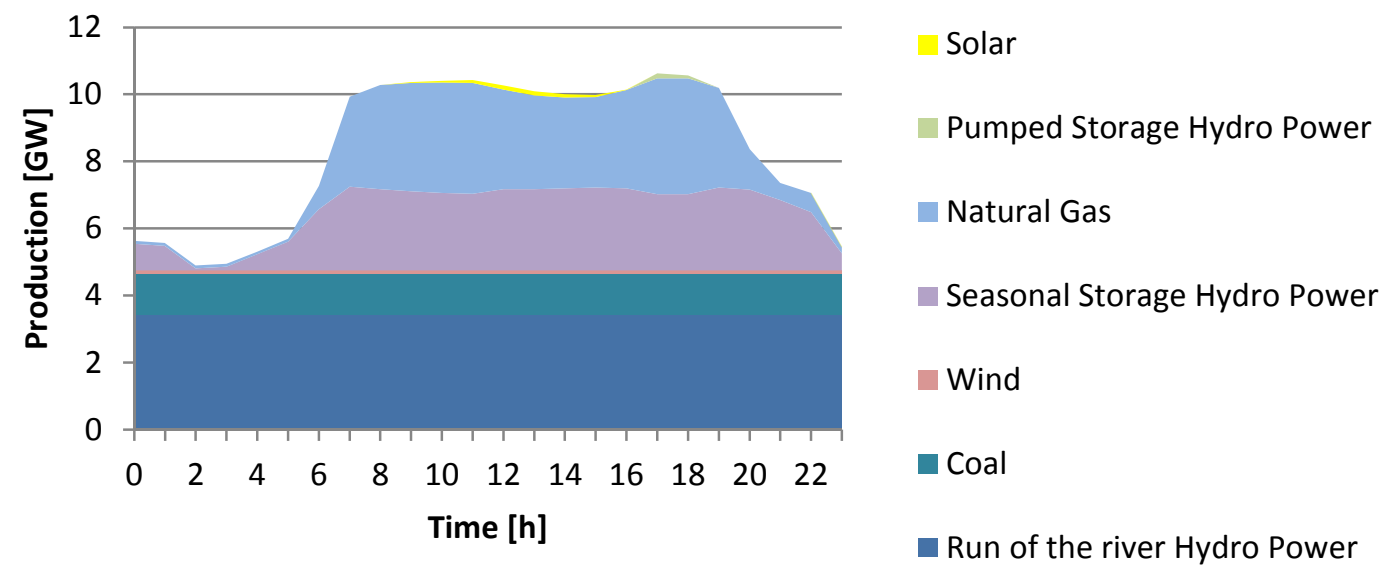

Figure 6.17: Power generation profile of Austria in case C1 
Figure 6.18 shows the power generation profile of Austria and Germany in scenario C1. Coal power is the main power source in this scenario. Almost $30 \mathrm{GW}$ of coal power are applied always in this case. Natural gas power is always on the margin in this case. Therefore the amount of pumped storage hydro power is almost zero because it is too costly to use pumped storage hydro power if natural gas is on the margin. The load profile with the storage application of pumped storage hydro power can be found in the appendix 6 for this scenario.

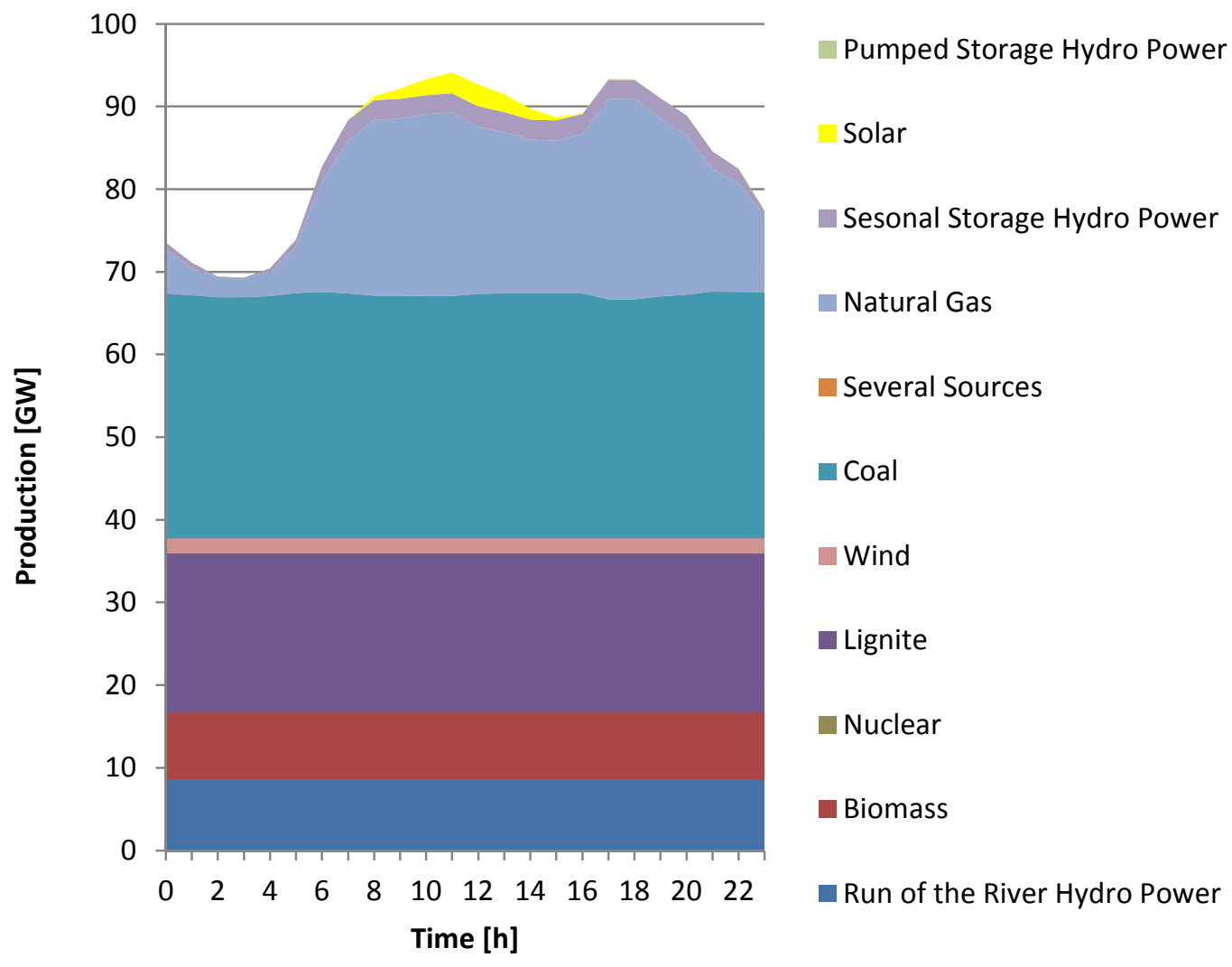

Figure 6.18: Power generation profile of Austria and Germany in case C1

\subsubsection{Scenario $\mathrm{C} 2$}

In case $\mathrm{C} 2$ a capacity factor of $20 \%$ is applied for the wind power plants. The power generation from the wind turbines is constant at $11.1 \mathrm{GW}$ over $24 \mathrm{~h}$. The power generation profile of Austria and Germany is shown in Figure 6.19 for this case. Coal power is used as base load with a max used capacity of $29.8 \mathrm{GW}$. During the night from hour 0 to 5 is coal on the margin in the system. In contrast to this natural gas is on the margin at day time. It can be also noticed that solar power and pumped storage hydro power is used to cover a part of the peak loads at hours 11 and 17.

The load profile of Austrian and Germany with the application of pumped storage hydro power can be found in appendix 7. During the night from hour 1 to 6 pumped storage is used to store energy which is generated by coal power plants. 


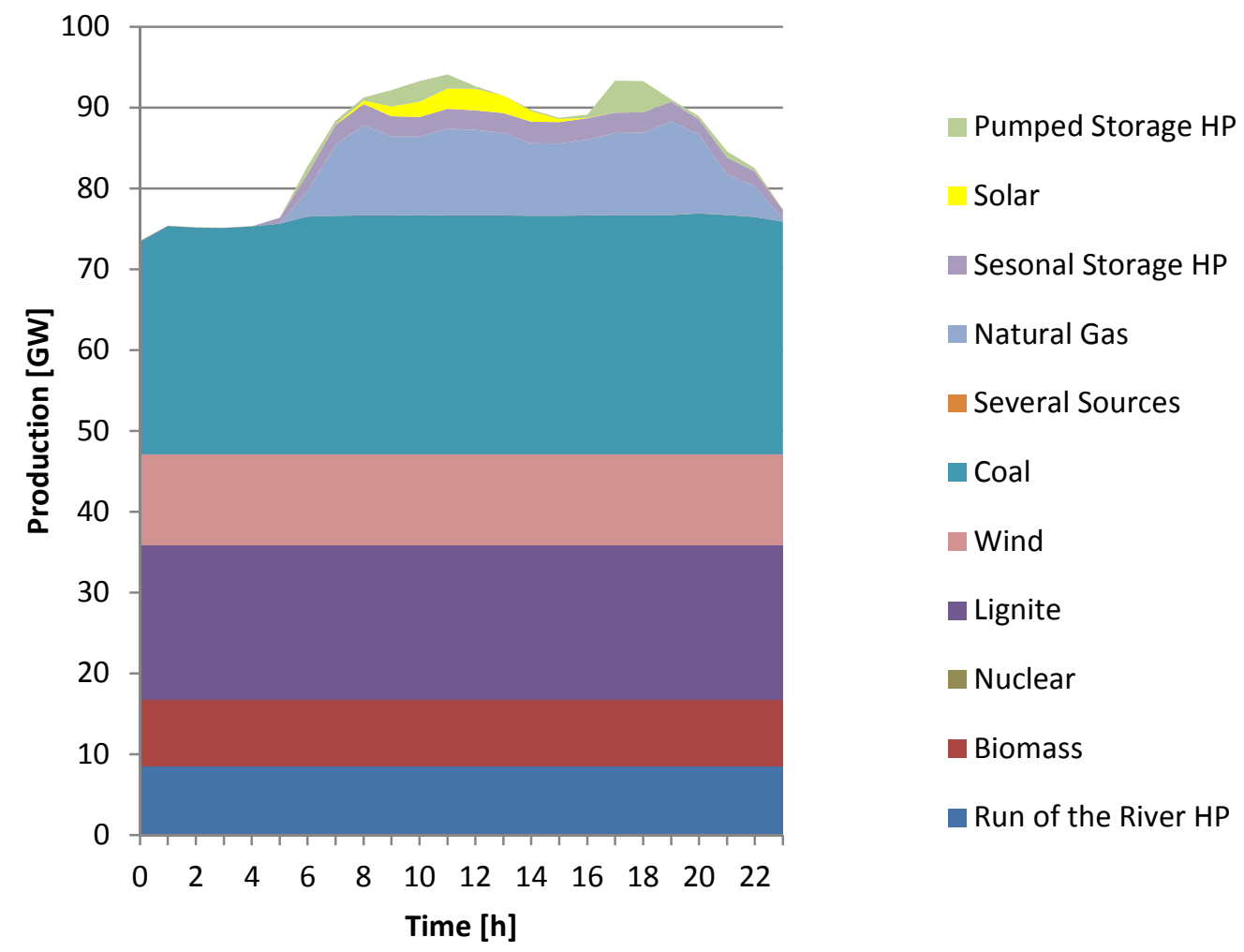

Figure 6.19: Power generation profile of Austria and Germany in case C2

Figure 6.20 shows the power generation profile of Austria in case C2. Power generation from pumped storage hydro power is low in this case. Natural gas power and seasonal storage hydro power is applied during daytime to cover the peak load in Austria.

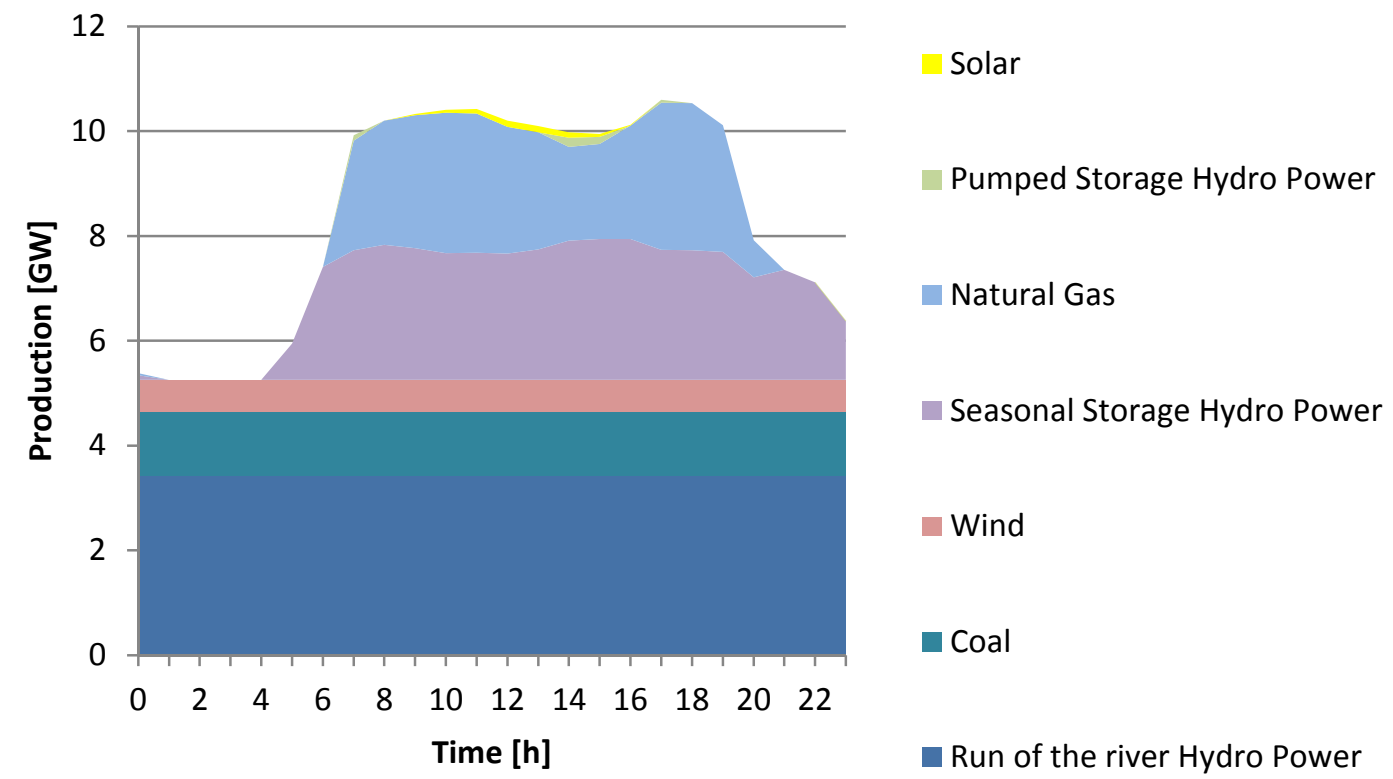

Figure 6.20: Power generation profile of Austria in case C2 


\subsubsection{Scenario C3}

The used wind power capacity factor for this scenario is $40 \%$. Thus the electric power generation from wind power is $22.4 \mathrm{GW}$ in this scenario. Coal power is not anymore used to its full extent. Particular from hour 0 to 6 less coal power capacity is running. The total capacity of coal power is not used during peak loads because generation from wind power is high. A small amount of natural gas power plants are running in order to satisfy the power flow constraints in the system.

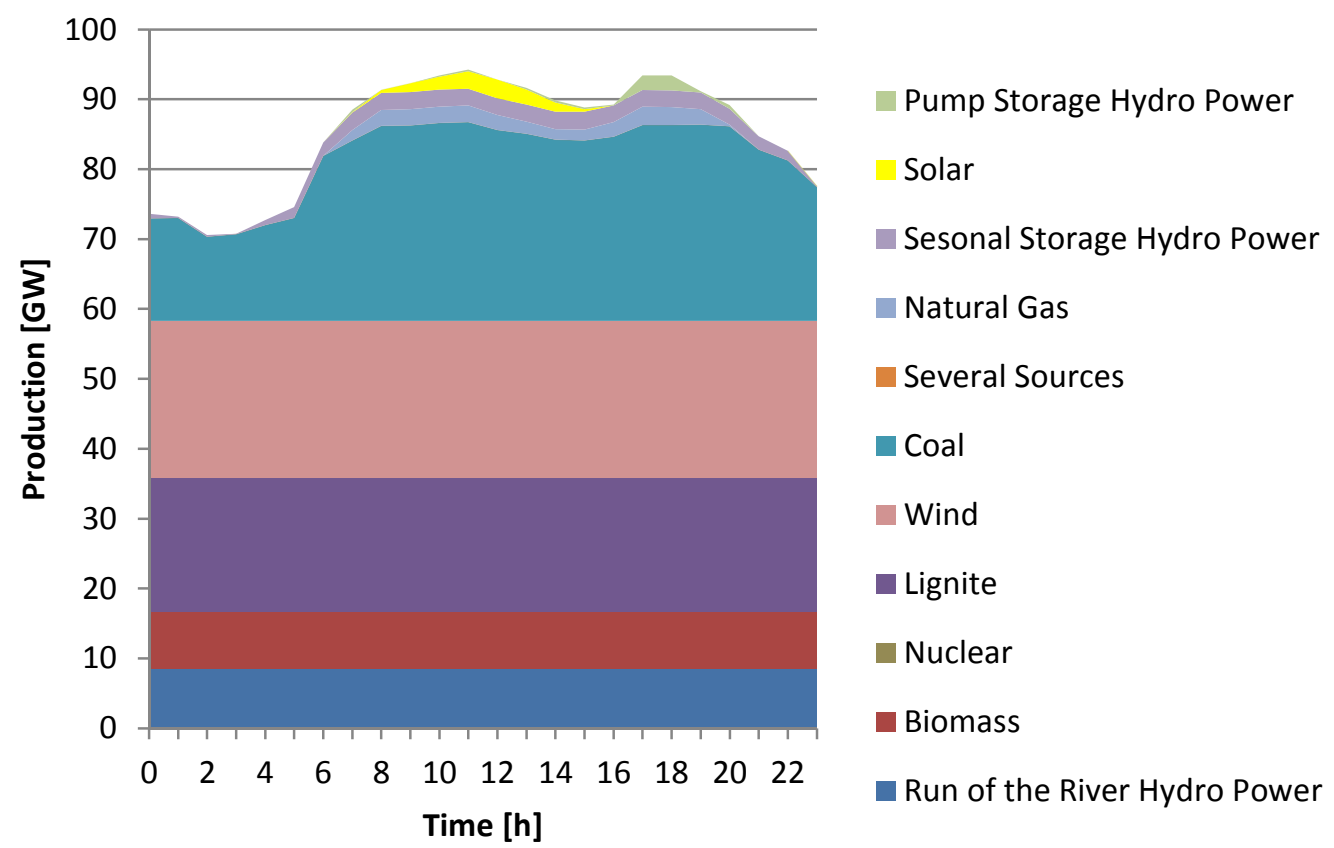

Figure 6.21: Power generation profile of Austria and Germany in case C3

The load profile and the storage application of pumped storage hydro power can be found in appendix 8 for this case. The model applies pumped storage hydro power from hour 0 to 6 . It can be noticed that the application of pumped storage hydro power is low because it is not much pumped storage hydro power capacity needed to satisfy the peak load.

Figure 6.22 shows the power generation profile in of Austria in case C3. The high amount of wind power in the system reduces the application of natural gas. The remaining utilization of natural gas is used to cover the peak demand in Austria.
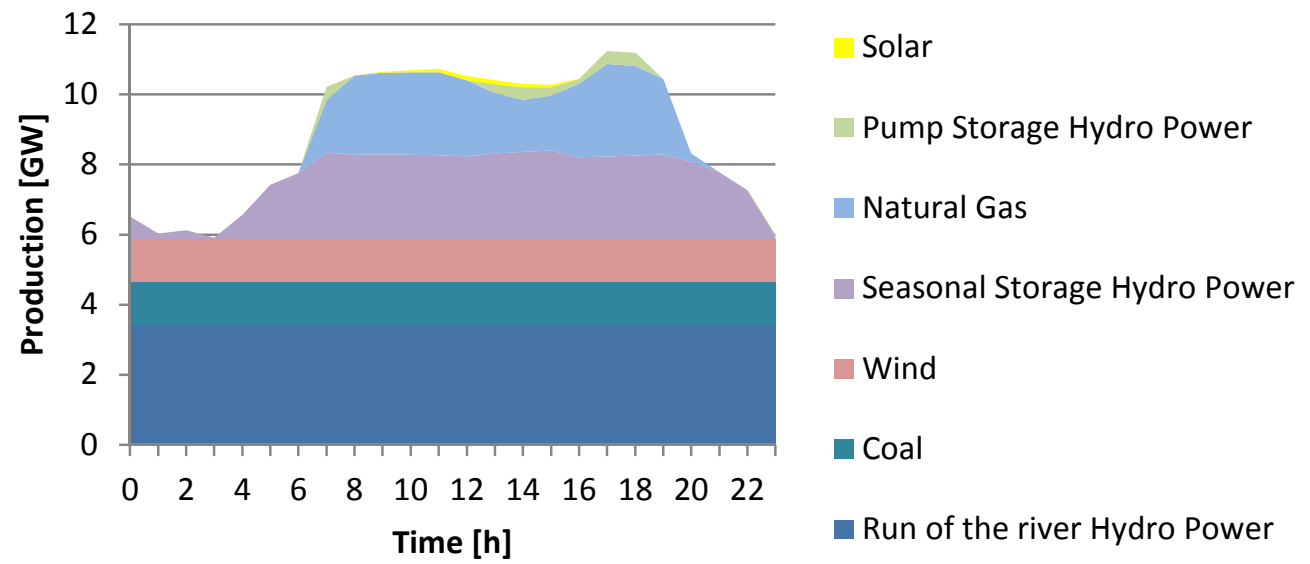

Figure 6.22: Power supply curve Austria 2022 Strong Wind 


\subsubsection{Power exchange between Germany and Austria in scenarios C}

Figure 6.23 shows the power exchange between Germany and Austria in scenarios $\mathrm{C}$ with no nuclear power in Germany in 2022 and new installed power plant capacities in the system. A positive exchange value refers to import of Austria from Germany, whereas a negative power exchange means export of Austria to Germany. Compared with the case A1 the imports of Austria are reduced during the morning hours in all $\mathrm{C}$ scenarios. During the daytime is also a change noticeable. Austria exports less energy to Germany and becomes an importer of electricity from Germany at this time in cases $\mathrm{C} 2$ and C3. It is interesting that the shapes of the curves $\mathrm{C} 2$ and $\mathrm{C} 3$ are similar. In those cases Austria imports from Germany much more electricity than in the reference case A1.

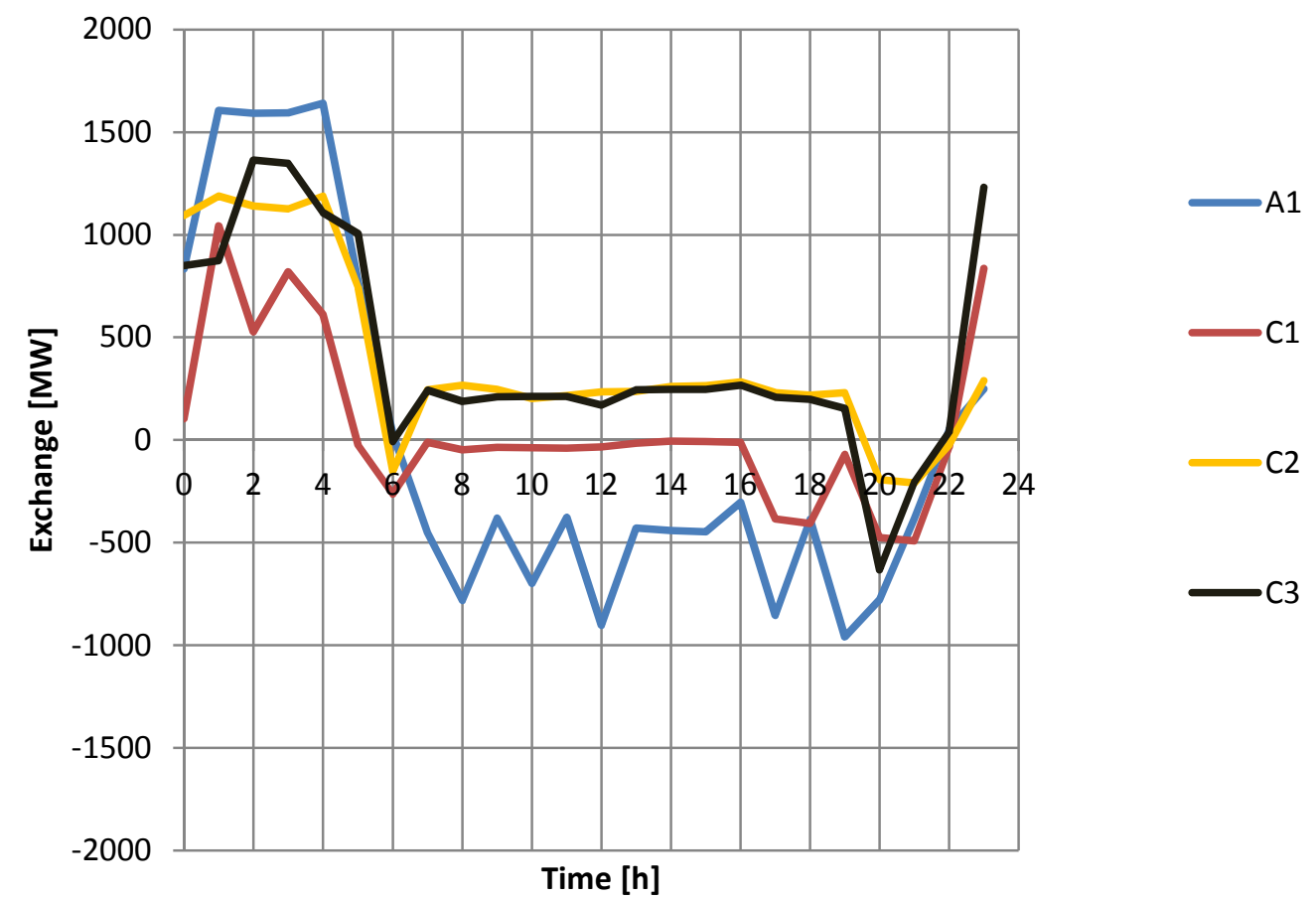

Figure 6.23: Power exchange between Austria and Germany in Scenarios C

The power exchange balance of a whole day is presented in Table 16. It can be noticed a significant increase of the imports of Austria in case $\mathrm{C} 2$ and $\mathrm{C} 3$. The huge amount of wind power capacity increases the exports of Germany if the wind conditions are good. Also the high availability of coal power in Germany increases the exports of Germany to Austria in case $\mathrm{C} 1$ compared with the reference case $\mathrm{A} 1$.

Table 16: Exchange balance between Austria and Germany in Scenarios $\mathrm{C}$ and $\mathrm{A1}{ }^{1}$

\begin{tabular}{cccc}
\hline A1 [MWh] & C1 [MWh] & C2 [MWh] & C3 [MWh] \\
\hline-200 & 1545 & 9328 & 9777 \\
\hline
\end{tabular}

${ }^{1}$ a negative value means export from Austria whereas a positive value refers to imports of Austria from Germany. 


\subsection{Summary and Comparison of electricity generation in Austria and Germany}

A summary of the results of the total electricity generation per fuel type in Austria and Germany is shown in Table 17. Coal and lignite power plants dominate the total power system of Austria and Germany. The table below shows also the total $\mathrm{CO}_{2}$ emissions in the different cases. An interesting result is that the $\mathrm{CO}_{2}$ emissions in case $\mathrm{C} 2$ increases by $17.7 \%$ compared with the case $\mathrm{A} 2$. Both cases use a wind power generation capacity factor which is close to the average onshore capacity factor over one year in Germany and Austria. The $\mathrm{CO}_{2}$ emissions in Germany increase due to a phase-out of nuclear power and the increase of wind power capacities in 2022 can only compensated this if the generation from wind power is very high.

Table 17: Total electricity generation $[\mathrm{GWh} / \mathrm{d}]$ and $\mathrm{CO}_{2}$ emissions in Austria and Germany

\begin{tabular}{lrrrrrrrrr}
\hline Generation system & A1 & A2 & A3 & B1 & B2 & B3 & C1 & C2 & C3 \\
\hline Biomass & 140 & 140 & 140 & 140 & 140 & 140 & 194 & 194 & 194 \\
Coal & 508 & 505 & 441 & 489 & 473 & 478 & 707 & 699 & 556 \\
Natural Gas & 217 & 102 & 22 & 534 & 400 & 267 & 363 & 152 & 27 \\
Lignite & 477 & 477 & 477 & 477 & 477 & 477 & 461 & 461 & 461 \\
Nuclear & 290 & 290 & 290 & 0 & 0 & 0 & 0 & 0 & 0 \\
Seasonal Storage HP & 43 & 43 & 43 & 43 & 43 & 43 & 43 & 43 & 43 \\
Several Sources & 39 & 38 & 31 & 38 & 37 & 39 & 0 & 0 & 0 \\
Pumped Storage HP & 7 & 25 & 20 & 33 & 21 & 16 & 0 & 19 & 7 \\
Solar & 6 & 6 & 6 & 6 & 6 & 6 & 13 & 13 & 13 \\
Wind & 27 & 150 & 300 & 27 & 150 & 300 & 44 & 268 & 536 \\
Run of the River HP & 138 & 138 & 138 & 140 & 138 & 138 & 207 & 207 & 207 \\
Total generation & 1890 & 1912 & 1906 & 1927 & 1883 & 1903 & 2032 & 2055 & 2043 \\
CO ${ }_{2}$ Emissions [kt/day] & 1079 & 1024 & 931 & 1205 & 1130 & 1075 & 1307 & 1205 & 1020 \\
\hline
\end{tabular}

The summary of the results of the Austrian power system is presented in Table 18. In Austria a lot of hydro power is used compared to the total generation. Therefore the $\mathrm{CO}_{2}$ Emissions are low and also not strong affected by a nuclear power phase-out in Germany in the future. However, due to increased import in the future the $\mathrm{CO}_{2}$ Emissions which are caused by Austria are higher. In the Austrian power system the changes are small in the future because it relies on imports from Germany also in 2022

Table 18: Total electricity generation [GWh/d] and $\mathrm{CO}_{2}$ emissions in Austria

\begin{tabular}{|c|c|c|c|c|c|c|c|c|c|}
\hline Generation system & A1 & A2 & $\mathbf{A 3}$ & B1 & B2 & $\mathbf{B 3}$ & C1 & C2 & C3 \\
\hline Natural Gas & 30 & 29 & 22 & 52 & 41 & 28 & 43 & 32 & 27 \\
\hline Coal & 29 & 29 & 29 & 29 & 29 & 29 & 29 & 29 & 29 \\
\hline Seasonal Storage HP & 43 & 43 & 43 & 43 & 43 & 43 & 43 & 43 & 43 \\
\hline Pumped Storage HP & 3 & 3 & 5 & 6 & 3 & 4 & 0 & 1 & 2 \\
\hline Solar & 0 & 0 & 0 & 0 & 0 & 0 & 1 & 1 & 1 \\
\hline Wind & 1 & 8 & 16 & 1 & 8 & 16 & 2 & 14 & 29 \\
\hline Run of the river HP & 82 & 82 & 82 & 82 & 82 & 82 & 82 & 82 & 82 \\
\hline Total generation & 188 & 195 & 197 & 213 & 207 & 202 & 201 & 201 & 213 \\
\hline $\mathrm{CO} 2$ Emissions [kt/day] & 40 & 39 & 36 & 50 & 45 & 39 & 46 & 41 & 39 \\
\hline
\end{tabular}


The electricity generation mix changes in each scenario due to different wind power conditions, available power plant capacities, demands. Figure 6.24 shows how the electricity generation mix changed compared to scenario A1. Negative values in the figure show the replaced power generation and a positive value shows the new added generation type compared to case A1.

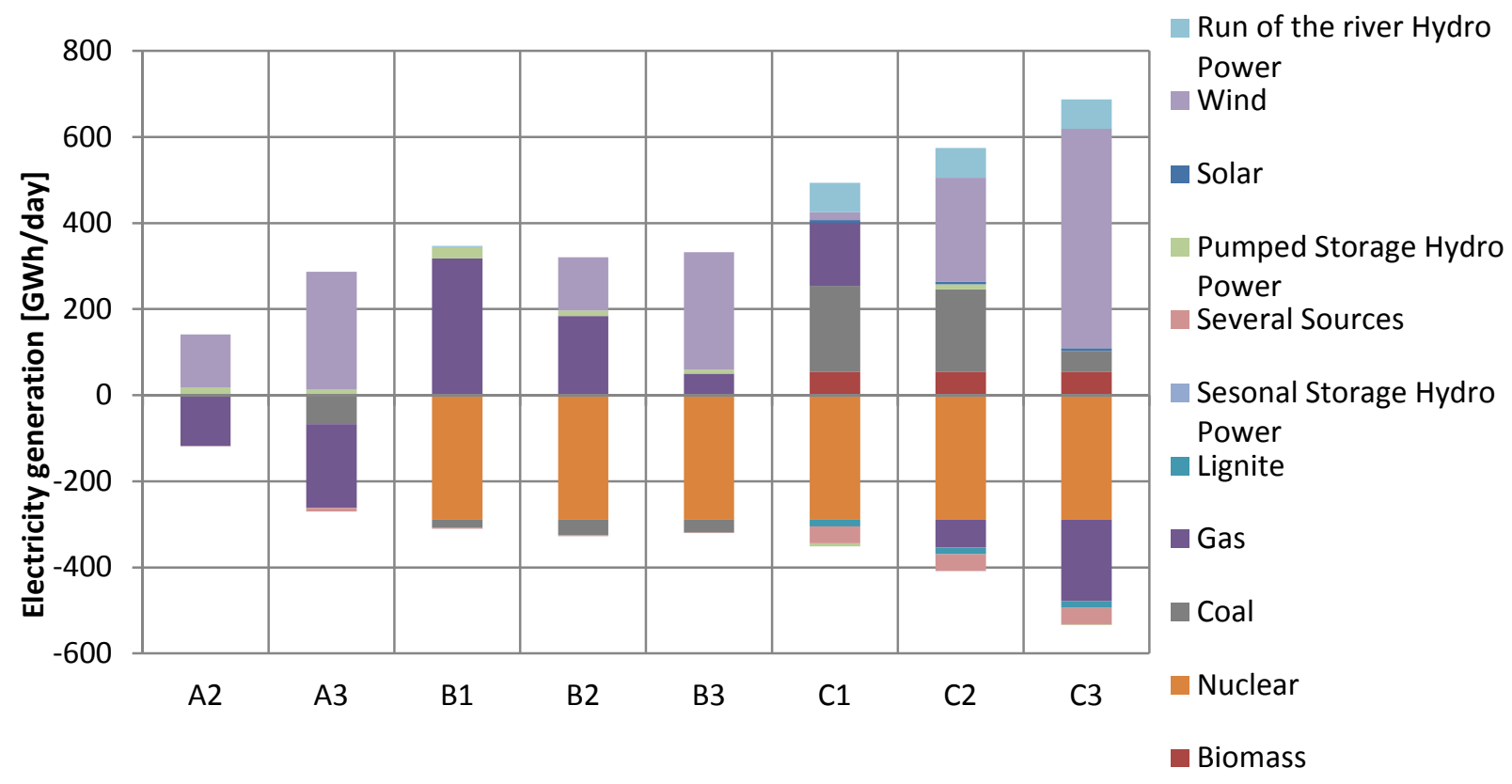

Figure 6.24: Electricity generation change in Austria and Germany compared to case A1

In A2 and A3 natural gas and further coal power is substituted by an increase of wind energy in the power system. The scenarios B show that a nuclear power phase out without changes in the power system increases the usage of natural gas a lot. A higher wind energy penetration will reduce the amount of natural gas in cases B. Coal and natural gas power increase a lot in case $\mathrm{C} 1$ because nuclear power is phased-out and the demand is increased. An increase of wind power will reduce at first the natural gas demand scenarios C. In C3 is also less coal used compared to C1 and C2.

Table 19 compares the generation of scenarios $\mathrm{B}$ and $\mathrm{C}$ with the corresponding cases $\mathrm{A}$. It can be noticed a strong increase of natural gas power in cases B because it is the cheapest available power source in this scenario. In scenarios $\mathrm{C}$ coal and natural gas power are also increased compared to the cases A. This results in much higher $\mathrm{CO}_{2}$ emissions in 2022 since the combustion of coal creates a lot of $\mathrm{CO}_{2}$. The high increase of natural gas in $\mathrm{B} 3$ is a result of the low usage of natural gas in the compared case A3.

Table 19: Generation change in Austria and Germany compared to corresponding case A [\%]

\begin{tabular}{lrrrrrr}
\hline & B1 & B2 & B3 & C1 & C2 & C3 \\
\hline Coal & -3 & -6 & 9 & 39 & 39 & 26 \\
Natural Gas & 147 & 293 & 1123 & 68 & 50 & 26 \\
Lignite & 0 & 0 & 0 & -3 & -3 & -3 \\
\hline
\end{tabular}

In Table 20 the generation in Austria of cases B and A is compared with the corresponding cases A. A strong increase of natural gas in Austria can be seen in scenarios C and B. In scenarios C increases the amount of natural gas between $46 \%$ and $10.2 \%$ depending on the wind conditions. It can be also 
noticed a significant reduction of pumped storage hydro power in Austria in 2022, whereas pumped storage hydro power increases by 109 percent in the case B1 due to the phase-out of nuclear power. Also in the cases B the amount of natural gas power increases strongly in the model.

Table 20: Changes of power generation in Austria compared to corresponding cases A [\%]

\begin{tabular}{lrrrrrr}
\hline & B1 & B2 & B3 & C1 & C2 & C3 \\
\hline Natural Gas & 75.7 & 42.5 & 26.8 & 46.0 & 10.2 & 25.9 \\
Pumped Storage Hydro Power & 109.1 & -3.7 & -16.9 & -91.5 & -86.5 & -56.3 \\
Wind & 0.0 & 0.0 & 0.0 & 77.5 & 77.5 & 77.5 \\
\hline
\end{tabular}

\subsection{Total cost of power generation in Austria and Germany}

Each scenario has different total costs due to changes of wind power generation, available power plant capacities, demand and the power grid settings. In Figure 6.25 are presented the total costs of Austria and Germany for all nine scenarios.

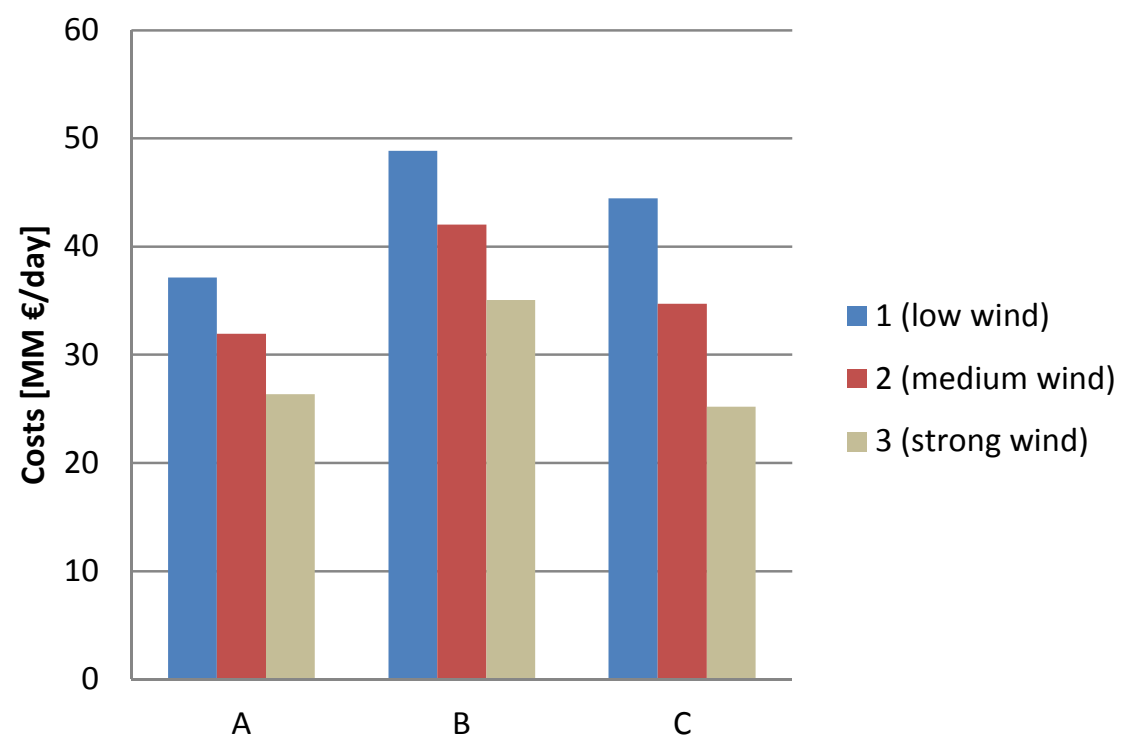

Figure 6.25: Total Costs of power generation in Austria and Germany

More wind power in the system always decreases total costs because the variable costs are set zero for it. A phase-out of nuclear power without changes in the system (scenarios B) generates higher costs because natural gas will be used more often in order to substitute nuclear power in Germany. In cases $\mathrm{C} 1$ and $\mathrm{C} 2$ the total costs are increased compared to the cases A1 and A2. However total costs are lowest in case $\mathrm{C} 1$ due to a high amount of installed wind power plants in the power system in 2022. Through the installation of more wind power in 2022 increases also the cost differences between the cases $\mathrm{C}$ with different wind conditions. Figure 6.26 compares the total costs of each scenario with the corresponding case A with the same wind condition. 


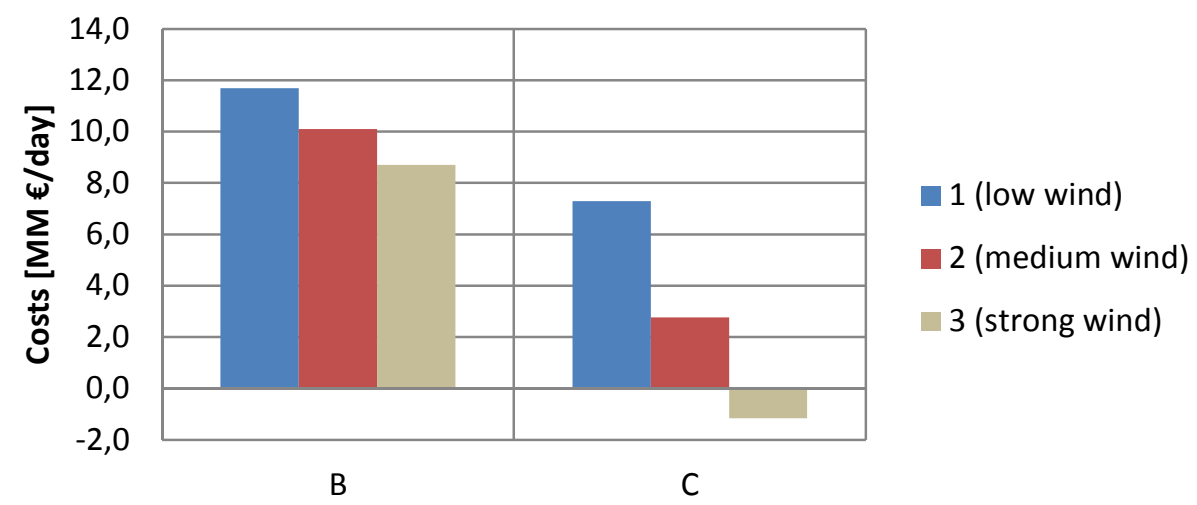

Figure 6.26: Total cost changes of cases $B$ and $C$ compared to cases $A$

In cases $\mathrm{B}$ the total costs will increase always strongly compared to the cases $\mathrm{A}$, whereas in cases $\mathrm{C}$ a strong cost increase appears at a lowest wind power generation level. The high amount of wind power decreases the total costs under strong wind conditions in scenario $\mathrm{C} 3$.

In the scenarios $\mathrm{C}$ it is also assumed that electricity demand increases by $8 \%$ compared to case $\mathrm{A}$ and B which represent the year 2013 The total cost change compared to the corresponding scenario A is shown in Figure 6.27. With the demand increase of 8\% in 2022 in mind, case $\mathrm{C} 2$ with $9 \%$ an increase of total costs is more competitive with the case A2. For the scenarios B the total costs are around 30\% higher than in the comparable cases A.

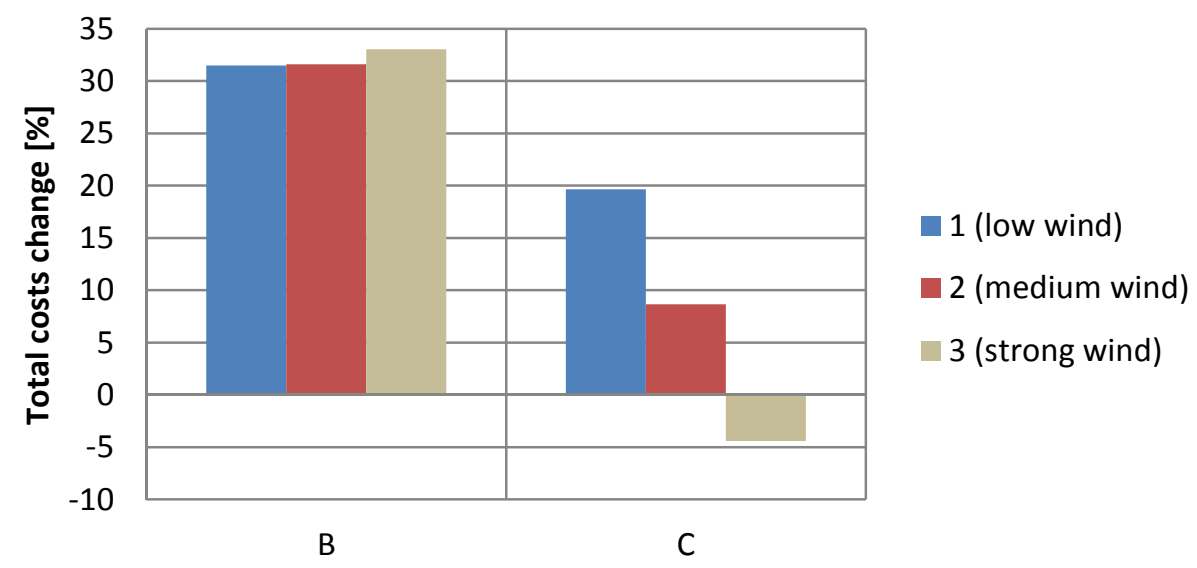

Figure 6.27: Total power generation cost differences compared to base Case in percent

\subsection{Wind power curtailment in the Austrian power system}

The model is using wind curtailment only in case C3. This is probably caused by a simple up scaling of the installed wind power capacity from values in 2013 to 2022. At node Neusiedl wind generation is too much and the system uses curtailment over a whole day in case C3. It can be noted that curtailment is not caused by transmission line capacity constraints. A reason for curtailment is that the nodal power balance could not be satisfied without wind power curtailment at the node Neusiedl. 


\section{8}

Locational marginal price in Austria

The locational marginal price (LMP) describes the cost if demand increases by 100MW at a specific node in the system. In order to simplify the analysis the LMP is analyzed at 11 am for important 380 KV nodes in Austria (See Figure 6.28).

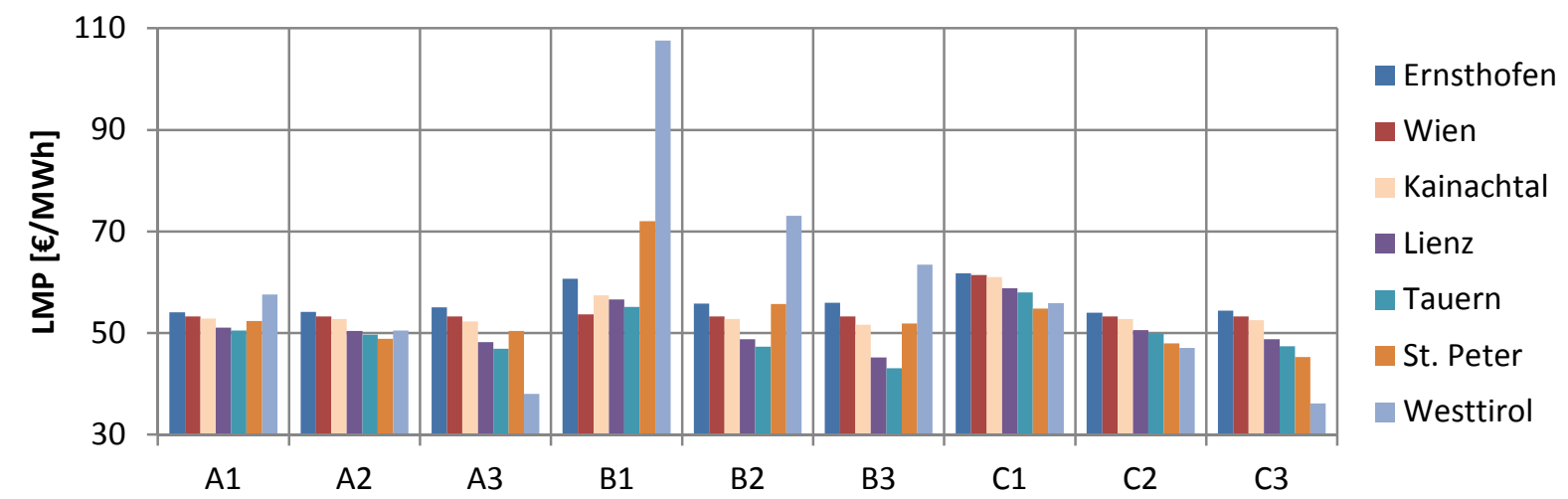

Figure 6.28: Locational Marginal Prices in Austria at 11 am

It can be noticed that the buses St. Peter and Westtirol are more sensitive to demand and scenario changes than other buses. Those buses are the closest ones to Germany. Therefore they are much stronger influenced by changes in the German power system. In Figure 6.29 is the LMP of each scenario compared with the corresponding case A.

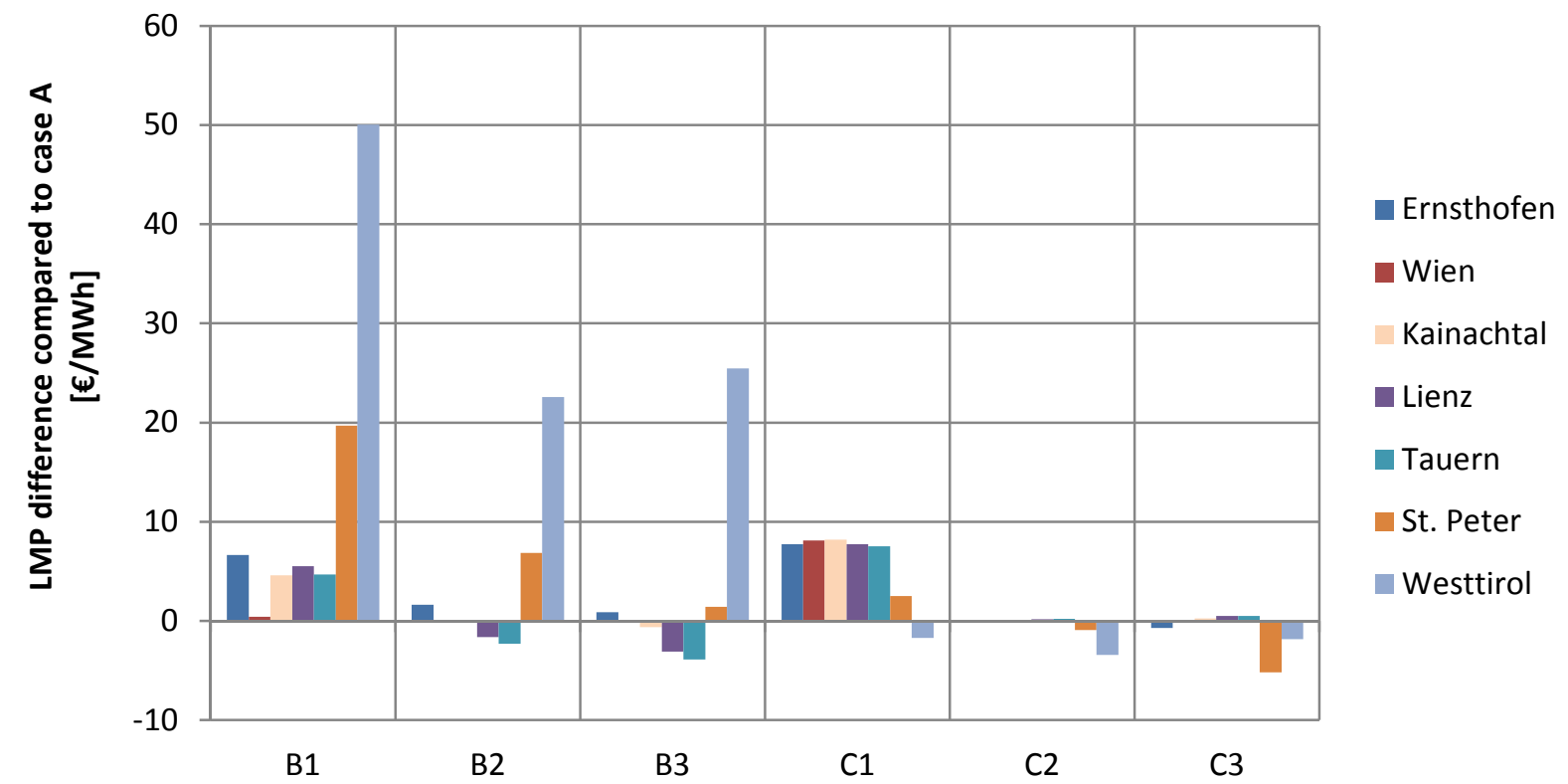

Figure 6.29: LMP difference in Austria at 11 am

Particularly at low wind conditions the LMP increases compared to cases A, whereas the LMP difference changes only slightly in the other scenarios, except at the nodes St. Peter and Westtirol. The changes of the locational market price are very low in scenarios $\mathrm{C} 1$ and $\mathrm{C} 2$ in 2022 . Only case $\mathrm{C} 1$ with low wind power generation shows a significant increase of the LMP in 2022. The behavior of the LMP over one day at node Wien is shown in Figure 6.30 for cases A and C. It can be noticed that the LMP is lower during low demand hours. The strongest price increase can be recognized in scenario $\mathrm{C} 1$ because of increased demand, no nuclear power and less wind power generation in this scenario. 


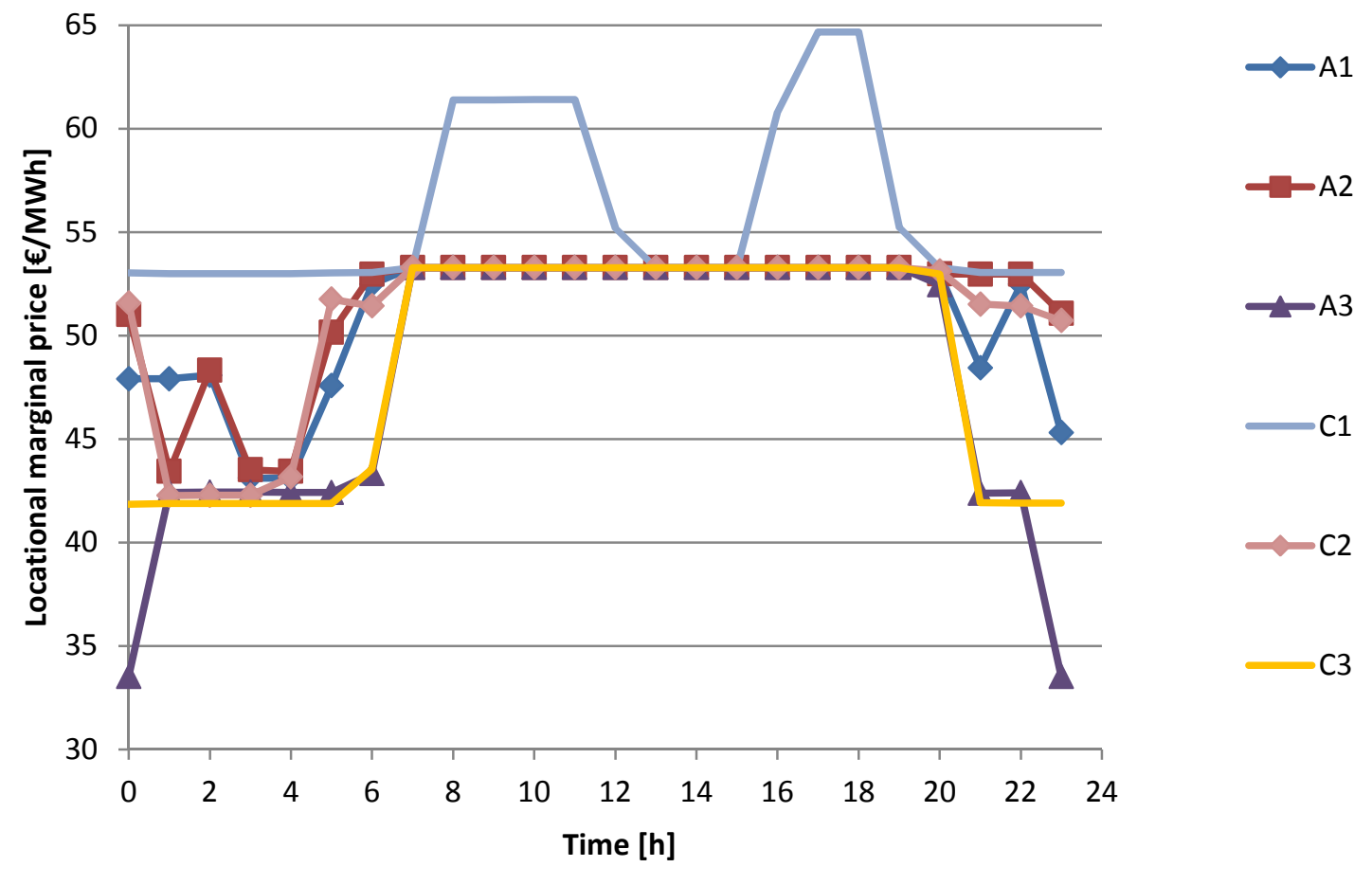

Figure 6.30: LMP curves of scenarios A and $\mathrm{C}$ at node Wien in Austria

\subsection{Impacts on transmission lines in Austria}

The phase-out of nuclear power in 2022 will change the power flow in the system. Thus more transmission lines can be congested in the future power system. The number of transmission line congestions for each scenario at 11 am is displayed in Figure 6.31. Congestion in the model is influenced by the allocation of power plants and operation of transformers between different voltage levels in the system.

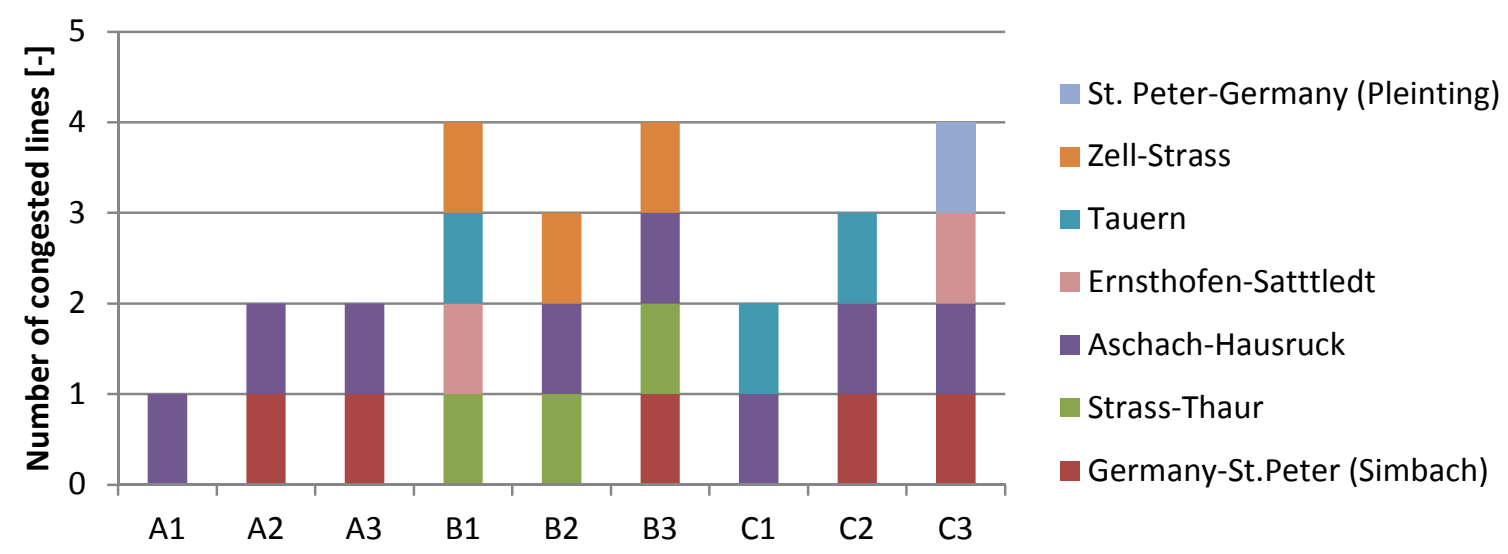

Figure 6.31: Number of congested transmission lines in model at 11 am

Case A1 shows congestion along the transmission line from Aschach to Hausruck. This congestion might be a result of placement of power plants in the model because the parallel $380 \mathrm{kV}$ transmission line is low charged. Congestion of this line is accepted for reasons of time but a different allocation of power plants could solve this congestion. Another often congested line is the connection between Germany and St. Peter. This is probably caused by the allocation of power plants in Germany which is 
not as accurate done as in Austria. It is assumed that those two congestions could have been avoided by an improvement of the model.

Congestion along the transmission lines Zell-Strass and Strass-Thaur in scenarios B are caused by the nuclear power phase out in Germany. The transmission line congestion Tauern refers to congestion between two $220 \mathrm{kV}$ nodes at Tauern. Additional lines in this area can be coupled or decoupled according to APG data[4]. Therefore this line is assumed to be not critical for a future scenario.

In case C3 transmission lines Ernsthofen-Sattledt and St. Peter-Germany are congested. The Congestion of St. Peter to Germany could be avoided by measures of TSO since a parallel $380 \mathrm{kV}$ line is installed in 2022 which has enough net transfer capacity. Decoupling of lines and transformers could avoid congestion on some lines in the scenarios. It can be also noticed that congestion appears only at $220 \mathrm{kV}$ Voltage level. All in all the congestion on the lines might be avoidable due to changes in the model and measures by TSO's. Only transmission lines Zell-Strass and Strass-Thaur are critical in the cases B1, B2 and B3 without nuclear power in Germany.

\subsection{Impact on pumped storage hydro power in Austria and Germany}

Pumped storage hydro power can play a key role in supplying a system with electricity during peak load. In Austria and Germany a pumped storage hydro power capacities of $3.3 \mathrm{GW}$ and $6.3 \mathrm{GW}$ are installed in 2013. The usage of pumped storage hydro power depends on which power plant type is on the margin during storage and generation mode of the pumped storage plant. Figure 6.32 shows the utilization of pumped storage hydro power in different scenarios.

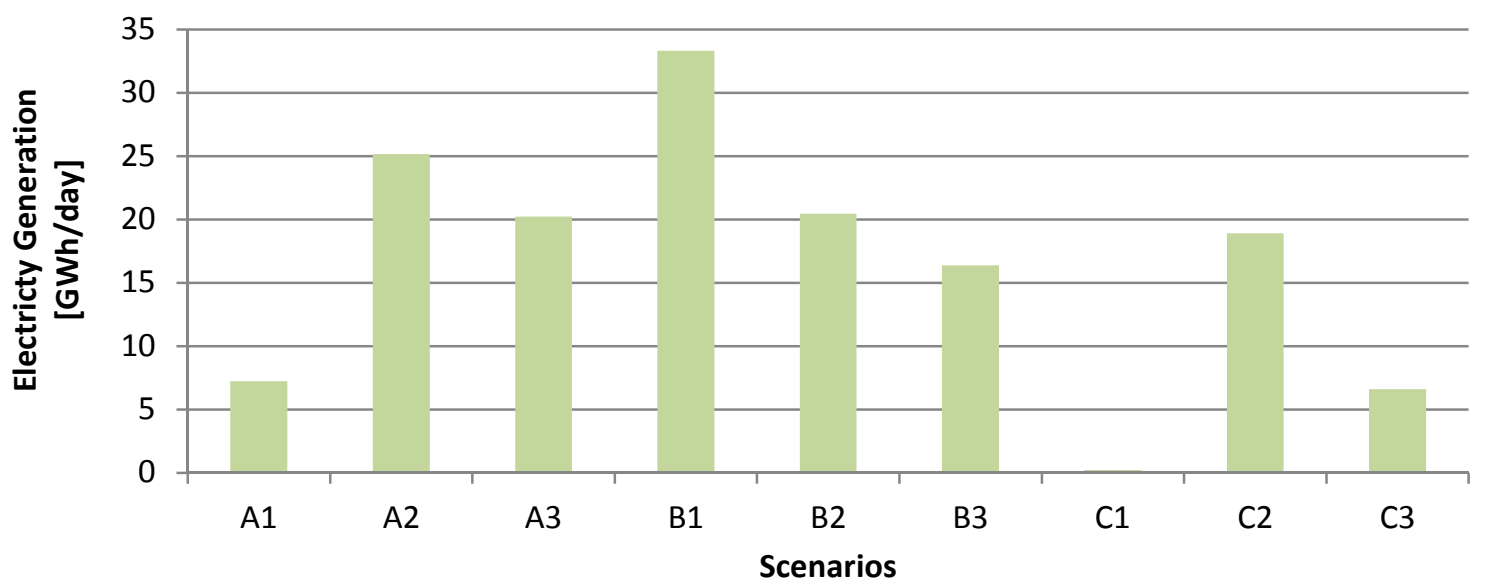

Figure 6.32: Electricity generation from pumped storage hydro power in Austria and Germany

In case A1 less storage is used because the base load coal power plants are running at nearly max capacity during the whole day. If wind power increases to a medium level (A2) much more storage is used because more coal power is available for pumped storage hydro power during the night. A further increase of wind power does not increase the use of pumped storage hydro power because the demand of one day limits the amount of the desired pumped storage hydro power generation.

Table 21 shows the deviation of the scenarios $\mathrm{B}$ and $\mathrm{C}$ compared to the corresponding case $\mathrm{A}$. A strong increase in case B1 can be noticed. On the other hand decreases the values always in scenarios $\mathrm{C}$ always compared to scenarios A. 
Table 21: Change of pumped storage hydro power in Germany and Austrian compared to cases A [\%]

\begin{tabular}{rrrrrr}
\hline B1 & B2 & B3 & C1 & C2 & C3 \\
\hline 361.6 & -18.6 & -19.0 & -96.8 & -24.8 & -67.4 \\
\hline
\end{tabular}

In the scenarios B natural gas power plants are on the margin because no new capacity is installed to compensate the nuclear power phase out in Germany. In the cases B the model tries to avoid the usage of gas power plants in Austria because they are still more expensive than importing electricity from Germany. Therefore pumped storage hydro power is used to store electricity from natural gas power plants in Germany to avoid the usage of natural gas power plants of Austria during peak load. The utilization of pump storage decreases with an increase of wind power because less generation from pumped storage is needed to avoid the costly natural gas power plants in Austria.

In cases $\mathrm{C}$ more coal power is installed and no nuclear power is used. During low wind condition natural gas power from Germany is always on the margin. Therefore no pumped storage is used in case $\mathrm{C} 1$ because it is unprofitable. An increase of wind power will shift the generation mix so that coal power is on the margin during night. This creates a profitable case for the application of pumped storage hydro power in the model. In scenario C3 the model decreases the usage of pumped storage hydro power because the demand for it is lower due to a high amount of wind power in the power system.

The assumption of the model that wind power is constant over one day is not beneficial for the usage of pumped storage since it is suitable for avoiding a reduction of the power output of base load power plants with coal and lignite during medium and high wind power generation peaks. Additionally, pumped storage hydro power might have a higher utilization over more days because the model only stores energy for peak load generation of the present day and cannot store energy for the next day.

\subsection{Comments on model setup}

The usage of power grid data for Germany from Hutcheon \& Bialek [5] causes results, which are fraught with uncertainties. Data from [5] only simulates the power exchange between the countries at a certain load level. It could not be evaluated if load and generation distribution of Hutcheon \& Bialek matches with the reality. Additionally, no transmission line limits are considered within in Germany in the model of Hutcheon \& Bialek. Therefore one has to be aware of this when discussing the results. A more detailed investigation of power flow in the German power grid based on this model is hence not reasonable.

Further improvement of the model could reduce congestion in the system. A more detailed allocation of the power plant capacity in Germany and Austria can remove congestion. This is time intensive and could not be done within this thesis. Measures by TSOs can also reduce congestion in the system. According to [4] transformers and transmission lines can be decoupled and coupled by the TSOs to influence the power flow in the system.

The model can be simplified if the number of nodes could be reduced. Since the source for the German power grid in the analysis is fraught with uncertainties it could be advantageous to reduce the number of nodes in the German part. A system reduction can reduce the number of buses a lot if each region in Germany is represented by one node. Another advantage of this would be that the allocation of power plants in Germany is easier and less sensitive to the results. Moreover this reduces the computing time of the model a lot and will allow the simulation of several weeks at once. 
Another suggestion for improvement would be a more detailed variable fuel price structure. This can optimize the power exchange results if several days are simulated. For the simulated day the applied variable fuel costs differences are sufficient since the power exchange curve of the model has similar shape as those of the real system. However a more differentiate power plant types and variable generation costs will influence usage of pumped storage hydro power and the power exchange between Austria and Germany.

The power plant capacity is up-scaled for scenarios $\mathrm{C}$ based on the allocated power plant capacity in cases A. This influences the power flow and should be considered if the power flow is too high within on some transmission lines. The Austrian part of the model is less affected because only solar and wind power capacities are up scaled in the scenarios $\mathrm{C}$.

Within this thesis only one winter day with a high demand is simulated, as because of the computing time of the model a longer time period was not reasonable. However it would be interesting to investigate how the model behaves under different seasons with a lot of solar power. Further it would be worthwhile to study the impact of wind power fluctuation over a day on pumped storage hydro power with the GAPS model. Due to the fact that nuclear power output is hard to regulate, it cannot balance the intermittent generation from RES. Therefore it could have additional benefits to shift the generation from nuclear power to coal power in combination with a high wind power penetration. 


\section{Conclusions and Future Work}

This section summarizes the key findings from the analysis of the different scenarios. The research questions are answered based on the results of chapter 6. Additional suggestions for future work and improvement of the model are made.

\subsection{Conclusions}

In this thesis, the Germany and Austria power systems have been modeled. The aim of the model is to investigate the effects of a nuclear power phase-out in Germany on Austria. Within this thesis nine different scenarios are analyzed. The scenarios $\mathrm{C}$ present the future case under consideration of increased demand, new transmission lines and new capacities in 2022. This scenario is the one which is most interesting due to its high likelihood in the future. Therefore the focus of the conclusion is on this case. Construction of a model which represents the real power system is a challenging task. Several limitations and assumptions had to be made due to available data and computing time. One of the main limitations is that only one day is simulated hence this model focuses on critical scenarios for the power system in 2022 . The results of the model are valid for a day with a high load.

- How do the total costs of power generation change in Austria and Germany after a nuclear power phase-out?

The total costs of the system will increase by $20 \%$ and $9 \%$ at low and medium wind conditions compared to the base cases. Whereas at strong wind conditions the total costs decrease by $4 \%$ due to the high wind power penetration in this case. Further it should be noticed that the demand also increases by $8 \%$ in 2022 in the GAPS model. Hence the change of total costs depends on the wind power penetration and the demand. All in all, the fluctuation of total costs increases due to a higher dependency on wind power but the total cost increase is moderate with respect to the demand increase in 2022. Analyses of the cases without nuclear power in Germany show that without investments in new coal power plants the total cost for power generation increases by around $30 \%$ compared to the costs in 2013.

- How is the locational marginal price in Austria affected by a nuclear power phase-out in Germany?

Effects of the nuclear power phase-out in Germany on the locational marginal price depend strongly on the wind conditions. At weak wind conditions the increase of the locational marginal price is high due to increased use of coal and gas power plants in 2022, whereas the locational marginal price stays almost the same at better wind conditions as before the nuclear power phase-out in 2022 .

- How does the electricity generation in Austria and Germany change after a nuclear power phase-out in Germany?

Nuclear power will be widely replaced by coal and natural gas power in the model. The usage of coal power increases between $39 \%$ and $26 \%$ in 2022 compared to scenarios of the present power system. Within the Austrian power system the utilization of natural gas increases between 46 and $10.2 \%$ in 2022 depending on the wind conditions in the power system. 
- Will the nuclear power phase-out in Germany cause congestion in the Austrian power system?

Congestion in the model is more critical in the scenarios of the present system without nuclear power. It could not be proven if measures of TSOs and investments in new power plant capacities in Germany and transmission lines will solve the critical congestion in the system because for this an improvement of the model is required. The model has to be optimized further in order to validate this question clearly.

- What are the effects of a nuclear power phase-out in Germany on the power exchange between Austria and Germany in 2022?

Power exchange between Austrian and Germany is influenced by the changes in the power system. In the case, where nuclear power plants are shut down without replacement by new installed capacities in 2013, Austria will become an electricity net exporter to Germany. How much electricity is exported from Austria to Germany depends on the wind conditions. At low wind conditions more electricity will be exported from Austria to Germany. In the future scenario for 2022 it is the opposite. Austria is a net importer of electricity from Germany in total. Imports of electricity of Austria from Germany are higher in the future. Nearly at every time period in each 2022 case Austria imports electricity from Germany. Thus the dependency on Germany of the Austrian power supply increases in 2022. In conclusion, the total costs and power grid operation of the future power system in Austria and Germany will have a high dependency on wind power generation.

- What are the effects of a nuclear power phase-out in Germany on the pumped storage hydro power?

Also pumped storage hydro power is strongly affected by the phase-out of nuclear power in Germany by 2022. During low wind conditions in 2022 the usage is almost zero on the simulated day. Also during better wind conditions the application of pump storage hydro power decreases a lot compared to the present system. Application of pump storage hydro power depends strongly on the marginal power plant and on the assumptions of the analyzed model. A different day with other load profile and RES generation will give a different result. Further pumped storage hydro power is less used in Austria in the investigated cases for 2022 compared to the case for 2013.

\subsection{Future work and improvement of the model}

As improvement for the future, a system reduction should be applied on the nodes of Germany in the model. This would allow the investigation of the model under the consideration of a longer time series. Further it would be interesting how the model behaves under different seasons since solar power plays an important role in the German power system. It should also be investigated how a fluctuation of wind power generation over one day affects the application of pumped storage hydro power in 2022 . 


\section{Bibliography}

[1] Federal Statistical Office Germany, "Electricty Generation,” 2013. [Online]. Available: https://wwwgenesis.destatis.de/genesis/online/data;jsessionid=09F69346303E5C3EE64C9B1919D70422.tomc at_GO_2_1?operation=begriffsRecherche\&suchanweisung_language=en\&suchanweisung=Elektri zit\%C3\%A4tserzeugung+\%28brutto\%29. [Accessed: 26-May-2014].

[2] Energie-Control Austria, "Hydro Power," Hydro Power. [Online]. Available: http://www.econtrol.at/de/konsumenten/oeko-energie/basiswissen/oekostrom-arten/wasserkraft. [Accessed: 16Sep-2014].

[3] GAMS, "GAMS Manuals," 2013. [Online]. Available: http://www.gams.com/docs/document.htm. [Accessed: 12-Nov-2014].

[4] Austrian Power Grid AG (APG), "Private conversation: Allowance to use Austrian power grid data." 2014.

[5] N. Hutcheon and J. Bialek, "Updated and Validated Power Flow Model of the Main Continental European Transmission Network," 2009. [Online]. Available:

http://www.powerworld.com/knowledge-base/updated-and-validated-power-flow-model-of-themain-continental-european-transmission-network. [Accessed: 27-May-2014].

[6] 50Hertz GmbH, Ampirion GmbH, TenneT TSO GmbH, and Transnet BW GmbH, "The transmission system operators." [Online]. Available:

http://www.netzentwicklungsplan.de/en/content/transmission-system-operators. [Accessed: 27May-2014].

[7] Bundesnetzagentur, “About Bundesnetzagentur.” [Online]. Available: http://www.bundesnetzagentur.de/cln_1421/EN/Areas/Energy/AboutUs/aboutus-node.html. [Accessed: 27-May-2014].

[8] APG, “About APG.” [Online]. Available: http://www.apg.at/en. [Accessed: 27-May-2014].

[9] European Energy Exchange AG, "EPEX SPOT Power Spot Market." [Online]. Available: http://www.eex.com/en/products/power/power-spot-market. [Accessed: 27-May-2014].

[10]German Energy Agency, "dena Grid Study II - Integration of Renewable Energy Sources in the German Power Supply System from 2015 - 2020 with an Outlook to 2025," Oct-2010. [Online]. Available: http://www.dena.de/fileadmin/user_upload/Projekte/Erneuerbare/Dokumente/dena_Grid_Study_II _-_final_report.pdf.

[11]Süddeutsche.de, "Gesetzespaket zur Energiewende - Kabinett beschließt Atomausstieg bis 2022." [Online]. Available: http://www.sueddeutsche.de/politik/gesetzespaket-zur-energiewendekabinett-beschliesst-atomausstieg-bis-1.1105474. [Accessed: 21-May-2014].

[12]“Atom act (Atomgesetz ATG)." version of 2013.08.28 BGBl p. 3313, 1985.

[13]Deutsches Atomforum e. V., "Kernkraftwerke in Deutschland." [Online]. Available: http://www.kernenergie.de/kernenergie/themen/kernkraftwerke/kernkraftwerke-indeutschland.php. [Accessed: 26-May-2014].

[14]Bundesnetzagentur, "Update of Bundesnetzagentur report on the impact of nuclear power moratorium on the transmission networks and security of supply," 25-May-2011. [Online]. Available:

http://www.bundesnetzagentur.de/SharedDocs/Downloads/EN/BNetzA/PressSection/ReportsPubl ications/2011/110527PressConferenceNuclearPowerMoratoriumpdf.pdf?_blob=publicationFile\& $\mathrm{v}=2$. [Accessed: 28-May-2014].

[15]F. Hoster, "Impact of a nuclear phase-out in Germany: results from a simulation model of the European Power Systems," Energy Policy, vol. 26, no. 6, pp. 507-518, 1998.

[16]B. Knopf, M. Pahle, H. Kondziella, F. Joas, O. Edenhofer, and T. Bruckner, "Germany's nuclear phase-out: Impacts on electricity prices, CO2 emissions and on Europe," Potsdam Institute for Climate Impact Research, 2012. [Online]. Available: http://www.pikpotsdam.de/members/knopf/publications/Knopf_Germanys\%20nuclear\%20phase-out.pdf. [Accessed: 26-May-2014]. 
[17]M. Fürsch, D. Lindenberger, R. Malischek, S. Nagl, T. Panke, and J. Trüby, "German nuclear policy reconsidered: Implications for the electricity market," 2011. [Online]. Available: http://www.econstor.eu/handle/10419/74404. [Accessed: 29-May-2014].

[18]F. Kunz, C. Hirschhausen, D. Möst, and H. Weigt, "Security of Supply and Electricity Network Flows after a Phase-Out of Germany's Nuclear Plants: Any Trouble Ahead?," Robert Schuman Centre for Advanced Studies, 2011. [Online]. Available: http://cadmus.eui.eu/handle/1814/13956. [Accessed: 28-May-2014].

[19]F. Leuthold, H. Weight, and C. Hirschhausen, "ELMOD - A Model of the European Electricity Market," 2008. [Online]. Available: http://papers.ssrn.com/sol3/papers.cfm?abstract_id=1169082.

[20]F. U. Leuthold, H. Weigt, and C. Hirschhausen, "A Large-Scale Spatial Optimization Model of the European Electricity Market," Netw. Spat. Econ., vol. 12, no. 1, pp. 75-107, Mar. 2012.

[21]K. Bruninx, D. Madzharov, E. Delarue, and W. D'haeseleer, "Impact of the German nuclear phase-out on Europe's electricity generation-A comprehensive study," Energy Policy, vol. 60, pp. 251-261, Sep. 2013.

[22]A. J. Wood and B. F. Wollenberg, Power generation, operation and control. John Wiley and Sons, 2012.

[23]H. Sadaat, Power System Analysis, Third edition. PSA Publishing, 2010.

[24] GAMS Support, "Private conversation 'Workspace Error,"” 05-Jun-2014.

[25]Bundesnetzagentur, "Power plant list (Kraftwerksliste)." [Online]. Available: http://www.bundesnetzagentur.de/DE/Sachgebiete/ElektrizitaetundGas/Unternehmen_Institutione n/Versorgungssicherheit/Erzeugungskapazitaeten/Kraftwerksliste/kraftwerksliste-node.html. [Accessed: 26-Mar-2014].

[26]ENTSO-E, "ENTSO-E's Scenario Outlook \& Adequacy Forecast (SO\&AF) 2013-2030,” 2013. [Online]. Available: https://www.entsoe.eu/fileadmin/user_upload/_library/publications/entsoe/So_AF_20132030/130403_SOAF_2013-2030_final.pdf. [Accessed: 02-Jun-2014].

[27] Austrian Power Grid (APG), “Masterplan 2030.” [Online]. Available: http://www.apg.at/de/netz/netzausbau/masterplan. [Accessed: 04-May-2014].

[28] Austrian Power Grid AG (APG), "Installed Power Plant Capacity in Austria," 2013. [Online]. Available: http://www.apg.at/en/market/generation/installed-capacity. [Accessed: 05-Jun-2014].

[29] ORF Österreichischer Rundfunk, "Shut down of gas power plant (Verbund mottet Kraftwerk Mellach ein)." [Online]. Available: http://steiermark.orf.at/news/stories/2647142/. [Accessed: 06Jun-2014].

[30]ENTSO-E, “Interconnected Network of ENTSO-E map,” 2012. [Online]. Available: https://www.entsoe.eu/Pages/default.aspx. [Accessed: 06-Jun-2014].

[31]AG Energiebilanzen e.V.(AGEB), "Electricity generation by source (Stromerzeugung nach Energieträgern)," 2013. [Online]. Available: http://www.agenergiebilanzen.de/EN/home/home.html. [Accessed: 06-Jun-2014].

[32] European Energy Exchange AG, "Transparency in Energy Markets." [Online]. Available: http://www.transparency.eex.com/en/. [Accessed: 27-May-2014].

[33]Frauenhofer Institut für Windenergie und Energiesystemtechnik (IWES), "Wind report 2011." [Online]. Available:

http://www.fraunhofer.de/content/dam/zv/de/forschungsthemen/energie/Windreport-2011-de.pdf. [Accessed: 06-Jun-2014].

[34]GeoModel Solar s.r.o, "SolarGIS Solar map Austria," 2011. [Online]. Available: http://solargis.info/doc/_pics/freemaps/1000px/ghi/SolarGIS-Solar-map-Austria-de.png. [Accessed: 06-Jun-2014].

[35]Austrian Wind Energy Association, "IG Windkraft." [Online]. Available: http://www.igwindkraft.at/?xmlval_ID_KEY[0]=1055/. [Accessed: 06-Jun-2014].

[36]E-Control, "Yearly statistic of electric energy (Jährliche Bilanz elektrischer Energie)." [Online]. Available: http://www.e-control.at/de/statistik/strom/betriebsstatistik/jahresreihen. [Accessed: 06Jun-2014].

[37] International Energy Agency and OECD Nuclear Energy Agency, Projected costs of generating electricity. Paris: International Energy Agency, Nuclear Energy Agency, Organisation for Economic Co-operation and Development, 2010. 
[38] Sustainable Energy Authority of Ireland(SEAI), "Fuel Cost Comparison Sheets," 2014. [Online]. Available: http://www.seai.ie/Power_of_One/Fuel_Cost_Comparisons/. [Accessed: 06-Jun-2014].

[39]D. Fricke, "Bundesnetzagentur: private conversation data for master thesis," 05-Feb-2014.

[40]ENTSO-E, "Exchange Data." [Online]. Available: https://www.entsoe.eu/data/dataportal/exchange/Pages/default.aspx. [Accessed: 06-Jun-2014].

[41]ENTSO-E, “Consumption Austria \& Germany- ENTSO-E.” [Online]. Available: https://www.entsoe.eu/data/data-portal/consumption/. [Accessed: 03-Jun-2014].

[42] Austrian Power Grid AG (APG), "Load Forecast." [Online]. Available: http://www.apg.at/en/market/load/load-forecast. [Accessed: 12-Jun-2014].

[43]IEA, World Energy Outlook 2012. International Energy Agency, 2012.

[44]J. J. Grainger and W. D. Stevenson, Power System Analysis. McGraw-Hill, 1994.

[45]F. Kiessling, P. Nefzger, J. . Nolasco, and U. Kaintyzk, Overhead Power Lines. Springer Verlag, 2003.

[46] Austrian Power Grid AG (APG), “APG Network Development Plan (Netzentwicklungsplan) 2013," 2013. [Online]. Available: http://www.apg.at/ /media/6C63EC3BDDC74FF4B88E7992E957D8A9.pdf.

[47]Bundesnetzagentur, "Network Development(Netzausbau)." [Online]. Available: http://www.netzausbau.de/cln_1431/DE/Vorhaben/BBPlG-Vorhaben/BBPIG-Vorhabennode.html. [Accessed: 04-Sep-2014].

[48] W. Hermann Josef, K. Marko K., B. Jörg, B. Thomas Große, F. Norbert, and K. Philipp, "CO2Emissions of Electricty Generation (CO2-Emissionen der Stromerzeugung ein ganzheitlicher Verlgeich)," BWK, vol. 10, pp. 44-52, 2007. 


\section{Appendices}

\section{Scenarios A}

\section{Appendix 1 Scenario A2}

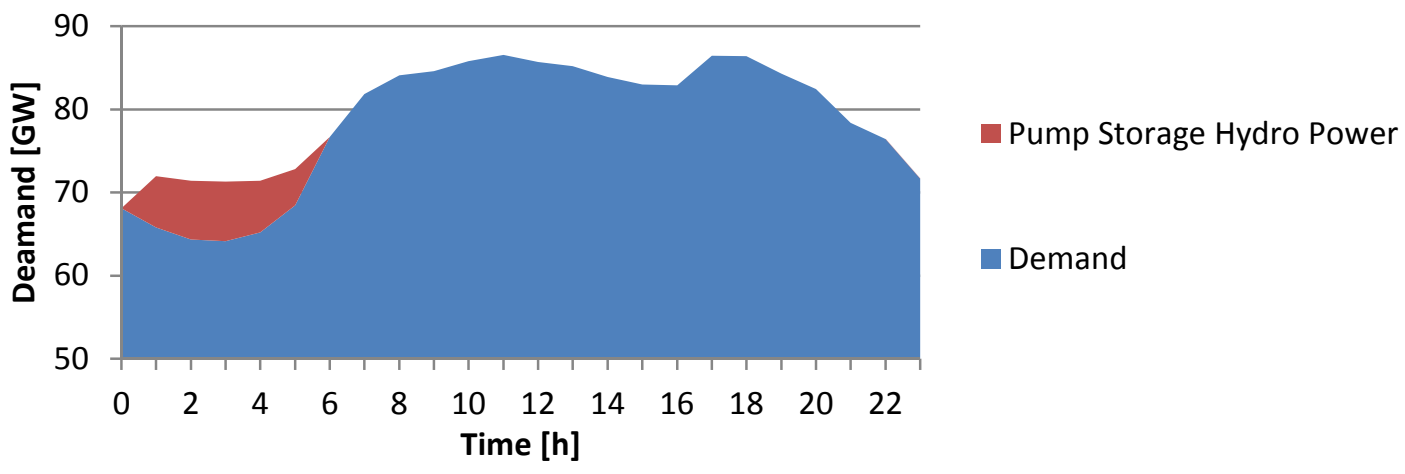

Figure A.1: Load profile of Austria and Germany in case A2

\section{Appendix 2 Scenario A3}

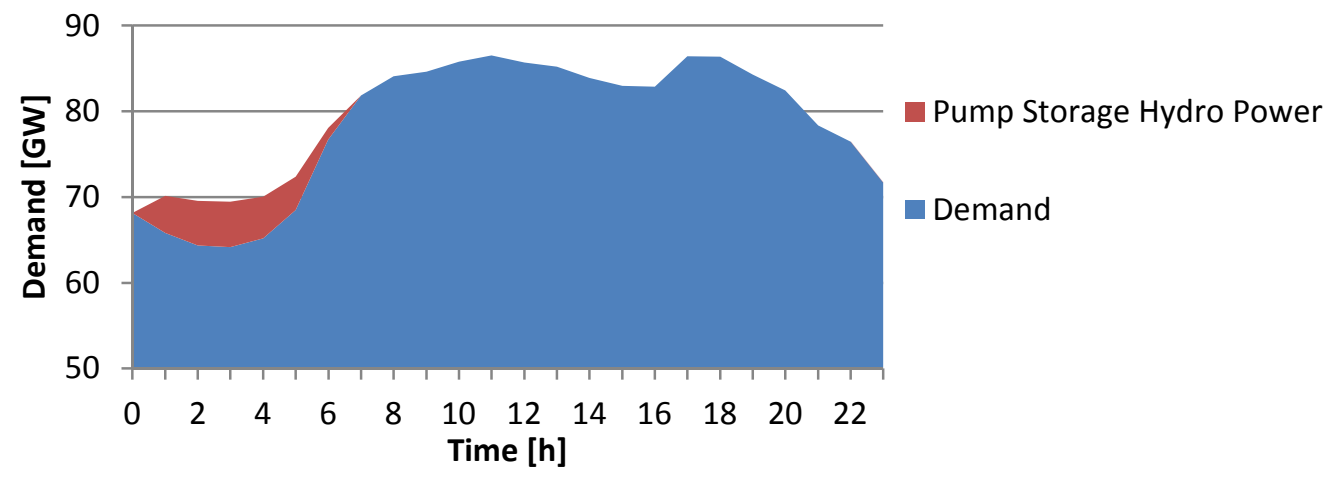

Figure A.2: Load profile of Austria and Germany in case A3 


\section{Scenarios B}

\section{Appendix 3 Scenario B1}

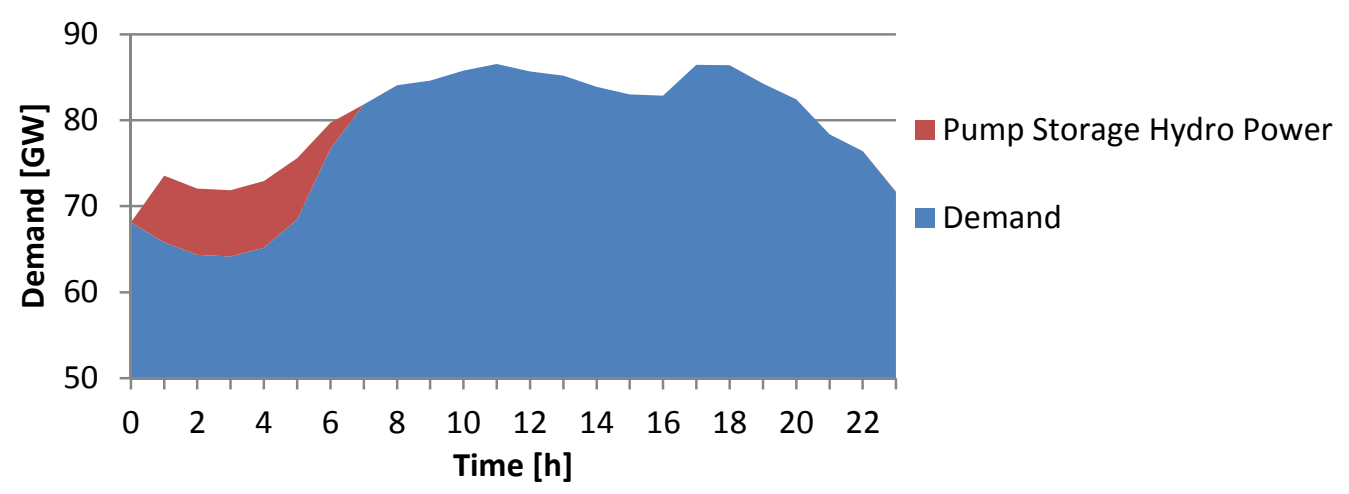

Figure A.3: Load profile of Austria and Germany in case B1

\section{Appendix 4 Scenario B2}

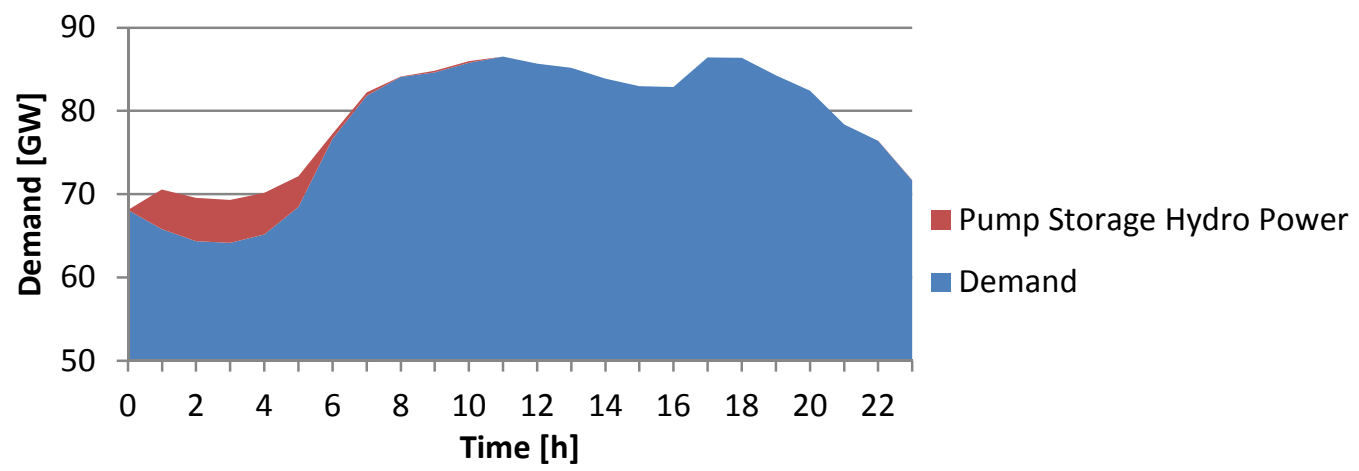

Figure A.4: Load profile of Austria and Germany in case B2

\section{Appendix 5 Scenario B3}

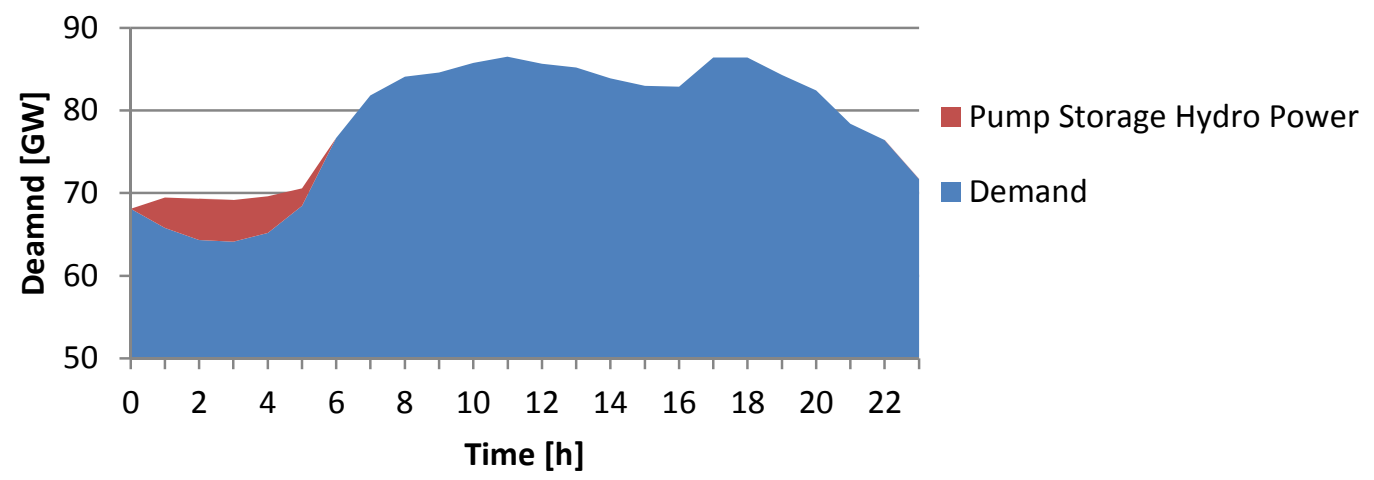

Figure A.5: Load profile of Austria and Germany in case B3 


\section{Scenarios C}

\section{Appendix 6 Scenario C1}

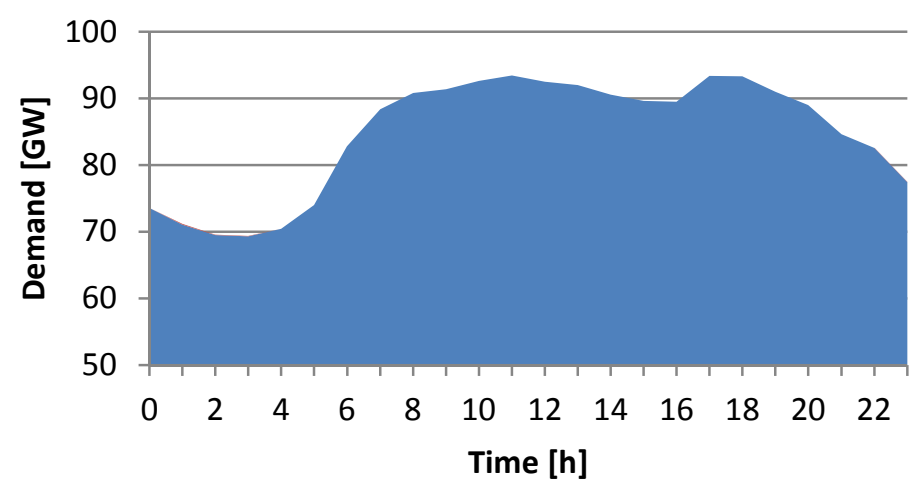

- Pump Storage Hydro Power

Demand

Figure A.6: Load profile of Austria and Germany in case C1

\section{Appendix 7 Scenario C2}

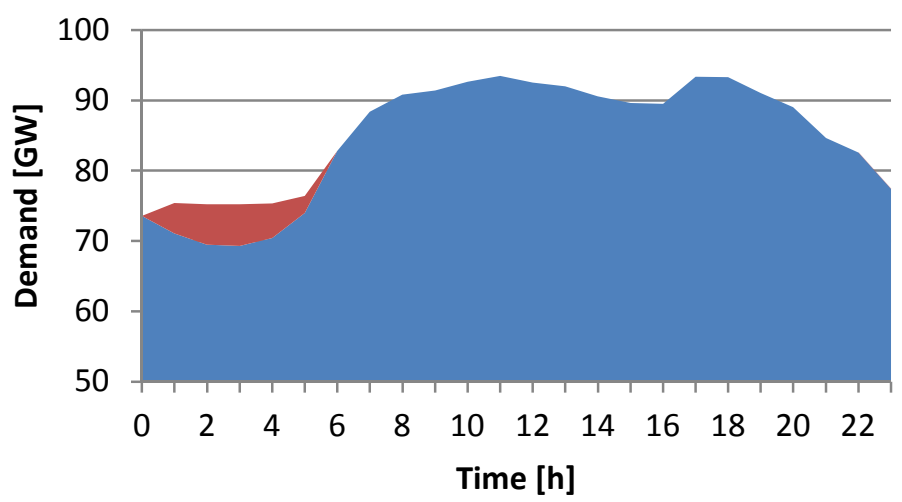

Pump Storage Hydro Power

Demand

Figure A.7: Load profile of Austria and Germany in case C2

\section{Appendix 8 Scenario C3}

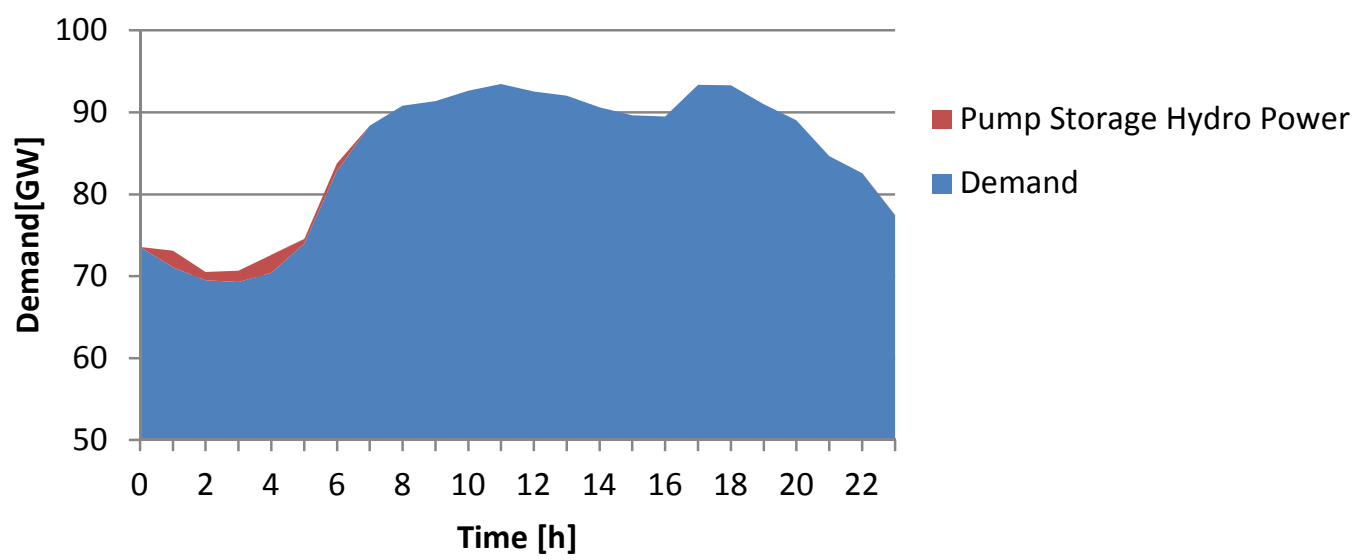

Figure A.8: Load profile of Austria and Germany in case C3 
Appendix 9 Demand in Austria and Germany

Table 22: Demand of Austria and Germany in 2013 in GW

\begin{tabular}{ccc}
\hline Hour & AT & DE \\
\hline 0 & 6.2 & 56.8 \\
1 & 6 & 54.6 \\
2 & 6 & 53.2 \\
3 & 5.9 & 53 \\
4 & 6 & 54 \\
5 & 6.4 & 56.9 \\
6 & 6.9 & 64.7 \\
7 & 7.7 & 72.2 \\
8 & 7.9 & 74.2 \\
9 & 8 & 74.6 \\
10 & 8.1 & 75.7 \\
11 & 8.1 & 76.5 \\
12 & 7.9 & 75.8 \\
13 & 7.8 & 75.4 \\
14 & 7.7 & 74.2 \\
15 & 7.7 & 73.3 \\
16 & 7.9 & 73 \\
17 & 8.3 & 76.2 \\
18 & 8.2 & 76.2 \\
19 & 7.8 & 74.5 \\
20 & 7.3 & 70 \\
21 & 6.8 & 66.4 \\
22 & 6.7 & 64.5 \\
23 & 6.4 & 60.4 \\
\hline & &
\end{tabular}

